\title{
An overview of fullerene chemistry
}

\author{
S SAMAL* and S K SAHOO \\ Department of Chemistry, Ravenshaw College, Cuttack 753 003, India \\ MS received 4 April 1996; revised 3 October 1996
}

\begin{abstract}
Fullerenes which were thought to be 'superaromatics' are actually 'superalkenes'. Reactions in fullerenes are varied, ranging from the addition of simple molecules like $\mathrm{H}_{2}$ to large molecules like dendrimers. The synthesis, structure, characterization, along with simple reactions like halogenation, oxygenation, metalation, cycloaddition, polymerization and dendrimer addition are discussed.
\end{abstract}

Keywords. Fullerenes; $\mathrm{C}_{60} ; \mathrm{C}_{70}$; characterization; reactions.

\section{Introduction}

Fullerenes and their derivatives possess a number of potentially useful physical, biological and chemical properties. Our interest in the chemistry of fullerenes led us to present this review in which we have attempted to furnish an overall picture of the properties of these novel molecules. The scope of the review is however limited. The conclusion of the authors contributing to this rapidly growing field of research are accepted and presented in a concise manner highlighting the salient features of the original work.

The technique developed by Krätschmer et al (1990) for preparing and isolating macroscopic quantities of $\mathrm{C}_{60}$, 'a new form of carbon', opened the way for exploring the molecular and bulk properties of these novel species. Kroto et al (1985) reported the nature and chemical reactivity of $\mathrm{C}_{60}$ species produced during the nucleation of carbon plasma. $\mathrm{C}_{60}$, which was found to be stable, was named buckminsterfullerene after Buckminster Fuller, American architect, engineer and constructor of geodesic dome. After the report of species up to 33 carbon atoms in the carbon arc (Hintenberger and Dorenburg 1959; Hintenberger et al 1961, 1963), Rohfling et al (1984) reported that much larger carbon clusters i.e. even numbered $C_{n}$ with $n=30-190$ could be produced by vapourization of graphite, among which $\mathrm{C}_{60}$ is the most stable one. $C_{60}$ (buckminsterfullerene) 1 and $C_{70}$ (falmarene) 2 and to some extent $\mathrm{C}_{84}$ are most accessible members of the family of closed cage molecules known as fullerenes (figure 1) formed entirely of carbon in $s p^{2}$-hybridized state. The fullerenes are considered as the third allotrope of carbon after diamond and graphite.

The stability of $\mathrm{C}_{60}$ molecule is due to the structure in which the carbon atoms are arranged at the 60 vertices of a truncated icosahedron composed of 32 faces, a

*Author to whom all correspondence should be addressed 


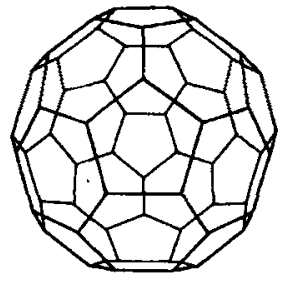

1

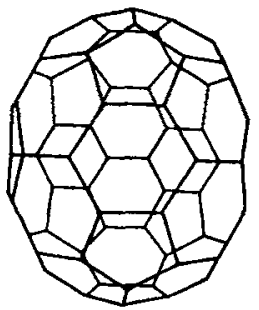

2

Figure 1. Buckminsterfullerene, $C_{60}\left(12\right.$ pentagons and 20 hexagons) and falmarene, $C_{70}$ (12 pentagons and 25 hexagons) (Fowler 1991).

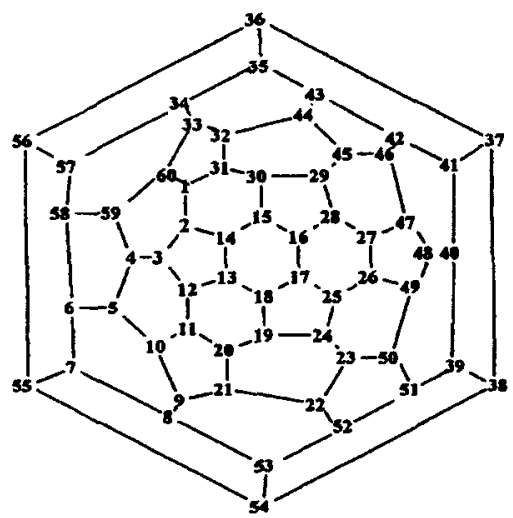

3

Figure 2. IUPAC numbering of carbon positions in $\mathrm{C}_{60}$ shown in Schegel diagram (Kroto et al 1991).

structure analogous to a soccer ball. Each molecule of fullerene family $\left(\mathrm{C}_{n}\right)$ consists of 12 pentagons and $m$ number of hexagons (other than one), conforming to the relation $m=(n-20) / 2$ (Euler's theorem). Therefore $C_{60}$ is composed of 32 faces of which 12 are pentagons and 20 are hexagons. The position of the different carbon atoms in $\mathrm{C}_{60}$ is described by IUPAC nomenclature as shown in figure 2 using Schegel diagram. Accordingly, $\mathrm{C}_{70}$ consists of 12 pentagons and 25 hexagons.

By the laser vaporization technique, $\mathrm{C}_{60}$ was first produced from a graphite target (Dietz et al 1981). It was initially thought that the graphitic sheet fragments might have been ablated from graphite target and rearranged to $C_{60}$. Subsequent considerations suggested that $\mathrm{C}_{60}$ was more likely to have formed by nucleation from carbon vapour consisting at least initially of carbon atoms and very small carbon molecules (Heath et al 1987). Krätschmer et al (1990) reported the presence 
of $\mathrm{C}_{60}$ in soot condensed from graphite in argon atmosphere which was identified by the observed isotope shifts of IR absorptions of ${ }^{12} \mathrm{C}$ and ${ }^{13} \mathrm{C}$. Large variety of carbonaceous materials such as carbon films (Creasy and Breena 1990), polyamides (Creasy and Breena 1988; Campbell et al 1990), coal (Greenwood et al 1990), polycyclic aromatic hydrocarbons (Lineman et al 1989) etc yield predominant $C_{60}$ peak on laser vapourization.

Charged species (positive and negative) are also formed along with neutral $\mathrm{C}_{60}$, and the nucleation rate order was neutrals $>$ cations $>$ anions (O'Brien et al 1986). $\mathrm{C}_{60}^{+}$was also detected by Homann et al (1987) in a sooting flame. Electrochemistry studies showed that at least three anionic forms of $\mathrm{C}_{60}\left(\mathrm{C}_{60}^{-1}, \mathrm{C}_{60}^{-2}\right.$ and $\left.\mathrm{C}_{60}^{-3}\right)$ and three anionic forms of $\mathrm{C}_{70}$ can be produced in solution (Cox et al 1991). Studies by Bard et al (1992) supported the strong dependence of the redox chemistry of $\mathrm{C}_{60}$ on both solvent and cation of supporting electrolyte and demonstrated that electrochemical reduction to the -6 state can be accomplished in liquid ammonia in the presence of $\mathrm{K}^{+}$. The development of a general method capable of generating stable $\mathrm{C}_{60}^{n-}$ species where $n=1-6$, was reported by Xie et al (1992). Using a suitably chosen optimal solvent composition, $\mathrm{C}_{60}$ and $\mathrm{C}_{70}$ were reduced to $\mathrm{C}_{60}^{6-}$ and $\mathrm{C}_{70}^{6-}$. Though earlier reports predicted $\mathrm{C}_{60}$ to be extremely stable, it was later reported by Bloomfield et al (1985) that $\mathrm{C}_{60}$ was susceptible to multiphoton fragmentation, and Bowers et al $(1988,1990)$ showed that $C_{60}$ undergoes metastable fragmentation and small carbon fragments $C_{n}(n=2,4,6, \ldots)$ are eliminated in the fragmentation process (O’Brien et al 1988).

STM studies of thin films of solid solutions showed the presence of $\mathrm{C}_{60}$ along with $C_{70}$ (Rao et al 1994). The distance between the two $C_{60}$ molecules is $1.47 \mathrm{~nm}$ while the distance between two $\mathrm{C}_{70}$ molecules in the absence of $\mathrm{C}_{60}$ in the vicinity is $1.19 \mathrm{~nm}$ and in the presence of $C_{60}$ it is $1.8 \mathrm{~nm}$. Haddon et al (1991) reported the excited state paramagnetic contributions to the $\pi$-electron ring current magnetic susceptibility. In case of fullerene there are $30 \pi$-bonds, which means that 60 electrons can move about freely and contribute to the magnetic susceptibility. Pauling ring current model predicts a ring current diamagnetic susceptibility 41 times that of $\pi$-electron ring current magnetic susceptibility of benzene. The diamagnetism of $\mathrm{C}_{60}$ was found to be small, which, according to Haddon et al (1991), was attributed to the excited state paramagnetic contributions to the $\pi$-electron ring current magnetic susceptibility.

Cast films of $\mathrm{C}_{60}$ on noble metal electrodes behave as $n$-type semiconductors in liquid junction cells (Miller et al 1991). Haddon et al (1991) reported alkali metal doped conducting films of $\mathrm{C}_{60}$ and $\mathrm{C}_{70}$, which was attributed to the formation of energy bands from the $\pi$-orbitals of $\mathrm{C}_{60}$ and $\mathrm{C}_{70}$, and is partially filled with carriers on doping and is an example of three dimensional organic conductors. The highest conductivities observed in the doped films are $4 \mathrm{~S} / \mathrm{cm}\left(\mathrm{Cs} / \mathrm{C}_{60}\right), 100\left(\mathrm{Rb} / \mathrm{C}_{60}\right)$, $500\left(\mathrm{~K} / \mathrm{C}_{60}\right), 20\left(\mathrm{Na} / \mathrm{C}_{60}\right), 10\left(\mathrm{Li} / \mathrm{C}_{60}\right)$, and $2\left(\mathrm{~K} / \mathrm{C}_{70}\right)$. Yamada et al $(1994)$ reported solar cells from fullerenes. The solar cells of doped- $\mathrm{C}_{60}$ as semiconducting material used the $n$ - or $p$-layers to form homo- or hetero-junctions. The cells have long life time. Haddon (1996) reported $\mathrm{C}_{70}$ thin film transistors made out of thin films of conductivity $2 \times 10^{-9} \mathrm{~S} / \mathrm{cm}$. Photoconducting films of poly(vinyl carbazole) doped with fullerenes have been reported (Wang 1992), and quantum yield for primary 
charge separation and initial ion pair distance are 0.9 and $19 \AA$ respectively. Transition metal complexes containing fullerene derivatized ligands might be interesting in solar energy studies (Maggini et al 1995).

A novel synthetic route to the formation of less air-sensitive fullerene superconductors by mixing oxygen-containing alkaline compounds with $\mathrm{C}_{60}$ is reported by Hwang et al (1994). The observed stability enhancement and the off-stoichiometry of $\mathrm{K}$ content may originate from the presence of oxygen which serves as an oxidative agent. Khairullin et al (1994) have systematically studied a new Na-doped $\mathrm{C}_{60}$ superconductor prepared from $\mathrm{NaN}_{3}$. The authors present the experimental results of the low field signal of microwave adsorption and ESR. Hirozawa (1995) reported superconductor thin films comprising a $\mathrm{C}_{60}$ layer and a group II element layer alternatively grown on a (100) plane of a substrate selected from $\mathrm{RbI}, \mathrm{RbBr}, \mathrm{RbCl}$, $\mathrm{RbF}, \mathrm{KI}, \mathrm{KBr}, \mathrm{KCl}, \mathrm{KF}, \mathrm{NaBr}, \mathrm{NaCl}$ or $\mathrm{NaF}$ and containing $\mathrm{Na}$ or $\mathrm{Li}$. The superconductive materials have a high superconductive transition temperature.

There are reports of interfacial electron transfer to both ground state and excited state triplet $\mathrm{C}_{60}$ and $\mathrm{C}_{70}$ in self organized planar lipid bilayers (Mauzerall and Huang 1992). The increase of positive photovoltage is due to the presence of $C_{60}$ in lipid bilayers. Because of their electron accepting properties and chemical stability, fullerenes could be used to accomplish photochemical charge separation in the supramolecular systems, initiating the first step of artificial photosynthesis.

There are several practical applications of fullerenes. Antifriction, antiwear and antiseize properties of lubricating oil are improved in the presence of $\mathrm{C}_{60}$ (Ginzburg et al 1995). The use of dissolved fullerene catalyst as inhibitor of coking reactions, thereby inhibiting formation of coke on a catalyst or catalyst support by eliminating nucleating points or growth regions for such coke formation is reported by Malhotra et al (1994). In petrochemical and refining industries, efficient production of many hydrocarbon products are often hindered by fouling, resulting from unwitting polymerization of reactive olefins like 1,3-butadiene, isoprene or styrene. It is shown that (McClaim 1995) ppm levels of fullerenes inhibit the thermal polymerization of activated olefins like styrene and butyl methacrylate. The extent of polymerization and the molecular weight of the recovered polymer are strongly dependent on fullerene concentration. Fullerenes apparently inhibit polymerization by scavenging monomer species that propagate chain growth. Fullerene antifoulants would offer several advantages over existing technologies since they contain no hetero atoms.

One of the most promising practical applications of the fullerenes involve their optical limiting properties (Maggini et al 1995). The preparation of glassy thin films containing fullerenes would offer the possibility of producing filters against optical damage in a number of applications such as protection from high energy laser light. The authors report the successful embedding of fulleropyrrolidines, which are prepared employing the 1,3-dipolar cycloaddition reaction of azomethine ylides to $\mathrm{C}_{60}$, in sol-gel $\mathrm{SiO}_{2}$ films and monoliths. Mixtures of cyclofluoroalkylated fullerenes are prepared by the thermal $[2+2]$ cycloaddition of fluoroalkenes to a solution or slurry of a fullerene. The cyclofluoro alkylated fullerene mixtures are useful as lubricants or additives to lubricants; in fluorocarbon and/or CFC based cooling systems; in adhesives for fluorocarbon based polymers and in gas separation membranes (Bekiarian et al 1995). 
The frictional behaviour of fullerenes have been studied by Zhao et al (1995). For the sublimated pure $\mathrm{C}_{60}$ films on $\mathrm{Si}(001)$, a high friction coefficient is observed under different loads and pin materials. For the $\mathrm{C}_{70}$ film, the friction coefficient shows pin dependence which changes from 0.5 with $\mathrm{Al}_{2} \mathrm{O}_{3}$ pin to about 0.9 with 440SS pin. The relatively high friction coefficient of $C_{60}$ and $C_{70}$ films is due to high friction coefficient of $\mathrm{C}_{60}$ and $\mathrm{C}_{70}$ particles to clump and compress into a high shear strength layer.

\section{Synthesis and extraction}

First Krätschmer et al (1990) and later Haufler et al (1990) gave the procedure for the production of macroscopic quantities of fullerenes. Krätschmer et al (1990), reported the evaporation of graphite electrodes in an atmosphere of $\sim 100$ torr of helium, the soot deposited as a film inside the evaporation chamber was collected and dispersed in benzene, $\mathrm{CS}_{2}$ or $\mathrm{CCl}_{4}$. The solution was then separated from the soot and dried by gentle heating which left a residue of dark brown to black crystalline material. Haufler et al (1990) used a $6 \mathrm{~mm}$ (O.D.) graphite rod kept in contact with graphite disk at $\sim 10^{-6}$ torr initially, and thereafter maintained the pressure of helium at 100 torr. The evaporation was accomplished by the contact arc process by $100-200 \mathrm{~A}$ current and an $\mathrm{mms}$ voltage of 10-20 V. The material was extracted from boiling toluene in a soxhlet extractor. A black powder, with a yield of $8-12 \%$ of the original graphite soot was obtained. Thin films and powder samples of the new material could be handled without special precautions. It was found to be stable in air for at least several weeks. Mass spectrometry and IR spectroscopy results suggest that $C_{60}$ and $C_{70}$ are the most dominant pure carbon species present in these samples.

Optical microscopic studies of the material after evaporation show a variety of crystals mainly rods, platelets and starlike flakes. All crystals exhibit a 6-fold symmetry. In transmitted light they appear red to brown, and in reflected light the larger crystals have a metallic appearance whereas platelets show interference colours.

A study by McElvany et al (1993) demonstrated the possibility of fullerene formation by coalescence of large cyclic species controlling reaction output by the size of the precursors. In an attempt towards the total synthesis of buckminsterfullerene, Abdourazak et al (1995) reported the synthesis of semibuckminsterfullerene 4 (a 'buckybowl'), the symmetrical half of buckminsterfullerene ('buckyball'). A number of such buckybowls $\left(\mathrm{C}_{30} \mathrm{H}_{n}\right)$ can result from 'halving' buckminsterfullerene (4-8) to produce two isometric bowl-shaped units (figure 3), followed by addition of hydrogens to the dangling bonds. While the possible dimerization of 4 to $\mathrm{C}_{60}$ remains to be explored, these buckybowls represent an exciting new class of compounds and will likely show some unique chemistry associated with its concave as well as convex surfaces. Rubin et al (1996) propose an unconventional approach to the rational synthesis of stable endohedral metal fullerene complexes from polyalkynyl precursors on the basis of their remarkable property of cyclo $[n]$ carbons to rearrange to fullerene in gas phase. The polyalkynyl precursor 


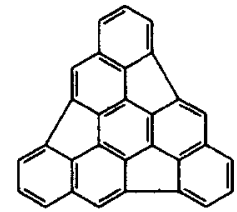

4

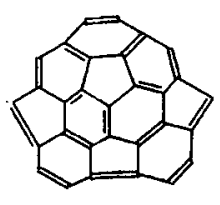

$\mathbf{s}$

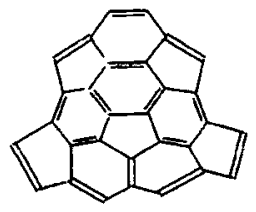

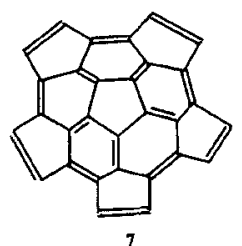

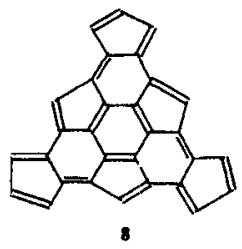

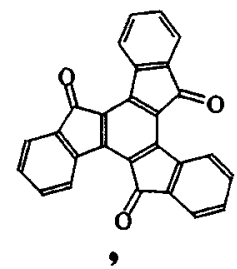

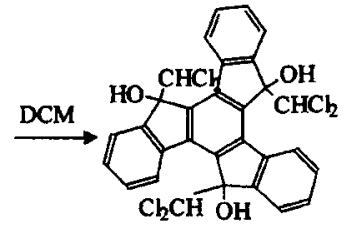

10

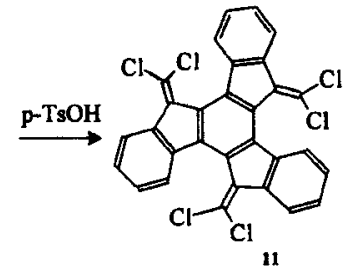

11

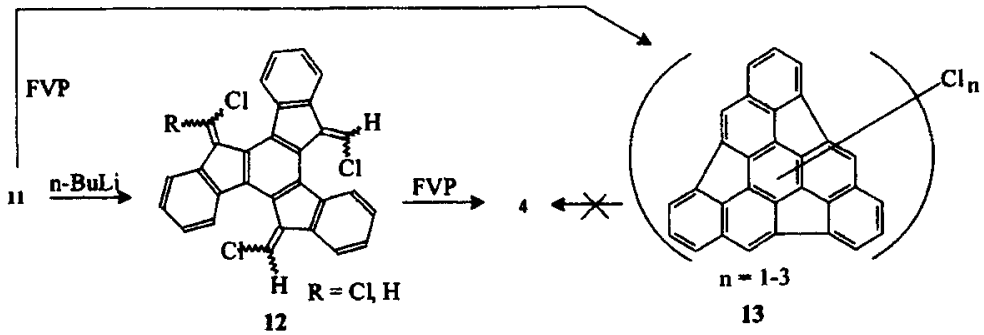

Figure 3. Synthesis of 'Buckybowl', the symmetrical half of $\mathrm{C}_{60}$ (DCM, lithium dichlorohexylamine; FVP, flash vacuum pyrolysis (Abdourazak et al 1995)).

cyclophane $\left(\mathrm{C}_{60} \mathrm{H}_{18}\right)$ is prepared from 1,3,5-triethynylbenzene. MALDI, FTMS and APCI negative ion mass spectroscopic studies on cyclophane show the formation of clusters of peaks ranging from $\mathrm{C}_{60} \mathrm{H}_{14}$ to $\mathrm{C}_{60} \mathrm{H}_{18}$, with $\mathrm{C}_{60} \mathrm{H}_{18}$ as a prominent ion.

Lamparth et al (1995) for the first time reported the formation of nitrogen heterofullerenes, $\mathrm{C}_{59} \mathrm{~N}^{+}$and $\mathrm{C}_{69} \mathrm{~N}^{+}$, which are formed by the fragmentation of regioselectively synthesized iminofullerene derivatives. The specific arrangement of the nitrogen addends facilitates the removal of a carbon atom from the fullerene core and the incorporation of a nitrogen atom. 


\section{Characterization of fullerene clusters}

Krätschmer et al (1990) characterized the new material by mass spectrometry, IR and UV absorption spectroscopy, X-ray and electron diffraction. Later Cox et al (1991) characterized the samples by using thermal desorption mass spectrometry with both electron impact ionization and chemical ionization detection, IR absorption, ESR, HPLC, electrochemistry and transmission electron microscopy.

Mass spectral studies indicated a very intense peak for $\mathrm{C}_{60}$ at $720 \mathrm{amu}$. It was evident from MS studies that air stable $C_{n}(n=62,64,66,68,70)$ species are present in the sample. The signal for $\mathrm{C}_{60}$ starts at about $300^{\circ} \mathrm{C}$ whereas the initial signal for $\mathrm{C}_{70}$ starts at about $350^{\circ} \mathrm{C}$. In $\mathrm{Cl}-\mathrm{MS}$, the intensity ratio between the molecular anion and protonated ion is $15: 1$, which indicated that electron capture was much more favourable than protonation, for both $\mathrm{C}_{60}$ and $\mathrm{C}_{70}$. Normal phase HPLC separation and FAB-MS indicated the ratio of $C_{60}$ and $C_{70}$ in the sample as 3:1. A 60 atom planar carbon cluster was estimated to be thermodynamically less stable than spherical $\mathrm{C}_{60}$.

HPLC purified samples of $\mathrm{C}_{60}$ and $\mathrm{C}_{70}$, dissolved in toluene and deposited onto $\mathrm{KBr}$ pellet showed four intense absorptions in the FTIR spectra at 1429, 1181, 576 and $527 \mathrm{~cm}^{-1}$ which are in accordance with icosahedral symmetry of $\mathrm{C}_{60}$. A number of additional weak signals are also present in the spectrum, which according to Krätschmer et al $(1990 \mathrm{a}, \mathrm{b})$ might be absorption by the $\mathrm{C}_{70}$ molecule or symmetry breaking produced by isotopes other than ${ }^{12} \mathrm{C}$ in $\mathrm{C}_{60}$ molecule or by mutual interaction of the $\mathrm{C}_{60}$ molecules in the material. Of these four dipole active vibrational modes, three at 1429,576 and $527 \mathrm{~cm}^{-1}$ lie very close to $C_{70}$ absorptions while the absorption at $1181 \mathrm{~cm}^{-1}$ corresponds to $\mathrm{C}_{60}$ only. The FTIR absorptions for $\mathrm{C}_{70}$ appear at 1132, 795, 674, 642 and $458 \mathrm{~cm}^{-1}$. Picosecond time-resolved near-IR spectra obtained by pump-probe measurement showed singlet and triplet excited state absorption for $\mathrm{C}_{60}$ in the region $700-1300 \mathrm{~nm}$ (Watanabe et al 1996).

Solution NMR spectra showed that $\mathrm{C}_{60}$ molecule had icosahedral point group symmetry (Johnson et al 1990; Taylor et al 1990). ${ }^{13} \mathrm{C}$ NMR spectra of $\mathrm{C}_{60}$ showed only one peak at $143 \mathrm{ppm}$, in accordance with 60 equivalent carbon atoms, while $\mathrm{C}_{70}$ gave five weak peaks at $150 \cdot 4,147 \cdot 9,147 \cdot 2,145 \cdot 2$ and $130.9 \mathrm{ppm}$ in the intensity ratio of $10: 20: 10: 20: 10$ corresponding to five types of carbons present (Ajie et al 1990; Cox et al 1991). Yannoni et al (1991) reported that in the solid state, lowering the ambient temperature down to $77 \mathrm{~K}$, the rotation of $\mathrm{C}_{60}$ ceases to an extent such that the carbon chemical shift anisotropy can be measured.

ESR spectra of $\mathrm{C}_{60}$ sample recovered by a toluene rinse of the $\mathrm{KBr}$ pellet showed no evidence of the presence of any free radicals at room temperature (Cox et al 1991). Singlet atom attachment to each symmetry-equivalent carbon site should result in the formation of a unique fulleryl radical for $C_{60}$. Lappas et al (1994) reported the muon spectra of $\mathrm{C}_{70}$ and identified all the five isomers, resulting from $\mathrm{Mu}$ (the light isotope of hydrogen) addition to the five inequivalent sites of $\mathrm{C}_{70}$.

D-term or nonadiabatic scattering in a resonance Raman spectrum for $\mathrm{C}_{60}$ indicated the presence of substantial nonadiabatic vibrionic coupling through $\mathrm{D}$ term scattering between certain excited electronic states of $\mathrm{C}_{60}$ (Armstrong and Lay 1994). 
Cyclic voltametry and differential pulse polarographic studies showed that three electrons could be added reversibly to $C_{n}$ cluster. First reduction wave potential for both $\mathrm{C}_{60}$ and $\mathrm{C}_{70}$ were same even in different solvents (Wudl et al 1991). Theoretical calculations also indicated a triply degenerate LUMO, which suggested that at least 3 electrons could be added relatively easily.

$\mathrm{C}_{60}$ also possesses very high electron affinity and ionization potential, electron capture produces more $s p^{3}$ character, which decreases the strain energy, while electron loss increases the $s p^{2}$ character increasing the strain energy.

$\mathrm{X}$-ray and electron diffraction studies indicated that $\mathrm{C}_{60}$ molecules form a regular lattice with a d-spacing of $8 \cdot 7 \AA$ corresponding to the $(100)$ reciprocal lattice vector of hexagonal lattice (Krätschmer et al 1990). These studies further suggest that the $\mathrm{C}_{60}$ molecules seem to assemble themselves into a somewhat ordered array as if they are effectively spherical, possessing partial crystallinity and shaped like soccer balls. $\mathrm{C}_{60}$ molecule has $\sim 7 \AA$ diameter cavity and the nearest neighbour distance is $10.02 \AA$. The difference represents the effective van der Waals diameter set by repulsion of the $\pi$-electron clouds extending outward from each carbon atom.

Thermodynamic properties reported by Mathews et al (1992) showed the enthalpy of sublimation to be $181.4 \pm 2.3 \mathrm{~kJ} / \mathrm{mol}$ at $700 \mathrm{~K}$ and the vapour pressure as a function of temperature represented by the empirical relation:

$$
\log \left(P / P_{\mathrm{a}}\right)=-9777 \pm 138 / \mathrm{T}(\mathrm{K})+11 \cdot 582 \pm 0 \cdot 126
$$

The STM studies for $\mathrm{C}_{60}$ and $\mathrm{C}_{70}$ layers on ordered $\mathrm{Au}(111)$ and $\mathrm{Au}(110)$ surfaces were reported by Weaver et al (1992) and the results showed the hexagonal close packed layer for both $\mathrm{C}_{60}$ and $\mathrm{C}_{70}$ on $\mathrm{Au}(111)$. On the $\mathrm{Au}(110)$ surface the molecules are less ordered but are held more rigidly.

Garrell et al (1991) used surface-enhanced Raman (SER) spectroscopy to obtain a clear picture of the surface interactions and the structure of $\mathrm{C}_{60}$ on gold. In the SER spectrum of pure $\mathrm{C}_{60}$ on gold, with no applied potential, 22 bands were clearly identified. The differences between the SER and Raman spectra provide evidence for, both $\mathrm{C}_{60}$ and $\mathrm{C}_{70}$, a loss of symmetry and a change in the electronic structure of $\mathrm{C}_{60}$ upon adsorption.

Simulation studies showed $\mathrm{C}_{60}$ to be stable against spontaneous disintegration up to $5000 \mathrm{~K}$ (Wang et al 1992). Intersystem crossing to produce triplet state $\mathrm{C}_{60}$ and $\mathrm{C}_{70}$ are efficient in this case and triplet state energy is found to be $\sim 33 \mathrm{Kcal} / \mathrm{mol}$ (Foote et al 1991). Both are very potent generators of singlet oxygen and are inert towards photooxidative damage to biological systems. But the production of singlet oxygen is useful for photobiological or photopolymerization applications. A strong paramagnetic current for five-membered rings and a mild diamagnetic current for six-membered rings are reported. Due to the overall neutrality of $\mathrm{C}_{60}$, the 'current per ring effect' must be larger in the five membered rings.

The successful preparation of a solid solution of $\mathrm{C}_{60}$ in a $\mathrm{SiO}_{2}$ glass matrix by means of sol-gel chemistry was reported by McBranch et al (1994). Raman spectroscopy and X-ray diffraction were used to verify that the synthetic route produces glasses with a homogeneous dispersion of intact fullerenes. The vibration spectrum of $\mathrm{C}_{60}$ is preserved in $\mathrm{C}_{60} / \mathrm{SiO}_{2}$ gel glass. 
$70 \mathrm{~nm}$ thick $\mathrm{SiC}$ films were fabricated on $\mathrm{Si}(100)$ wafers under ultrahigh vacuum conditions by depositing $\mathrm{C}_{60}$ molecules on substrates held at $900^{\circ} \mathrm{C}$ (Chen et al 1994). The composition and morphology of the films are measured using IR spectroscopy and atom force microscopy.

Oxygen-induced changes in optical properties, structure and conductivity of buckminsterfullerene films have been studied by Makrarova et al (1995). O-exposure leads to surface layer formation on the fullerene film. A small amount of oxygen molecules penetrate into the bulk film causing depth-variation of the film-optical parameters, refractive index and extinction coefficient which is attributed to the electronic states in the HOMO and LUMO bands.

$\mathrm{C}_{60}$ films up to $1000 \AA$ thick were grown by sublimation at room temperature onto $\mathrm{Si}(100)$ and $\mathrm{Si}(111)$ substrates that were prepared with surface passivation against dangling bonds. $X$-ray diffraction measurements reveal that films deposited on such substrates have a high degree of (111)-textured crystallinity which is absent in films deposited on untreated $\mathrm{Si}$, Implications for possible device applications are also discussed (Hebard et al 1995).

Stable Langmuir monolayers of monosubstituted $\mathrm{C}_{60}$-malonic acid were formed on pure water and on solutions containing $\mathrm{Ca}^{2+}$ or $\mathrm{Cd}^{2+}$ ions (Patel et al 1996). The results of surface pressure-area isotherm studies for $\mathrm{C}_{60}\left[\mathrm{C}(\mathrm{COOH})_{2}\right]$ suggested that the divalent cations intercalate between monolayers to give expanded films that can be compressed to solid phases, but on further compression revert back to close-packed monolayers depleted of metal ions.

$\mathrm{C}_{60}$ molecules were incorporated into the interlayer of a layered $\mathrm{Mg} / \mathrm{Al}$ double hydroxide compound and the physicochemical properties of these spherical molecules arranged in two dimensional arrays were examined (Wen-Yi et al 1996). To identify the $\mathrm{C}_{60}$ environment solid state ${ }^{13} \mathrm{C}$ NMR was employed. The results indicate that $\mathrm{C}_{60}$ molecules do not rotate as freely as in the pure solid form and experience rather intimate interactions with either the interlayer proton-containing species or the lattice atoms.

Endo et al (1996) adopted electrochemical methods to obtain $\mathrm{A}_{x} \mathrm{C}_{60}(\mathrm{~A}=\mathrm{Rb})$ film from an organic electrolyte solution including $\mathrm{C}_{60}$ molecules. The used solution was a mixture of $0.3 \mathrm{mM}^{-\mathrm{C}_{60}}, 0.1 \mathrm{~N}-\mathrm{RbClO}_{4}$ and $\mathrm{DMF}$. The particles in the obtained film had a spindle like shape and grew up to the size of $\sim 1 \mu \mathrm{m}$ depending on the reaction temperature. Raman spectra of the film showed the existence of solid $\mathrm{C}_{60}$ and revealed the features of polymeric $\mathrm{RbC}_{60}$.

A novel complex thin film of 2,6-bis(2,2-bicyanovinyl)pyridine (BDCP) and $\mathrm{C}_{60}$ have been fabricated by vacuum co-evaporation of BDCP and $\mathrm{C}_{60}$ from different evaporation sources (Ouyang et al 1996). The $\mathrm{C}_{60}-\mathrm{BDCP}$ thin films have shown totally different optical and electronic properties from the films of both the BDCP and $\mathrm{C}_{60}$. Stable and reproducible electronic bistable properties have been observed in sandwich like devices $\mathrm{Ag} / \mathrm{C}_{60}-\mathrm{BDCP} / \mathrm{Ag}$.

Fullerenes, due to their strong electron accepting ability can be hole generators in conducting polymers sensitizing photoinduced charge transfer. The photoconductivity of poly(2,5-dialkoxy-p-phenylene-vinylene) is enhanced by several orders of magnitude upon introduction of several mole \% of $C_{60}$ (Yoshino et al 1993). Positive polarons photogenerated with increased efficiency due to automization of 
excitons and/or photopumping from fullerene are considered to be responsible for enhanced photoconductivity. Photoluminescence of polymer is strongly quenched upon $\mathrm{C}_{60}$ doping due to dissociations of excitons accompanied by electron transfer to fullerene. The resonant nonlinear optical (NLO) properties and excited dynamics of pristine, chemically and photochemically modified $\mathrm{C}_{60}$ are studied at $590.5 \mathrm{~nm}$ by time-resolved degenerate four wave mixing and nonlinear transmission (Kafafi et al 1994). The chemically modified fullerene consists of (i) composite films of $\mathrm{C}_{60}$ with meso-tetraphenyl porphine (TPP) prepared by vacuum vapour deposition and (ii) spin-coated films of solutions $\mathrm{C}_{60}$ mixed with the conjugate polymer, poly-[2methoxy,5-(2'-ethylhexyloxy)-p-phenylene vinylene] (MEH-PPV). Photopolymerization of $\mathrm{C}_{60}$ leads to an enhancement of its physical properties without substantial alteration of its NLO properties. $\mathrm{C}_{60}$ and TPP form a ground state charge-transfer complex with an enhanced NLO response. $\mathrm{C}_{60}$ and MEH-PPV form a chargetransfer complex in the excited state, which gives rise to more than an order of magnitude increase in the NLO response for $\mathrm{C}_{60}$, poly- $\mathrm{C}_{60}, \mathrm{C}_{60}$ : TPP and $\mathrm{C}_{60}$ : MEH-PPV films. Lee et al (1994) reported the results of comprehensive measurements of photoconductivity in films of $\mathrm{MEH}-\mathrm{PPV}$ and $\mathrm{MEH}-\mathrm{PPV} / \mathrm{C}_{60}$ composites. The peak transient photoconductivity of MEH-PPV is proportional to the light intensity and electric field, and independent of temperature. The transient photoconductivity (life time and magnitude) of MEH-PPV increases substantially on increasing the concentration of $\mathrm{C}_{60}$ in $\mathrm{MEH}-\mathrm{PPV} / \mathrm{C}_{60}$ composite films. To account for the observed photoinduced absorption, Conwell et al (1995) determined the position of $\mathrm{C}_{60}$ relative to $\mathrm{MEH}-\mathrm{PPV}$ chains. With the use of Monte-Carlo cooling algorithm, the most probable position of $\mathrm{C}_{60}$ is in channel formed by the alkoxide chains, its center $\sim 10 \AA$ from that of the $\mathrm{MEH}-\mathrm{PPV}$ backbone. Photoexcitations in MEH-PPV and $\mathrm{MEH}-\mathrm{PPV} / \mathrm{C}_{60}$ composites were also studied by photoinduced absorption and absorption detected magnetic resonance spectroscopy (Wei et al 1996). The authors provide direct evidence that the prominent triplet photoexcitations in pristine $\mathrm{MEH}-\mathrm{PPV}$ are effectively quenched in $\mathrm{MEH}-\mathrm{PPV} / \mathrm{C}_{60}$.

The introduction of $1 \%$ of fullerenes into polystyrene matrix leads to a significant increase in the electrical conductivity of the system (Aleshin et al 1995). Films of fullerene containing PS are prepared by mixing toluene solutions of PS and $C_{60}$ and developed on $\mathrm{Si}, \mathrm{GaAs}$ and glass substrates. The general features of charge transfer processes in fullerene/conducting polymers (CP) systems, such as energetics of photoinduced charge transfer (PCT) between $\mathrm{C}_{60}$ and $\mathrm{CP} \pi$-electronic states, geometry of $\pi-\pi$ overlapping and the role of self trapping effects to polaronic states on $\mathrm{C}_{60}$ and CP chains on the PCT dynamics are analysed (Yoshino et al 1995).

\section{Reactivity of fullerenes}

Stability of fullerenes is a balance between strain and aromaticity. Although previously $\mathrm{C}_{60}$ was predicted to be stable, later it was found to be much more reactive. Stability of this molecule was attributed to it being the smallest fullerene in which all the 12 pentagons are isolated from each other. Schmalz et al (1986), Hosoya (1986), Brendsdal and Cyvin (1989), and Klein et al (1986) (counting the Kekule structure of 


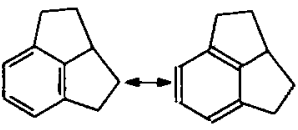

14

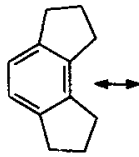

16

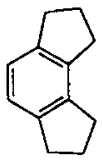

17

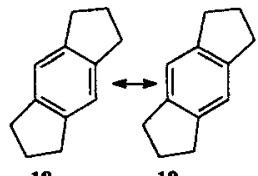

19

Figure 4. A hexagon fused to two pentagons is shown as three resonating pairs. In structure 16 a double bond does not exist on a five-membered ring.

buckminsterfullerene) reported that 12,500 resonance structures are possible in $\mathrm{C}_{60}$. Let us consider a situation where a six-membered ring containing three alternate $\pi$-bonds is fused to two five-membered rings. Three possibilities would arise, each existing as a resonating pair (figure 4). Of the six possible structures, in one structure (16) there is no double bond at the $[5,6]$-ring junction. A double bond in a fivemembered ring increases strain and therefore decreases stability. For fullerene to be structurally stable, all the double bonds should be placed in such a manner that there would be no double bonds at the $[5,6]$-ring junction. Hence out of the 12,500 possible resonating structures of fullerene, there is only one structure in which the double bonds are localized, no double bonds being present at the [5,6]-ring junction making fullerene a reactive molecule containing $60 \pi$-bonds. Thus $\mathrm{C}_{60}$ exhibits less aromaticity than benzene. Due to the lack of delocalization, the bond length of $\mathrm{C}=\mathrm{C}$ bonds in fullerene are less than that in benzene. The reactivity of $\mathrm{C}_{60}$ is not like that of electron rich planar aromatic molecules. The $\mathrm{C}-\mathrm{C}$ double bonds of $\mathrm{C}_{60}$ react like those of very electron deficient arenes and alkenes. Therefore $\mathrm{C}_{60}$ behaves as an electron deficient 'superalkene' rather than as a 'superaromatic'. Due to electron attracting nature, it readily reacts with nucleophiles.

Fullerenes do not undergo any substitution reaction because of nonattachment of any hydrogen or other groups to the carbon framework. But, these molecules undergo various types of addition reactions with polyconjugated and electron deficient alkenes, and also polymerization reaction with various reagents are known. The derivatives of fullerene show a wide range of solubility and differ in many respects from parent molecule.

$\mathrm{C}_{60}$ appears to be more electrophilic than $\mathrm{C}_{70}$ evidenced from ${ }^{1} \mathrm{H}$ NMR of hydrogenated fullerene. Fullerenes undergo halogenation, oxygenation, metalation and methylation via either thermal, photochemical, electrophilic, nucleophilic or radical path. There are twelve pentagons in $\mathrm{C}_{60}$ arranged in the form of six pyracylene units (20) (figure 5). Six electrons can be reversibly added to both $\mathrm{C}_{60}$ and $\mathrm{C}_{70}$ across the pyracylene unit present in fullerene. Addition of one electron to each pyracylene unit creates aromaticity in one of the pentagonal rings (figure 6). This is the driving force for octahedral addition.

$\mathrm{C}_{60}$, with icosahedral $\left(I_{\mathrm{h}}\right)$ symmetry, has only one type of carbon atom and two types of $\mathrm{C}-\mathrm{C}$ bonds i.e. at the $[6,6]$ - and $[5,6]$-ring fusion sites. But $\mathrm{C}_{70}$ has $D_{5 \mathrm{~h}}$ symmetry and it consists of 5 types of carbon atoms (figure 7), i.e. a-e and eight types of $\mathrm{C}-\mathrm{C}$ bonds (Balch et al 1991). Thus $\mathrm{C}_{60}$ can be substituted multiple times by electron rich reagents, and a total of at least 12 carbon atoms of the $\mathrm{C}_{60}$ framework can participate in bonding. 


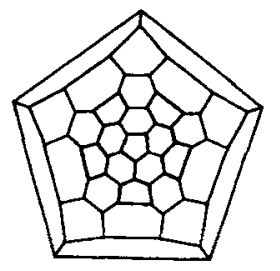

20

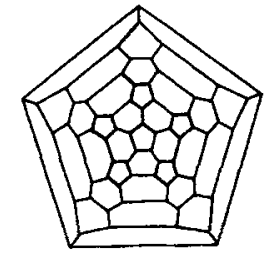

21

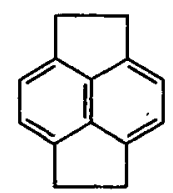

22

Figure 5. Schegel diagram of $C_{60}(20)$ and $C_{70}$ (21) showing the arrangement of the pentagons and the hexagons forming the pyracylene units (22) (Taylor and Walton 1993).

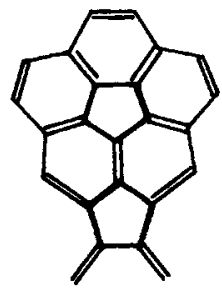

23

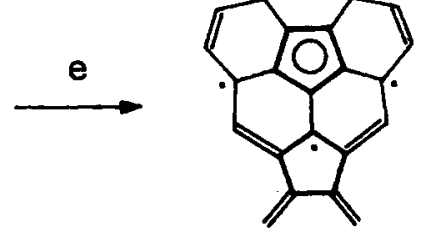

24

Figure 6. Addition of electron to a pyracylene unit creates aromaticity in the pentagonal rings (Taylor et al 1993).

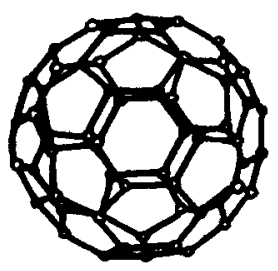

25

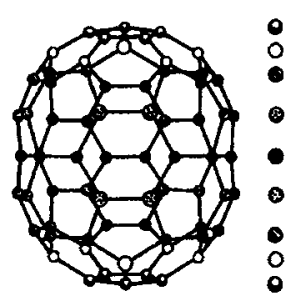

26

Figure 7. $\mathrm{C}_{60}$ has one type of carbon atom and two types of $\mathrm{C}-\mathrm{C}$ bonds whereas $\mathrm{C}_{70}$ has five types of carbon atoms and eight types of $\mathrm{C}-\mathrm{C}$ bonds (Balch et al 1991a).

$\mathrm{C}_{60}$ and $\mathrm{C}_{70}$ are decomposed by light, with oxygen and ozone playing the crucial role. Mass spectroscopy studies indicate that the molecules undergo complete fragmentation. Fragmentation is less if carried out under nitrogen. Films of $\mathrm{C}_{60}$ degrade on storage because of the ability of $\mathrm{C}_{60}$ to chemisorb oxygen and on heating in oxygen, $\mathrm{C}_{60}$ gradually gets oxidized. IR and NMR spectra of the degraded products (Taylor et al 1991) indicate that $\mathrm{C}-\mathrm{H}$ (including aromatic $\mathrm{C}-\mathrm{H}$ ), $\mathrm{C}=\mathrm{O}, \mathrm{C}-\mathrm{O}, \mathrm{C}=\mathrm{C}$, substituted aromatic or alkene, $\mathrm{C}=\mathrm{C}, \mathrm{C}_{2} \mathrm{H}_{5}, \mathrm{CH}_{2}$, alkyl- $\mathrm{O}, \sim \mathrm{CH}_{2}-\mathrm{O}$ groups are 
present. Ozonolysis of fullerene $\mathrm{C}_{60}$ generated a mixture of oxidized products having ketone, ester and epoxide functionalities (Malhotra et al 1994).

$\mathrm{C}_{60}$ acts as both oxidizing and reducing agent. The oxidizing properties of $\mathrm{C}_{60}$ are evident from the oxidation of $\mathrm{H}_{2} \mathrm{~S}$ to sulphur in the presence of $\mathrm{C}_{60}$. Similarly, $\mathrm{C}_{60}$ also undergoes reduction under Birch reduction conditions by hydrogen with $\mathrm{Pt}$ catalyst, diimide, hydrogen transfer reagents such as dihydrophenanthrene and diborane in THF to give hydrofullerene i.e. $\mathrm{C}_{60} \mathrm{H}_{18}, \mathrm{C}_{60} \mathrm{H}_{36}$ and $\mathrm{C}_{60} \mathrm{H}_{2}$ (Taylor and Walton 1993). $\mathrm{C}_{70}$ also undergoes reduction, and hexaanion formed is more stable in case of $\mathrm{C}_{70}$ and the addition across each pyracylene unit yields $\mathrm{C}_{70} \mathrm{H}_{12}$.

\section{Exo- and endohedral complex chemistry}

The structure of $\mathrm{C}_{60}$ is comprised of rigid spheres of radius $4.98 \AA$ with fcc packing ( $a=14 \cdot 1 \AA$ ), leaving two vacant tetrahedral sites and one octahedral site per $\mathrm{C}_{60}$ molecule. These sites are of sufficient size to accommodate spheres of radius $1 \cdot 12 \AA$ and $2.06 \AA$ respectively. Due to the $\sim 7 \AA$ diameter of $\mathrm{C}_{60}$ cavity, other elements and small molecules can be encapsulated into the cavity, which alters its physical and chemical properties (Freiser et al 1991).

McElvany and Callahan (1991) reported the protonation of $\mathrm{C}_{60}, \mathrm{C}_{70}, \mathrm{C}_{76}, \mathrm{C}_{80}$ and $\mathrm{C}_{84}$, which were detected by triple quadruple and $\mathrm{FT}$ mass spectrometry and the proton affinity lies between that of ammonia and hexamethyl benzene, being close to $\mathrm{NH}_{3}$, and proton affinity of $\mathrm{C}_{70}$ is greater than that of $\mathrm{C}_{60}$. Proton transfer could occur between $\mathrm{CH}_{5}^{+}, \mathrm{H}_{3} \mathrm{O}^{+}, \mathrm{CH}_{3} \mathrm{OH}_{2}^{+}$and $\mathrm{NH}_{4}^{+}$and the fullerene nucleus.

$\mathrm{C}_{60} \mathrm{H}^{+}$can also be generated by the reaction of $\mathrm{C}_{60}^{+}$ions with atomic hydrogen and this can react with another hydrogen atom giving rise to fullerene ion and molecular hydrogen. This reaction is thermodynamically allowed. The molecular hydrogen is responsible for surface recombination of instellar dust grains. $\mathrm{C}_{60}^{+}, \mathrm{C}_{60}^{2+}$, $\mathrm{C}_{70}^{+}$and $\mathrm{C}_{70}^{2+}$, all can react with atomic hydrogen (Petrie et al 1992) and finally $\mathrm{C}_{60} \mathrm{H}_{n}^{+}, n$ up to 3 and $\mathrm{C}_{60} \mathrm{H}_{n}^{2+}, n$ up to 4 are formed. A slow hydride transfer between $\mathrm{C}_{60}^{2+}$ and the saturated hydrocarbon molecules such as $\mathrm{C}_{3} \mathrm{H}_{8}, n-\mathrm{C}_{4} \mathrm{H}_{10}$ and $i-\mathrm{C}_{4} \mathrm{H}_{10}$ has been observed in SIFT experiments (Bohme et al 1992):

$$
\mathrm{C}_{60}^{2+}+\mathrm{RH} \longrightarrow \mathrm{C}_{60} \mathrm{H}^{+}+\mathrm{R}^{+}
$$

Endohedral complex with heliu in be formed by the high energy collision of $\mathrm{C}_{60}$ and $\mathrm{C}_{70}$ radical cations with helium target to form $\mathrm{C}_{n} \mathrm{He}^{+}(n=48-58)$ (Gross 1991). This group of workers also studied (Gross et al 1992) high energy collisions of $\mathrm{C}_{n} \mathrm{He}^{+}$ with $\mathrm{D}_{2}, \mathrm{~N}_{2}, \mathrm{NO}$ or $\mathrm{O}_{2}$. A four sector tandem mass spectrometer was used to study the collision reactions. It was observed that the small target gases got incorporated into the intact fullerene radical cations resulting in endohedral complexes.

$\mathrm{C}_{60}$ under single collision conditions over the energy range from 2 to $78 \mathrm{eV}$ (Anderson et al 1992) reacts with $\mathrm{C}^{+}$giving rise to $\mathrm{C}_{61}^{+}$, which decays to $\mathrm{C}_{60}^{+}$and $\mathrm{C}$ resulting from charge transfer. The exchange has been demonstrated by ${ }^{13} \mathrm{C}$ labelling, the ${ }^{13} \mathrm{C}$ projectile undergoing exchange with $\mathrm{C}$ atoms in the $\mathrm{C}_{60}$ target.

Green et al (1994) reported the incorporation of elemental phosphorous into hexagonal packed $C_{60}$ to give $\left[\left(P_{4}\right)_{2} C_{60}\right.$, and solid state $N M R$ shows that $P_{4}$ 


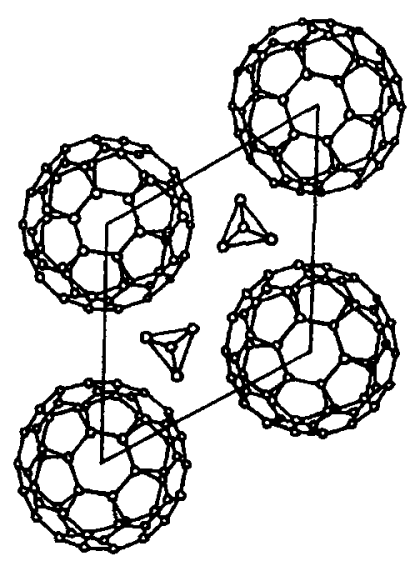

27

Figure 8. Incorporation of $P_{4}$ tetrahedra to the trigonal prismatic sites of $\mathrm{C}_{60}$ (Green et al 1994).

tetrahedra occupy trigonal prismatic sites and confirm the retention of molecular nature of the $\mathrm{P}_{4}$ guest (figure 8). Intercalation of $\mathrm{Li}$ into solid $\mathrm{C}_{60}$ is reported and the electrochemical formation of $\left[\left(\mathrm{C}_{6} \mathrm{H}_{5}\right)_{4} \mathrm{P}\right]_{3}\left(\mathrm{C}_{60}\right) \mathrm{Cl}_{2}$ as microcrystalline powder is obtained. $\mathrm{Na}_{x} \mathrm{C}_{60}(\mathrm{THF})_{y}$ is the first metallic single crystal of $\mathrm{C}_{60}$ grown by an electrocrystalline process (Kobayashi et al 1994). The formation of single crystal $\left\{\mathrm{N}\left[\mathrm{P}\left(\mathrm{C}_{6} \mathrm{H}_{5}\right)_{3}\right]^{2+}\right\} \mathrm{C}_{60}$ is reported (Kobayashi et al 1993). A phosphine or phosphinite bearing fullerene was synthesized by the reaction of a lithiated phosphine borax or a phosphinite borane with $\mathrm{C}_{60}$ followed by removal of the $\mathrm{BH}_{3}$ group, the substituent undergoing complexation with $\mathrm{BH}_{3}$ and $\mathrm{PtCl}_{2}$ selectively on the phosphorous atom (Nakamura et al 1994).

The formation of $\mathrm{C}_{60} \mathrm{~S}_{16}$ and $\mathrm{C}_{70} \mathrm{~S}_{48}$ has been reported by the addition of $\mathrm{S}_{8}$ rings to $C_{60}$ and $C_{70}$ respectively (Roth and Adelmann 1992). $A C_{60} 2 S_{8}$ complex was produced by reaction of $\mathrm{C}_{60}$ with $\mathrm{S}$ in trichloroethylene and its single crystal $X$-ray surface was studied at room temperature (Buravov et al 1994). The crystal structure of the $\mathrm{C}_{60} 2 \mathrm{~S}_{8}$ complex is a packing of fullerene molecules which form hexagonal channels along the c-axis with eight-membered cyclic molecules of $S_{8}$ with the crown conformation inside the channels. The mean value of the $\mathrm{C}_{60}$ sphere radius is 3.49 (2) $\AA$. Each $C_{60}$ molecule is linked to eight $S_{8}$ molecules with the shortened intermolecular contacts C......S 3.41(3) $\AA$ which testifies to a significant extent of localization of electron density in the $\mathrm{C}_{60}$ molecule.

$\mathrm{C}_{60}$ undergoes hydrosilylation in the presence of $\mathrm{Pt}$ or Co catalyst. With HSiMe $(\mathrm{OEt})_{2}$ hydrosilylation is accompanied by some condensation of the silicon moiety producing $\mathrm{H}_{n} \mathrm{C}_{60}-[\mathrm{SiMe}(\mathrm{OEt}) \mathrm{OR}]_{n+m}$ where $\mathrm{R}=\mathrm{Et}$ or $\mathrm{SiMe}(\mathrm{OEt}) \mathrm{H}$ (West et al 1994). Hydrolysis of the product with $\mathrm{Si}(\mathrm{OEt})_{4}$ gave a yellow-orange sol-gel glass with average composition $\mathrm{H}_{12} \mathrm{C}_{60}\left[\left(\mathrm{SiMe}_{2} \mathrm{O}\right)_{3} \mathrm{SiMe}_{2} \mathrm{H}\right]_{12}$. Hydrosilylation of $\mathrm{C}_{60}$ with a linear siloxane polymer containing $\mathrm{Si}-\mathrm{H}$ bonds along the chain led to 
multiple substitution onto the $\mathrm{C}_{60}$ framework with the siloxane effectively "wrapping up' the fullerene.

The discovery of superconductivity and ferromagnetism in salts of $\mathrm{C}_{60}$ has focussed attention on the electronic and structural properties of fulleride ion $\mathrm{C}_{60}^{n-}$. Both $\mathrm{C}_{60}^{2-}$ and $\mathrm{C}_{60}^{3-}$ salts have been isolated and their electronic ground state disobey Hund's rule and as in the case of $\mathrm{C}_{60}^{-}$, the Jahn-Teller theorem predicts a distortion from icosahedral symmetry to remove orbital degeneracy in the $\left(t_{1 \mathrm{u}}\right)^{n}$ LUMO (Paul et al 1994).

The metal fullerene complexes were produced by laser vapourization of the metal-graphite mixture under high temperature/argon flow conditions (Smalley et al 1985, 1988). $\mathrm{MC}_{60}^{+}$, the formation of which was detected by FTMS and is found to be very stable and can be fragmented only under extreme activation conditions of multiphoton absorptions at high ArF excimer laser and then by sequential loss of the $\mathrm{C}_{2}$ species (Smalley et al 1988). Exohedral $\mathrm{MC}_{60}^{+}, \mathrm{M}=\mathrm{Li}-\mathrm{Cs}, \mathrm{Fe}, \mathrm{Co}, \mathrm{Ni}, \mathrm{Cu}, \mathrm{Rh}$, $\mathrm{La}, \mathrm{U}$ and $\mathrm{VO}$ were formed by the direct attachment of $\mathrm{M}^{+}$with $\mathrm{C}_{60}$ and varying the amount of $\mathrm{C}_{60}^{+}$by charge transfer. In all the above cases the metals are attached externally to the fullerene cage (Freiser and Huang 1991; Freiser et al 1994).

The synthesis of alkali metal intercalated fullerite superconductors $\left(\mathrm{M}_{x} \mathrm{C}_{60}, x=3\right)$ are reported by Fischer and Smith (1991). Wudl et al (1992) reported the superconductivity for $\mathrm{K}_{3} \mathrm{C}_{60}$ at $18 \mathrm{~K}$. Broderick (1994) reported the solution phase synthesis of superconducting $\mathrm{M}_{3} \mathrm{C}_{60}$ via soluble alkali metal fulleride precursors. Intercalation of alkali metals by reduction of fullerene to give fullerides $\mathrm{M}_{n} \mathrm{C}_{60}(\mathrm{M}=\mathrm{Li}-\mathrm{Cs}$ and $n=0.5-6$ ) is reported (Murphy et al 1993). The synthesis of intercalated compounds of fullerenes using thermal decomposition of azides of $\mathrm{K}$ and $\mathrm{Na}$ was reported by Okotrub et al (1994). The preparation of $\mathrm{K}_{3} \mathrm{C}_{60}$ and $\mathrm{K}_{2} \mathrm{NaC}_{60}$ is by reacting $\mathrm{KN}_{3}$, $\mathrm{NaN}_{3}$ and $\mathrm{C}_{60}-\mathrm{C}_{70}$ mixtures at $\sim 390^{\circ} \mathrm{C}$. The presence of $\mathrm{C}_{70}$ affects the amount of superconducting phase formed and lowers the $T_{c}$. Henry et al (1995) reported the reaction of face-centered cubic $\mathrm{Na}_{3} \mathrm{C}_{60}$ with ammonia at room temperature. The product $\left(\mathrm{NH}_{3}\right)_{6} \mathrm{Na}_{3} \mathrm{C}_{60}$ in which both octahedral and tetrahedral interstices in the fulleride array are occupied, despite the similarity in $\mathrm{C}_{60}^{3-}$ packing to that in $\mathrm{CsC}_{60}$, shows no superconductivity above $6 \mathrm{~K} . \mathrm{M}_{6} \mathrm{C}_{60}$ and $\mathrm{M}_{6} \mathrm{C}_{70}(\mathrm{M}=\mathrm{Cs}, \mathrm{K}, \mathrm{Na})$ exhibit remarkable catalytic activities in $\mathrm{H}_{2}-\mathrm{D}_{2}$ exchange and olefin hydrogenation at low temperature. The catalytic activities of $\mathrm{M}_{6} \mathrm{C}_{60}$ in $\mathrm{H}_{2}-\mathrm{D}_{2}$ exchange are strongly dependent on metal size, reactivity decreasing in the order $\mathrm{Cs} \gg \mathrm{K} \gg \mathrm{Na}$. The synthesis of a new ternary fulleride $\mathrm{Ba}_{2} \mathrm{CsC}_{60}$ was reported by Duggan et al (1996) by reduction of $\mathrm{C}_{60}$ by metals in liquid ammonia followed by crystallization at high temperature. The fulleride adopts a novel orientation ordering of the anions in which the $\mathrm{Ba}$ cations occupy the tetrahedral sites and $\mathrm{Cs}$ the octahedral sites.

$\mathrm{Fe}^{+}$undergoes ligand exchange reactions with preformed $\mathrm{C}_{60}$ and $\mathrm{C}_{70}$ to generate $\mathrm{FeC}_{60}^{+}$and $\mathrm{FeC}_{70}^{+}$(Freiser et al 1991). Freiser et al (1992) reported the direct attachment reaction of $\mathrm{CoC}_{60}^{+}$with $\mathrm{C}_{60}$ to form $\mathrm{Co}\left(\mathrm{C}_{60}\right)^{2+}$. It also putsed in ethylene, propene, 1-butene and isobutene to form $\mathrm{C}_{n} \mathrm{H}_{2 n} \mathrm{CoC}_{60}^{+}(n=2-4)$, which undergoes ligand displacement reaction with $\mathrm{C}_{60}$ to form $\mathrm{Co}\left(\mathrm{C}_{60}\right)^{2+}$ :

$$
\begin{aligned}
& \mathrm{CoC}_{60}^{+}+\mathrm{C}_{n} \mathrm{H}_{2 n} \longrightarrow \mathrm{C}_{n} \mathrm{H}_{2 n} \mathrm{CoC}_{60}^{+} \\
& \mathrm{C}_{n} \mathrm{H}_{2 n} \mathrm{CoC}_{60}^{+}+\mathrm{C}_{60} \longrightarrow \mathrm{Co}\left(\mathrm{C}_{60}\right)^{2+}+\mathrm{C}_{n} \mathrm{H}_{2 n}
\end{aligned}
$$


$\mathrm{Fe}$ (benzyne) ${ }^{+}$and $\mathrm{Fe}$ (biphenylene) ${ }^{+}$react with $\mathrm{C}_{60}$ to form $\mathrm{Fe} \mathrm{C}_{60}\left(\mathrm{C}_{6} \mathrm{H}_{4}\right)^{+}$and $\mathrm{FeC}_{60}\left(\mathrm{C}_{6} \mathrm{H}_{4}\right)^{2+}$. The former also undergoes charge transfer reaction with $\mathrm{C}_{60}$ to form $\mathrm{C}_{60}^{+}$(Freiser et al 1995). Here $\mathrm{C}_{60}$ behaves like a highly polarizable alkene and an electron deficient arene.

$$
\begin{aligned}
& \mathrm{Fe}^{+}+\mathrm{C}_{6} \mathrm{H}_{5} \mathrm{Cl} \longrightarrow \mathrm{FeC}_{6} \mathrm{H}_{4}^{+}+\mathrm{HCl} \\
& \mathrm{FeC}_{6} \mathrm{H}_{4}^{+}+\mathrm{C}_{6} \mathrm{H}_{5} \mathrm{Cl} \stackrel{\longrightarrow}{\longrightarrow} \mathrm{Fe}\left(\mathrm{C}_{6} \mathrm{H}_{4}\right)^{2+}+\mathrm{HCl} \\
& \mathrm{Fe}\left(\mathrm{C}_{6} \mathrm{H}_{4}\right)^{n+}+\mathrm{C}_{60} \stackrel{n=1,2}{\longrightarrow} \mathrm{C}_{60} \mathrm{Fe}\left(\mathrm{C}_{6} \mathrm{H}_{4}\right)^{n+} \\
& \stackrel{{ }_{n=1}}{\longrightarrow} \mathrm{C}_{60}^{+}+\mathrm{Fe}\left(\mathrm{C}_{6} \mathrm{H}_{4}\right) \\
& \mathrm{C}_{60} \mathrm{Fe}\left(\mathrm{C}_{6} \mathrm{H}_{4}\right)^{n+}+\mathrm{C}_{6} \mathrm{H}_{5} \mathrm{Cl} \stackrel{n=1,2}{\longrightarrow} \mathrm{C}_{60}\left(\mathrm{C}_{6} \mathrm{H}_{4}\right)^{n+}+\mathrm{C}_{6} \mathrm{H}_{5} \mathrm{FeCl}
\end{aligned}
$$

$\mathrm{C}_{60}^{+}$reacts with $\mathrm{Fe}(\mathrm{CO})_{5}$ in gas phase to give $\mathrm{Fe}(\mathrm{CO})_{4} \mathrm{C}_{60}^{+}$and $\mathrm{Fe}(\mathrm{CO})_{3} \mathrm{C}_{60}^{+}$by the elimination of $\mathrm{CO}$ and $2 \mathrm{CO}$ respectively in equal amounts. $\mathrm{C}_{60}$ acts like two electron donor species similar to an alkene ligand, exhibiting a rich exo-coordination chemistry (Freiser et al 1992; Kellogg et al 1992). Chromium coordinated $\mathrm{C}_{60}^{-}$ has been identified from ESR measurements (Wudl et al 1991).

Chai et al (1991) found that lanthanum fullerene complex $\mathrm{LaC}_{82}$ is soluble in toluene and can be extracted by this solvent. ESR spectra indicated charge-transfer complex of the form $\mathrm{La}^{3+} \mathrm{C}_{82}^{3-}$ (Johnson et al 1992). Similarly Shinohara et al (1992) reported the presence of metallofullerenes such as $\mathrm{YC}_{60}, \mathrm{YC}_{70}, \mathrm{YC}_{82}$ and $\mathrm{Y}_{2} \mathrm{C}_{82}$. ESR spectra of these complexes also indicate charge separation state of $\mathrm{Y}^{3+} \mathrm{C}_{\mathbf{8 2}}^{\mathbf{3}-}$. Reactions of excimer laser vapourized and excited fullerene $\mathrm{C}_{60}$ with $\mathrm{La}, \mathrm{Y}, \mathrm{Eu}$ and Gd were carried out in the mixtures of $\mathrm{C}_{60} / \mathrm{La}_{2} \mathrm{O}_{3}, \mathrm{C}_{60} / \mathrm{Y}_{2} \mathrm{O}_{3}, \mathrm{C}_{60} / \mathrm{Eu}_{2} \mathrm{O}_{3}$ and $\mathrm{C}_{60} / \mathrm{Gd}_{2} \mathrm{O}_{3}$ (Huang et al 1995). The reaction products $\mathrm{MC}_{60}, \mathrm{MC}_{60-2 n}$ and $\mathrm{MC}_{60+2 n}(\mathrm{M}=\mathrm{La}, \mathrm{Y}, \mathrm{Eu}, \mathrm{Gd})$ were identified by a reflection type time-of-flight mass spectrometer. The products were subjected to reactions with $\mathrm{H}_{2} \mathrm{O}, \mathrm{O}_{2}$ and $\mathrm{N}_{2} \mathrm{O}$. The metallofullerenes are nonreactive toward these molecules due to the endohedral nature of the materials.

Fullerenes with a metal inside the cage have long attracted attention as new chemical entities with novel properties as summarized in a recent review on endohedral complex (Bethune et al 1993). Endohedral complex $\mathrm{M} @ \mathrm{C}_{60}^{+}(\mathrm{M}=\mathrm{La}, \mathrm{K}, \mathrm{Cs}$, $\mathrm{He}, \mathrm{Ne}, \mathrm{Ar}, \mathrm{Y}, \mathrm{H}_{2}$ ) have been formed in the gas phase and $\mathbf{M} @ \mathbf{C}_{70}^{+}$can be formed by the reaction of $\mathbf{M} @ \mathrm{C}_{60}^{+}$and $\mathrm{C}_{70}$ (Gross 1991; Ross and Callahan 1991; Gross et al 1992; Freiser et al 1995). Cosmic ray interactions may also lead to the formation of endohedral complexes of H, D and He trapped in fullerene cages.

$\mathrm{La}$, radioactive ${ }^{159} \mathrm{Gd}$ and ${ }^{161} \mathrm{~Tb}$ can be encapsulated into the fullerene cage by neutron irradiation. The radioactive endohedral metallofullerenes were found to be stable and separable as normal metal complexes. By means of density functional calculations, the ionization energies and electron affinities of $\mathrm{Sc} @ \mathrm{C}_{82}, \mathrm{Y} @ \mathrm{C}_{82}$ and La @ $\mathrm{C}_{82}$ are predicted by Nagase and Kobayashi (1994). The results are compared with those of typical empty fullerenes such as $\mathrm{C}_{60}$ and $\mathrm{C}_{70}$. The endohedral metallofullerenes are regarded as a sort of 'super atom'. The charges on the metal is little changed even when $\mathrm{M} @ \mathrm{C}_{82}$ loses or accepts an electron. This allows the formal view that electron removal or gain takes place on the $\mathrm{C}_{82}$ cage, with the metals acting as a positive core. The first derivatization of an endohedral metallofullerene 
La@ $\mathrm{C}_{82}$ yielding an exohedral adduct was reported by Akasaka et al (1995). These workers also studied the variation of chemical properties of the endohedral complex with different encapsulated metal atoms. $\mathrm{Gd} @ \mathrm{C}_{82}$ was derivatized with $1,1,2$, 2-tetramesityl-1,2-disilirane by photoirradiation and thermal reaction. Though the disilirane did not add thermally to empty fullerenes such as $\mathrm{C}_{60}, \mathrm{C}_{70}$ and $\mathrm{C}_{82}$, a facile thermal addition to $\mathrm{Gd} @ \mathrm{C}_{82}$ took place. This is because $\mathrm{Gd} @ \mathrm{C}_{82}$ is a stronger electron acceptor than empty fullerenes.

Edelmann (1995) in a recent review discussed several endohedral metallofullerenes $\mathrm{Ln} @ \mathrm{C}_{2 n}(\mathrm{Ln}=\mathrm{Sc}, \mathrm{Y}, \mathrm{La}, \mathrm{Ce}, \mathrm{Gd} ; n=37-45), \mathrm{Ln}_{2} @ \mathrm{C}_{80}(\mathrm{Ln}=\mathrm{Sc}, \mathrm{La}), \mathrm{Sc}_{2} @ \mathrm{C}_{2 n}$ $(n=37,41,42)$ and $\mathrm{Sc}_{3} @ \mathrm{C}_{82}$. Scandium preferably forms endohedral fullerene complexes with two atoms trapped inside the fullerene cage $\left(\mathrm{Sc}_{2} @ \mathrm{C}_{74}, \mathrm{Sc}_{2} @ \mathrm{C}_{82}\right.$ and $\left.\mathrm{Sc}_{2} @ \mathrm{C}_{84}\right)$. Other major species that form during the course of reaction are $\mathrm{Sc} @ \mathrm{C}_{82}$ and $\mathrm{Sc}_{3} @ \mathrm{C}_{84}$. In $\mathrm{Sc}_{3} @ \mathrm{C}_{82}$, the three $\mathrm{Sc}$ atoms form an equatorial triangle. Metallofullerenes of Sc, $\mathrm{Y}$ and La are produced by arc-vapouring mixtures of graphite and lanthanide oxide rods in helium atmosphere. The yield is however only $0 \cdot 1 \%$ of the product soot. A 10-fold increase in the yield of La@ $\mathrm{C}_{82}$ is achieved by adopting graphite rod with lanthanum carbide instead of lanthanum oxide rods in helium atmosphere. The metal-filled complex is associated with empty fullerenes, which are separated by silica-packed HPLC column in which tetraphenylporphyrin moieties are anchored to silica surface through carboxyl groups.

Nagashima et al (1992) reported an organometallic polymer $\mathrm{C}_{60} \mathrm{Pd}_{n}$, which was prepared from $\mathrm{C}_{60}$ and $\mathrm{a} \mathrm{Pd}^{\circ}$ and the ratio can be varied by thermal disproportionation. In this case palladium atom acts as a binder of $\mathrm{C}_{60}$ by coordination to the $\pi$-electron on the aromatic surface and two $\mathrm{C}_{60}$ atoms are bound to one palladium atom. This polymeric species are neutral, amorphous and stable to air. $\left(\mathrm{R}_{3} \mathrm{P}\right)_{2} \mathrm{PdC}_{60}$ (toluene) $(\mathrm{R}=\mathrm{Ph}$, cyclohexyl) were prepared in high yields by treating $\mathrm{Pd}_{2}(\mathrm{dba})_{3}\left(\mathrm{dba}=\right.$ dibenzylideneacetone) with $\mathbf{R}_{3} \mathbf{P}$ in toluene followed by treating with $\mathrm{C}_{60}$ (Anon 1994). Pt complexes of $\mathrm{C}_{60}$ and $\mathrm{C}_{70}$ were synthesized and characterized by using spectroscopic analysis (Iyoda et al 1995). The X-ray data of $\left(\mathrm{Ph}_{3} \mathrm{P}\right)_{2} \mathrm{Pt}\left(\eta^{2}-\mathrm{C}_{60}\right)$ containing no solvent of crystallization affords definite bond lengths and angles. Organopalladium or platinum complexes $\left(\eta^{2}-\mathrm{C}_{60}\right) \mathrm{M}(\mathrm{CNR})_{2}$ $\left(\mathrm{M}=\mathrm{Pt}, \mathrm{Pd} ; \mathrm{R}={ }^{\mathrm{t}} \mathrm{Bu}, 2,6-\mathrm{Me}_{2} \mathrm{C}_{6} \mathrm{H}_{3}, 2,4,6-\mathrm{Me}_{3} \mathrm{C}_{6} \mathrm{H}_{2}\right.$, cyclohexyl) were synthesized from $\mathrm{C}_{60} \mathrm{M}_{n}(\mathrm{M}=\mathrm{Pd}, \mathrm{Pt}$ ) and from the corresponding isonitriles (Nagashima et al 1996).

Treatment of $\mathrm{C}_{60}$ with stoichiometric amounts of both $\left[\mathrm{Cp} * \mathrm{Ru}(\mu-\mathrm{H})_{2}\right]$ $\left(\mathrm{Cp}^{*}=\mathrm{C}_{5} \mathrm{H}_{5}\right)$ and $\left(\mathrm{Cp}^{*} \mathrm{RuCl}_{2}\right)_{2}$ produced $\mathrm{Cp}^{*} \mathrm{Ru}_{2}(\mu-\mathrm{H})(\mu-\mathrm{Cl})\left(\mathrm{C}_{60}\right)$, which contains a $\mathrm{Ru}$ fragment bound to two conjugated $\mathrm{C}-\mathrm{C} \pi$-bonds (Mavunkal et al 1995). The related $\mathrm{C}_{60}$ derivative $\mathrm{Cp}_{2}^{*} \mathrm{Ru}_{2}(\mu-\mathrm{Cl})_{2}\left(\mathrm{C}_{60}\right)$ was obtained by using two equivalent of $\left(\mathrm{Cp}^{*} \mathrm{RuCl}_{2}\right)_{2}$. Formation of a transient cationic species $\left(\mathrm{Cp}^{*} \mathrm{RuC}_{60}\right)^{+}$is suggested from $\mathrm{FAB}$ mass analysis. $\mathrm{Ru}-\mathrm{C}_{60}$ compounds were prepared by reaction of $\mathrm{Ru}_{3}(\mathrm{CO})_{12}$ with $\mathrm{C}_{60}$ in refluxing toluene (Wohlers et al 1996). The resulting airstable solid consists of an amorphous matrix in which we embedded small Ru metal particles of an average size of $2.5 \mathrm{~nm}$. The catalytic activity of $\mathrm{Ru}-\mathrm{C}_{60}$ compounds at different temperatures is shown in prototype reactions like the liquid phase hydrogenation of cyclohexene at $300 \mathrm{~K}$ or the hydrogenation of $\mathrm{CO}$ in the FischerTropsch synthesis at $500 \mathrm{~K}$. Photolysis of a $2: 1$ mixture of $\mathrm{Mo}(\mathrm{CO})_{4}$ (diphos) 


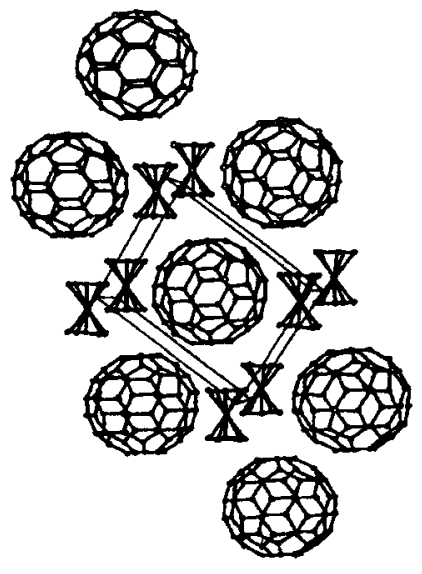

28

Figure 9. Cocrystallization of $\mathrm{C}_{60}$ with ferrocene (Taylor and Walton 1993).
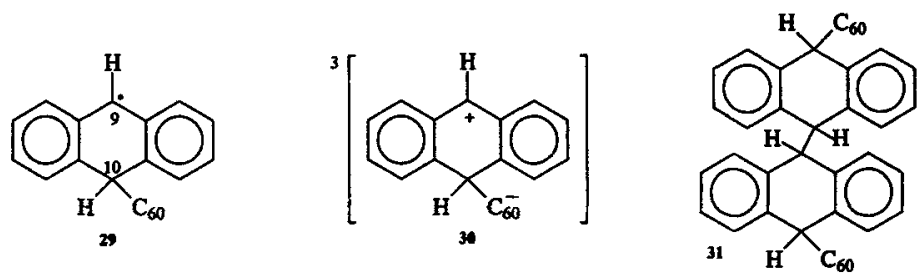

Figure 10. EPR-active adduct of ${ }^{3} \mathrm{C}_{60}$ to anthracene: biradicals and zwitterions (Klemt et al 1995).

(diphos = 1,2-diphenyl phosphinatoethane) and activated alumina with toluene provides the derivatives $\mathrm{C}_{60}\left[\mathrm{Mo}(\mathrm{CO})_{3} \text { (diphos) }\right]_{n}$ in varying yields depending on the value of $n$ (Hsu and Shapley 1995).

Fullerenes show a marked tendency to crystallize with solvent molecules trapped in the lattice to form host-guest complexes such as $\left[\mathrm{C}_{60}(\gamma \text {-cyclodextrin })_{2}\right]$ (Anderson et al 1992; Kuthner et al 1992) and [ $\mathrm{C}_{60}\left(1,4\right.$-hydroquinone) ${ }_{3}$ (Ermer 1991). $\mathrm{C}_{60}$ also formed charge-transfer complex with [bis(ethylenedithio) tetrathiafulvene] (Izuoka et al 1992).

$\mathrm{C}_{60}$ co-crystallized with ferrocene to give black $\mathrm{C}_{60}$ (ferrocene) ${ }_{2}$ and this species is stabilized by weak intermolecular charge transfer interactions (figure 9) (Kroto et al 1992). There are reports of various inclusion complexes such as $\left[\mathrm{Fe}\left(\eta-\mathrm{C}_{5} \mathrm{H}_{5}\right)_{2}\right]_{2} \mathrm{C}_{60}$ (Kroto et al 1992), $\left[\left(\mathrm{I}_{2}\right)_{2} \mathrm{C}_{60}\right]$ (Cox et al 1992) and benzene solvated species, $\left[\mathrm{C}_{60} \cdot 4 \mathrm{C}_{6} \mathrm{H}_{6}\right]$ (Kroto et al 1992; Balch et al 1993). $\mathrm{C}_{60}$ reacts with anthracene thermally and photochemically. From EPR studies Klemt et al (1995) proposed that the EPR-active intermediates are triplet zwitterions or biradicals (figure 10). A covalently functionalized fullerene comprising an electron donating aniline group coupled to 

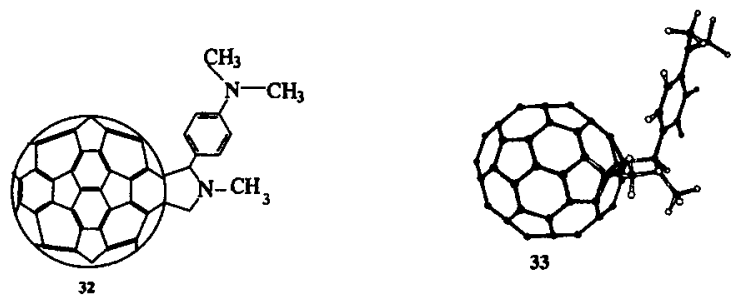

Figure 11. Bridged $\mathrm{C}_{60}$-aniline system: the first active fullerene diad and AM1 structure of the compound (Williams et al 1995).

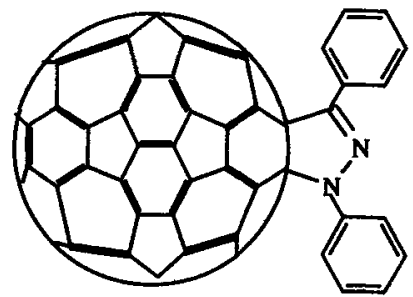

34

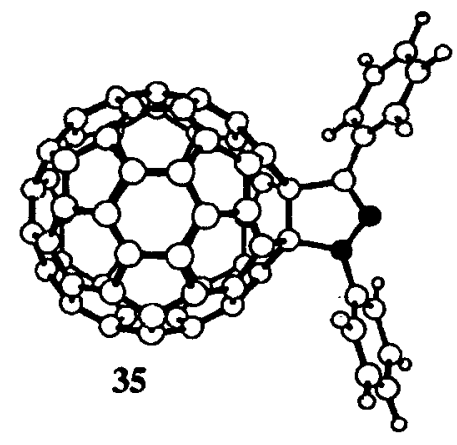

35

Figure 12. Intramolecular charge-transfer interaction in 1,3-diphenyl-2-pyrazoline ringfused $C_{60}$ with AM1 structure of the cycloadduct (Matsubara et al 1995).

fullerene unit by a saturated heterocyclic bridge (figure 11) is shown to undergo a photoinduced electron transfer process (Williams et al 1995). Charge-transfer interaction between benzene ring and a $\mathrm{C}_{60}$ sphere is studied in 1,3-diphenyl-2-pyrazoline ring fused $\mathrm{C}_{60}$ (figure 12) (Matsubara et al 1995). It is observed that the $\mathrm{N}$ phenyl group interacts with $\mathrm{C}_{60}$ more strongly than the $\mathrm{C}$-phenyl groups. Electrontransfer reaction between $\mathrm{C}_{60}$ radical ion and carbazole cation $\left(\mathrm{Car}^{+}\right)$to produce an excited state of $\mathrm{C}_{60}$ has been studied by Gupta and Santhanam (1994):

$$
\begin{aligned}
& \mathrm{C}_{60}^{-}+\mathrm{Car}^{+} \longrightarrow \mathrm{C}_{60}^{*}+\mathrm{Car} \\
& \mathrm{C}_{60}^{*} \longrightarrow \mathrm{C}_{60}+h v .
\end{aligned}
$$

Polar neutrals featuring electronegative atoms such as $\mathrm{O}$ or $\mathrm{N}$ can also form adducts with $\mathrm{C}_{60}^{2+}$ in the gas phase (Bohme et al 1992, 1993). The various polar neutrals are $\mathrm{NH}_{3}, \mathrm{CH}_{3} \mathrm{NH}_{2}, \mathrm{C}_{2} \mathrm{H}_{5} \mathrm{NH}_{2}, \mathrm{RCN}\left(\mathrm{R}=\mathrm{CH}_{3}, \mathrm{C}_{2} \mathrm{H}_{5}, \mathrm{C}_{3} \mathrm{H}_{5}, n-\mathrm{C}_{3} \mathrm{H}_{7}\right.$ and i- $\mathrm{C}_{3} \mathrm{H}_{7}$ ), $\mathrm{CH}_{3} \mathrm{COCH}_{3}, \mathrm{CH}_{3} \mathrm{COCH}_{2} \mathrm{CH}_{3}, \mathrm{HCOOH}$ and $\mathrm{CH}_{3} \mathrm{COOH}$. In some of the cases the formation of secondary adducts is observed. But in case of $\mathrm{C}_{60}^{++}$and $\mathrm{C}_{60}^{\cdot 3+}$ only mono and tertiary adducts are formed. So it is possible by gas phase ion 


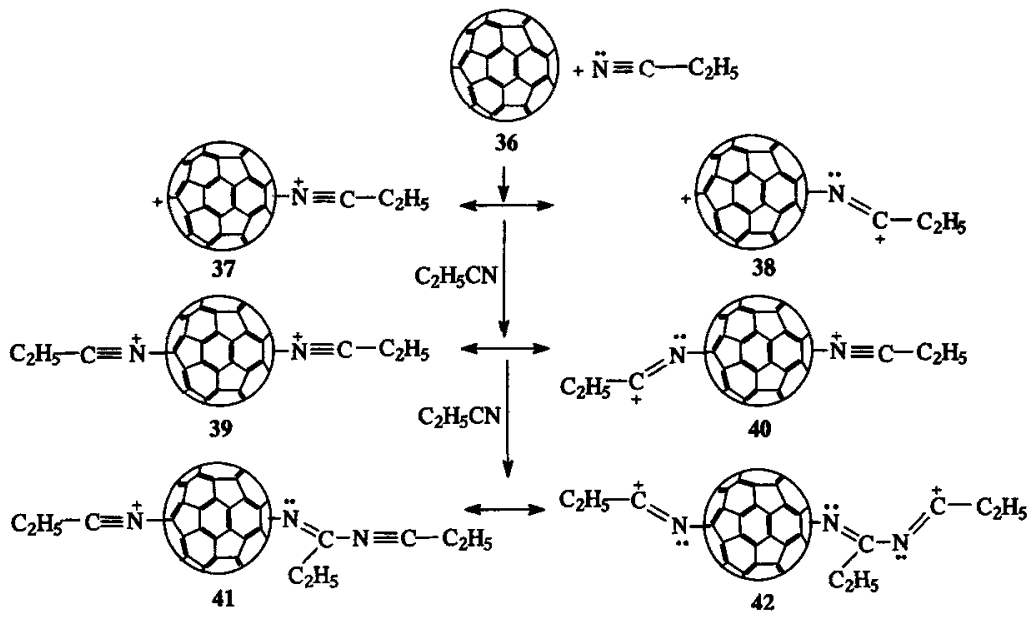

Figure 13. Attachment of $\mathrm{C}_{2} \mathrm{H}_{5} \mathrm{CN}$ as 'handles' to $\mathrm{C}_{60}$.(Bohme et al 1993).

molecule reaction to add one 'handle' to $\mathrm{C}_{60}^{\cdot+}$, two to $\mathrm{C}_{60}^{2+}$ (figure 13) and three to $\mathrm{C}_{60}^{\mathbf{3}+}$. Charge transfer reactions have also been reported for two fullerene dications $\left(\mathrm{C}_{60}^{2+}\right.$ and $\left.\mathrm{C}_{70}^{2+}\right)$ reacting with benzene, naphthalene, anthracene, $\mathrm{C}_{60}$ and $\mathrm{C}_{70}$ under SIFT conditions. Solutions of $\mathrm{C}_{60}$ and a substituted naphthalene give rise to a new adsorption band that is not observed from solutions containing only $\mathrm{C}_{60}$ or the naphthalene (Scurlock and Ogilby 1995). The absorption maximum of this new band successively shifts to a longer wavelength as the ionization potential of the naphthalene decreases. These data reflect a $\mathrm{C}_{60}$-naphthalene cooperative adsorption from a ground state contact complex to form an excited-state complex with chargetransfer character. A 1:1 inclusion complex has been synthesized by the reaction of p-tert-butyl-calix[8] arene with $\mathrm{C}_{60}$ in toluene solution, and identified with IR spectra, elemental analysis, X-ray powder diffraction and solid state ${ }^{13} \mathrm{C}$ NMR studies (Cai et al 1995) which led to the conclusion that $\mathrm{C}_{60}$ is encapsulated in hydrophobic cavity of p-tert-butyl calix [8] arene. This implies that the interaction between $\mathrm{C}_{60}$ and $p$-tert-butyl-calix[8]arene is weak.

\section{Addition reactions}

\subsection{Addition of hydrogen}

$\mathrm{C}_{60}$ may catalyze autooxidation of hydrides. Under Birch reduction conditions, $\mathrm{C}_{60} \mathrm{H}_{18}, \mathrm{C}_{60} \mathrm{H}_{36}$ and $\mathrm{C}_{60} \mathrm{H}_{2}$ have been isolated and found to be strongly acidic (Haufler et al 1990). $\mathrm{C}_{60} \mathrm{H}_{2}$ is unstable in the presence of $\mathrm{C}_{60}$. A $T_{\mathrm{h}}$ symmetry has been inferred for $\mathrm{C}_{60} \mathrm{H}_{36}$. The proposed structure of $\mathrm{C}_{60} \mathrm{H}_{36}$ consists of only isolated double bonds and not conjugated or aromatic double bonds. This is due to the 
ability of the latter to undergo Birch reduction. Transfer hydrogenation of $\mathrm{C}_{60}$ with dihydroanthracene produces $\mathrm{C}_{60} \mathrm{H}_{18}$ or $\mathrm{C}_{60} \mathrm{H}_{36}$ depending on the reaction conditions (Buhl et al 1995). Hydrogen radical induced hydrogenation of fullerite (a mixture of crude $\mathrm{C}_{60}$ and $\mathrm{C}_{70}$ ) was also reported to produce $\mathrm{C}_{60} \mathrm{H}_{36}$ at elevated temperature. The computed endohedral ${ }^{3} \mathrm{He}$ NMR chemical shifts of the $\mathrm{C}_{60} \mathrm{H}_{36}$ isomers can be related semiquantitatively to the ring current and anisotropic effects of benzene and ethylene moieties present.

The direct solid state synthesis of $\mathrm{C}_{60} \mathrm{H}_{2}$ was carried out by controlling the amount of hydrogen introduced into the reaction with $C_{60}$ (Morosin et al 1994). Palladium hydride has been used as the source of hydrogen. In addition to $\mathrm{C}_{60} \mathrm{H}_{2}$, small amounts of $\mathrm{C}_{60} \mathrm{H}_{4}$ have been obtained. Electrochemical behaviour of $\mathrm{C}_{60} \mathrm{H}_{2}$ is very similar to the parent fullerene i.e. $\mathrm{C}_{60}$, with $\mathrm{C}_{60} \mathrm{H}_{2}$ being only slightly difficult to reduce (Guarr et al 1993). The addition of a single electron is sufficient to induce conversion of $\mathrm{C}_{60} \mathrm{H}_{2}$ to $\mathrm{C}_{60} \cdot \mathrm{C}_{60} \mathrm{H}_{2}$ undergoes a net oxidation under 'reducing' conditions.

Darwish et al (1996) reviewed the previous work on polyhydrogenation of fullerenes. The most probable structure of the hydrides, based on their aromaticity is presented.

Zinc/conc. $\mathrm{HCl}$ is an excellent and rapid reducing agent for benzene or toluene solutions of fullerenes at room temperature. The polyhydrogenated species are unstable towards light and undergo oxidative degradation. In absence of light and oxygen, $\mathrm{C}_{60} \mathrm{H}_{36}$ exhibits high thermal stability. Further reduction of $\mathrm{C}_{60} \mathrm{H}_{34}$ gives trimethylene adducts.

\subsection{Addition of halogens}

Halogens can add to the carbon framework of $\mathrm{C}_{60}$ clusters. A maximum of twentyfour groups can be added to $\mathrm{C}_{60}$ without any two groups being adjacent. Figure 14 shows 24 nonadjacent sites in the $\mathrm{C}_{60}$ framework.

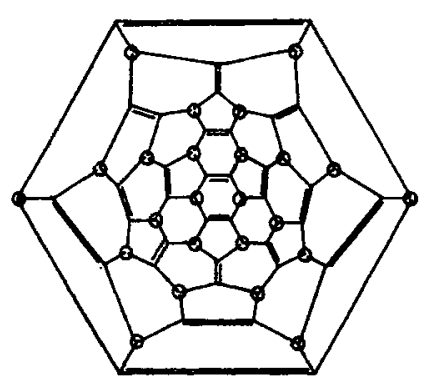

43

Figure 14. Schegel diagram showing twentyfour nonadjacent sites in $\mathrm{C}_{60}$ (Taylor and Walton 1993). 
Halogens such as fluorine, chlorine, bromine and iodine can add to the fullerene framework in different proportions giving varieties of products. In the stabilities of the various isomers generated by the addition of halogens to the conjugated double bonds of $\mathrm{C}_{60}$ to form $\mathrm{C}_{60} \mathrm{X}_{n}$ have indicated a strong preference for 1,2 addition with $\mathrm{X}=\mathrm{F}$ and $\mathrm{Cl}$, while preference for 1,4 addition with $\mathrm{X}=\mathrm{Br}$ and $\mathrm{I}$ (figure 15) due to large size of $\mathrm{Br}$ and $\mathrm{I}$ in comparison to other. The 1,2-isomers will be clearly destabilized by steric interaction as $\mathrm{X}$ becomes larger.

Mass spectrometric results provide evidence that the reaction of $\mathrm{C}_{60}$ with bromine and $\mathrm{FeCl}_{3}$ in benzene produces the species $\mathrm{C}_{60} \mathrm{Ph}_{n}(n=6,8,12$ and 16), indicating that Friedel-Crafts reaction of benzene by brominated $\mathrm{C}_{60}$ intermediates had occurred.

Bromination of $\mathrm{C}_{60}$ in neat bromine gives evidence for the uptake of 28 bromines to give a quantitative yield of yellow bromine soluble microcrystals, which is believed to be $\mathrm{C}_{60} \mathrm{Br}_{24}$ along with some $\mathrm{C}_{60} \mathrm{Br}_{8}$ and $\mathrm{C}_{60} \mathrm{Br}_{6}$ (figure 16) as determined from $X$-ray diffraction analysis (Tebbe et al 1992). The product $\mathrm{C}_{60} \mathrm{Br}_{24}$ displays $T_{\mathrm{h}}$ symmetry, only slightly distorted from the parent $I_{h}$ symmetry. The bromo compound decomposes to $\mathrm{C}_{60}$ on heating and the stability order is fluoro $>$ chloro $>$ bromo and $\mathrm{C}_{60} \mathrm{Br}_{24}>\mathrm{C}_{60} \mathrm{Br}_{8}>\mathrm{C}_{60} \mathrm{Br}_{6}$. The instability of $\mathrm{C}_{60} \mathrm{Br}_{8}$ and $\mathrm{C}_{60} \mathrm{Br}_{6}$ may reflect<smiles>[X]C1C=Cc2ccccc2C1[X]</smiles>

44<smiles>[X]C1C=CC([X])c2ccccc21</smiles>

45

Figure 15. $[1,2]$ and $[1,4]$ addition of halogens to conjugated system of $C_{60}$.

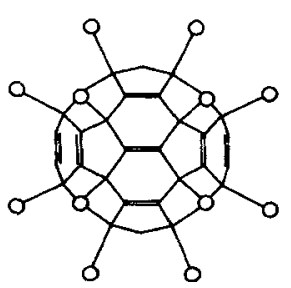

46

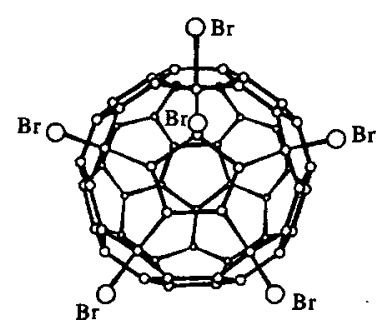

47

Figure 16. Brominated $\mathrm{C}_{60}$ as $\mathrm{C}_{60} \mathrm{Br}_{24}$ alongwith some $\mathrm{C}_{60} \mathrm{Br}_{6}$ (Tebbe et al 1992; Taylor et al 1992). 
the presence of four and two double bonds in pentagonal rings in their respective structures and $\mathrm{C}_{60} \mathrm{Br}_{6}$ contains an eclipsing steric interaction (Taylor et al 1992). The bromine adds to the carbon framework by 1,4-addition to fused pairs of six-membered rings with the closest $\mathrm{Br}, \mathrm{Br}$ placement being 1,3. The composition of the crystal determined by elemental analysis showed that 25 to 28 bromine atoms were present in each $\mathrm{C}_{60}$. Vibrational spectra indicate that the product contains a centre of symmetry and maximum symmetry possible is $T_{\mathrm{h}}$. This structure has well defined pattern of $72 \mathrm{C}-\mathrm{C}$ bonds and $18 \mathrm{C}=\mathrm{C}$ bonds. Spectral data of 'free $\mathrm{Br}_{2}$ ' suggest that the composition of molecular structure as $\mathrm{C}_{60} \mathrm{Br}_{24}\left(\mathrm{Br}_{2}\right)_{0.5-2}$. (Average value of $\mathrm{C}-\mathrm{Br}, \mathrm{C}-\mathrm{C}$ and $\mathrm{C}=\mathrm{C}$ bond distances are 1.993(6), 1.500(19) and 1.339(6) $\AA$ respectively with the estimated standard deviations). Bromine attached to carbon at the 1 and 4 positions causes 12 of the 20 six-membered rings to adopt to boat conformation and the remaining eight six-membered rings with bromine at the 1,3and 1,5-positions adopt to chair conformations.

The treatment of $\mathrm{C}_{60}$ with chlorine in chloroorganic solvents at various temperatures did not result in any detectable reaction, but in a hot glass tube under a slow stream of chlorine gas, the reaction takes place readily. On the average, twenty-four chlorine atoms are added to the skeleton which is confirmed by elemental analysis (Olah et al 1991).

The FTIR spectrum shows a strong C-Cl stretch $\left(848 \cdot 5 \mathrm{~cm}^{-1}\right)$ and is distinct from IR spectrum of the parent molecule. The $22 \cdot 4 \mathrm{MHz}$ solid state ${ }^{13} \mathrm{C}$ NMR spectrum showed broad absorptions at 50-150 ppm. In FAB and FIMS mass spectrometry under mild ionization conditions, polychlorofullerenes lose chlorine to give only peak at $\mathrm{C}_{60}\left(\mathrm{M}^{+}, 720\right)$ and $\mathrm{C}_{70}\left(\mathrm{M}^{+}, 840\right)$. There are reports of addition of ICI to $\mathrm{C}_{60}$ in toluene at room temperature to give a polychloro derivative $\mathrm{C}_{60} \mathrm{Cl}_{6}$. The ${ }^{13} \mathrm{C} \mathrm{NMR}$ spectra suggest $\mathrm{C}_{60} \mathrm{Cl}_{6}$ to be isostructural with $\mathrm{C}_{60} \mathrm{Br}_{6}$. Reaction of iodine monochloride with a benzene solution of $\mathrm{C}_{70}$ produced $\mathrm{C}_{70} \mathrm{Cl}_{10}$ (Birkett et al 1995). The compound decomposes slowly in air, which was attributed to instability arising from the adjacent and eclipsed chlorines. The proposed structure is unique for a halogenated fullerene in having no double bonds in pentagons (figure 17).

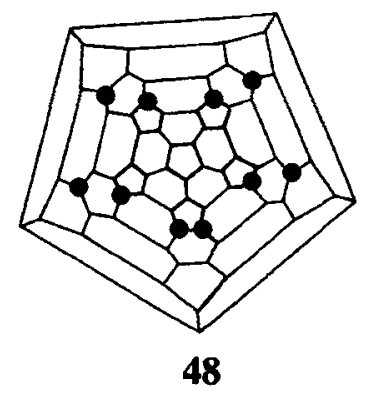

Figure 17. Structure of $\mathrm{C}_{70} \mathrm{Cl}_{10}$ showing possible positions of chlorine atoms (Birkett et al 1995a). 


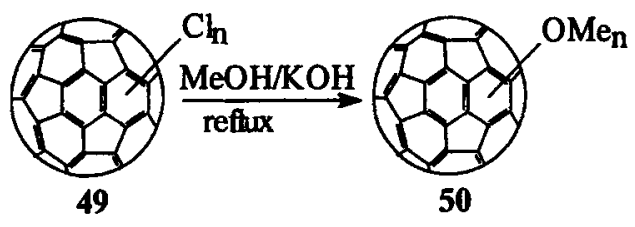

Figure 18. Replacement of chlorine atoms by methoxy groups.

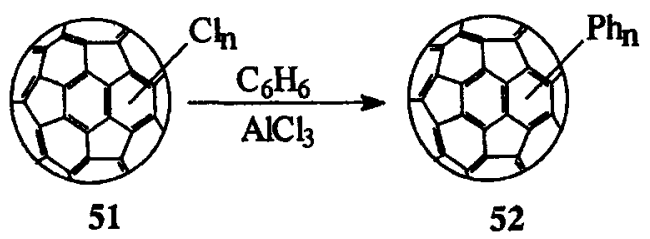

Figure 19. Friedel-Crafts reaction with benzene.

Methoxy groups can replace all chlorine atoms from polychlorinated derivative to give polymethoxy derivative (figure 18), which is confirmed by mass spectrometry (polymethoxylation up to 26 methoxy groups $\mathrm{M}^{+}, 1526$ ) and ${ }^{1} \mathrm{H}$ NMR (a broad envelope of methoxy group centered at $\delta 3 \cdot 7$ ). Further, there is a sequential loss of methoxy group from $\mathrm{C}_{60}(\mathrm{OMe})_{26}$ to finally produce $\mathrm{C}_{60}(\mathrm{OMe})$. This observation of addition of 26 methoxy groups confirms that there are more than 24 chlorine atoms in the polychlorinated derivative.

Polychlorinated fullerene also undergoes Friedel-Crafts reaction with benzene to produce polyphenylated product (figure 19), containing up to 22 phenyl groups. ${ }^{13} \mathrm{C}$ NMR spectrum shows a broad absorption at $\delta 128 \mathrm{ppm}$, indicating phenylation. FAB mass spectrometry indicates substitution by at least 22 phenyl groups $\left(\mathrm{M}^{+}, 2414\right)$ with no residual chlorine remaining in the product.

In contrast to the polybrominated and polychlorinated product, addition of 60 fluorines to $\mathrm{C}_{60}$ has been reported (Taylor et al 1991). But stability decreases beyond $\mathrm{C}_{60} \mathrm{~F}_{48}$ making subsequent addition of fluorine very slow. Fluoro compounds are much more soluble and reactive but their formation is difficult to control. Fluorinated $\mathrm{C}_{70}$ seems to be less stable than fluorinated $\mathrm{C}_{60}$. Fluorination is very slow and steric crowding is predicted to increase the $\mathrm{C}-\mathrm{C}$ bond length by about $0.05 \AA$ and decrease the $\mathrm{C}-\mathrm{F}$ bond strength by $15 \%$ relative to that in $\mathrm{CF}_{4}$. Fluorinated $\mathrm{C}_{60}$ undergoes nucleophilic substitution by hydroxide ion and the rate of the reaction decreases as the fluorine content reduces (figure 20). Higher fluoro-fullerenes are strong oxidizing and fluorinating agents. The double charged anions of $\mathrm{C}_{60} \mathrm{~F}_{\boldsymbol{x}}$ ( $x=48$ and 46) can be generated in the gas phase by sequential electron capture (Zhou and Gary 1994). The reaction of $C_{60}$ and $C_{70}$ with $M_{n F}$ under vacuum at elevated temperatures resulted in high purity $\mathrm{C}_{60} \mathrm{~F}_{36}$ and $\mathrm{C}_{70} \mathrm{~F}_{36 / 38 / 40} . \mathrm{C}_{60} \mathrm{~F}_{36}$ has been characterized by mass spectra showing an intense peak at 1404 amu. 2D 


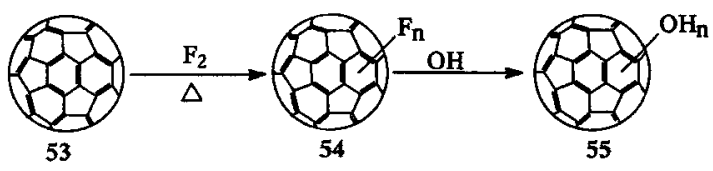

Figure 20. Nucleophilic substitution of fluorine by hydroxide ion in polyfluorinated $C_{60}$.
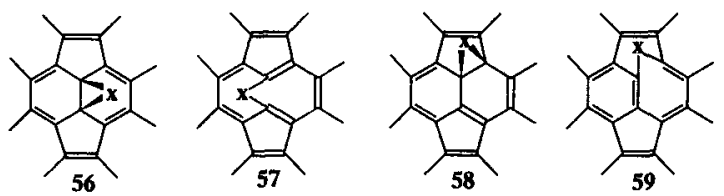

Figure 21. Four possible additions: $[6,6]$-closed, $[6,6]$-open, $[5,6]$-closed, $[5,6]$-open.

(COSY) ${ }^{19} \mathrm{~F}$ NMR study indicated that the product consists of four isomers. Fluorination of $\mathrm{C}_{70}$ was carried out and the mass spectra showed main peaks at 1524 , 1562 and $1600 \mathrm{amu}$, indicating that the product is a mixture of $\mathrm{C}_{70} \mathrm{~F}_{36 / 38 / 40}$ with $\mathrm{C}_{70} \mathrm{~F}_{38}$ as the major component.

\section{Addition leading to ring expansion and bridging}

Fullerenes undergo addition reaction with various types of reagents forming oxygen, carbon, nitrogen and metallic bridges. Addition may take place across either $[6,6]$ ring junction or $[5,6]$-ring junction and the rings are either open fulleroid or closed fullerene structures. Thus a total of four configurations are possible i.e. $[6,6]$-open, $[6,6]$-closed, $[5,6]$-open and $[5,6]$-closed (figure 21 ). If the derivative of fullerene contains cyclopropane rings $([5,6]$-closed and $[6,6]$-closed), the molecule is called methanofullerene, otherwise it is called fulleroid ([5,6]-open and $[6,6]$-open).

\subsection{Carbon bridging}

$\mathrm{C}_{60}$ undergoes 1,3-dipolar addition reaction with ethyl diazoacetate and diphenyl diazomethane followed by elimination to introduce $\mathrm{R}_{2} \mathrm{C}(\mathrm{R}=\mathrm{H}, \mathrm{Ar})$ groups into carbon framework (Suzuki et al 1991) (figure 22). In the reaction of diphenyl diazomethane with $\mathrm{C}_{60}$, the addition takes place across one of the $[6,6]$-ring junctions. These reactions proceed by the elimination of $\mathrm{N}_{2}$ to produce $\mathrm{Ph}_{2} \mathrm{C}_{61}$. Six molecules of diphenyl diazomethane can add to $\mathrm{C}_{60}$ to give $\mathrm{Ph}_{12} \mathrm{C}_{66}$. Suzuki et al (1992) prepared the pyrazoline 64 by addition of diazomethane to $\mathrm{C}_{60}$. Thermolysis of the pyrazoline furnished the rearranged product $\mathrm{C}_{61} \mathrm{H}_{2}$ (69) (figure 23) with methylene insertion into a 5,6 'long' bond of $\mathrm{C}_{60}([5,6]$-open). Smith and co-workers (1993) 

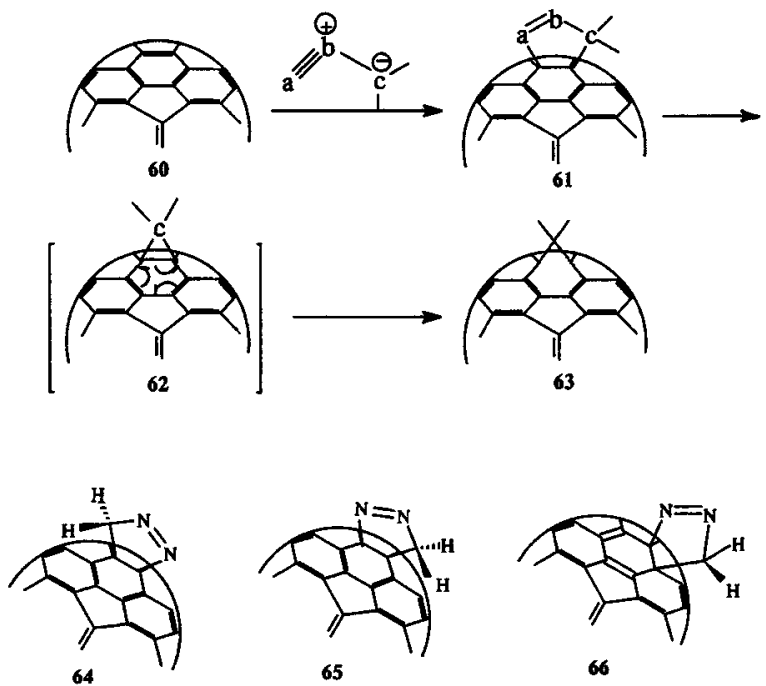

66

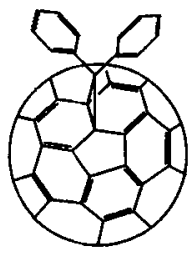

67

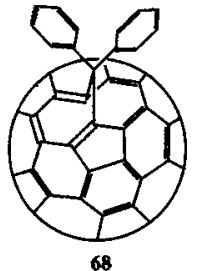

68

Figure 22. Addition-elimination reactions in fullerene leading to the synthesis of $\mathrm{H}_{2} \mathrm{C}_{61}$ and $\mathrm{Ph}_{2} \mathrm{C}_{61}$, both closed and open isomers (Suzuki et al 1991).

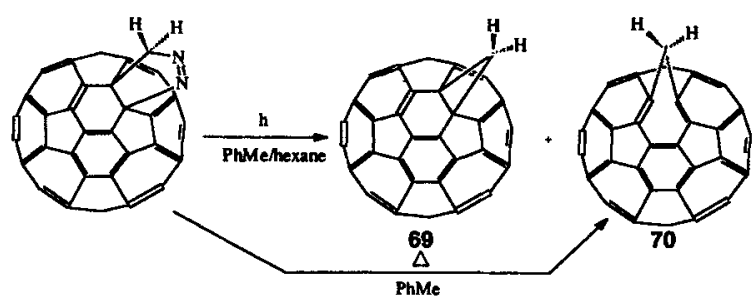

Figure 23. Thermolysis and photolysis of the pyrazoline to give isomeric annulene and methanofullerene (Smith et al 1993).

explored the photolysis of 64 and obtained a mixture of annulene 69 alongwith the isomeric methanofullerene 70 derived from methylene insertion into a 6,6 'short' bond $([6,6]$-closed $)$.

Although it was previously suggested $[6,6]$-open structure to be most stable one, the later report by Prato et al (1993) showed from spectroscopic studies and MNDO 
calculations the addition to lead to a mixture of methanofullerene and methanoannulene. Among all the isomers possible, lowest energy product is 70. The energetic preference for structure $\mathbf{7 0}$ of fullerene derivatives is due to most number of double bonded $[6,6]$-ring junctions and greatest number of 5-radialene rings in these structures. The $[5,6]$-open isomer is stable under kinetically controlled conditions while the $[6,6]$-closed isomer is stable under thermodynamically controlled conditions. Osterodt et al (1994) reported the first X-ray crystal structure of a methanofullerene (figure 24), confirming the cyclopropane structure for $[6,6]$-ring-methano-bridged fullerenes.

There are four 6,6- and four 6,5-ring junctions in $C_{70}$ (figure 25). Like $C_{60}, C_{70}$ was expected to react with diazomethane involving one or more of the four types of 6,6-ring fusions. The X-ray crystal structure (Roth and Adelmann 1992) of the clathrates $\mathrm{C}_{70} \cdot 6 \mathrm{~S}_{8}$, in agreement with earlier $a b$ initio calculations on the isolated fullerenes (Scuseria 1991; McKenzie et al 1992), revealed that the bonds $i$ and ii are

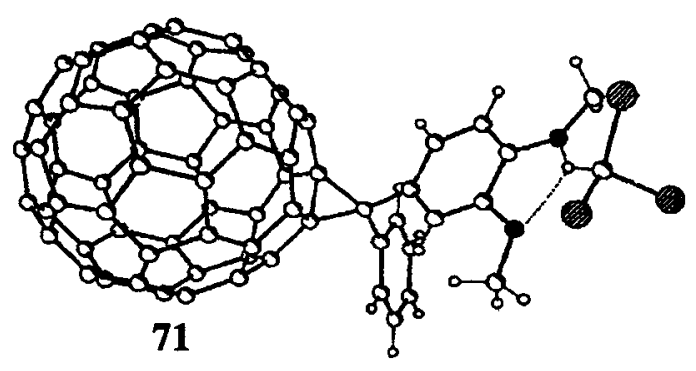

Figure 24. X-ray crystal structure of [(3,4-dimethoxyphenyl)phenylmethano][60]fullerene confirming the cyclopropane structure for [6,6]-ring-methano-bridged fullerenes. A chloroform molecule is shown as hydrogen bonded to the methoxy group (Osterodt et al 1994).
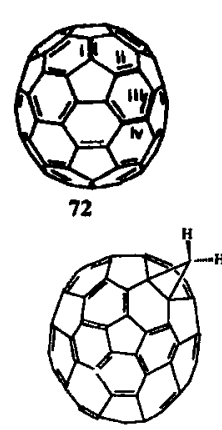

76

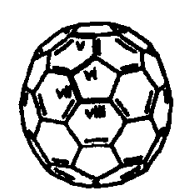

73

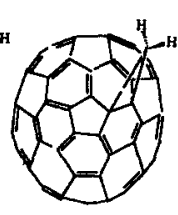

77

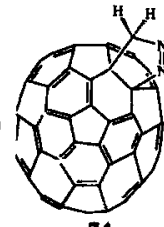

74

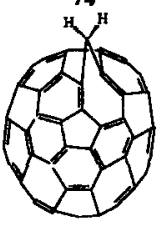

78
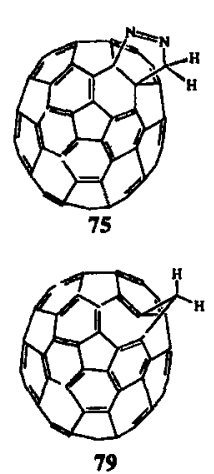

Figure 25. The eight different bonding sites in $\mathrm{C}_{70}$, two isomeric pyrazolines and their thermal and photochemical decomposition products (Smith et al 1995). 


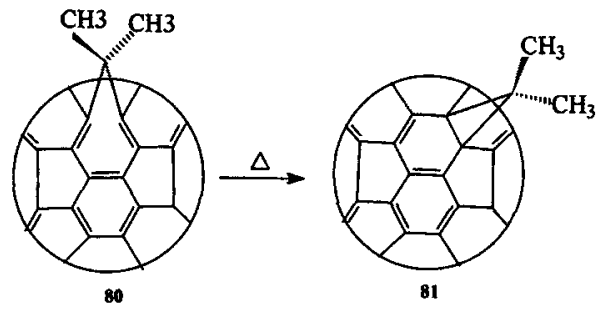

Figure 26. Thermal isomerization of annulene to cyclopropane (Smith et al 1995).
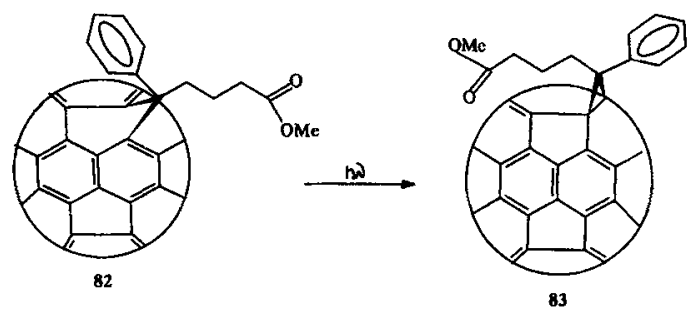

Figure 27. Zimmerman rearrangement of a fulleroid to methanofullerene (Wudl et al 1995).

by far the shortest bonds in $\mathrm{C}_{70}$, suggesting that they would prove to be most reactive. Hawkins et al (1993) observed that bond $\mathbf{i}$ is more reactive than $\mathbf{i i}$, which they attributed to greater local curvature. Thus toluene solution of $\mathrm{C}_{70}$ reacts with etherial diazomethane at $0^{\circ} \mathrm{C}$ to produce a mixture of isomeric pyrazolines derivative $\left(74,75\right.$ ) (figure 25), which, upon photolysis, gives two isomeric $\mathrm{C}_{71} \mathrm{H}_{2}$ cyclopropanes $(\mathbf{7 6}, 77)$. Thermolysis of the pyrazolines produces two isomeric annulenes (78, 79), which is confirmed by NMR and UV spectroscopy (Smith et al 1994, 1995). Smith et al (1995) also studied the reaction of dimethyldiazomethane with $\mathrm{C}_{60}$, which led to $\mathrm{C}_{63} \mathrm{H}_{6}$ annulene 80 (figure 26), the latter upon heating is converted to the cyclopropane isomer 81 with an activation energy of $\sim 25 \mathrm{kcal} \mathrm{mol}^{-1}$. Wudl et al (1995) reported photochemical conversion of a fulleroid (82) carrying phenyl and methyl butyrate substituents on the methane carbon to its methanofullerene isomer via di- $\pi$-methane (Zimmerman) rearrangement (figure 27). The ${ }^{13} \mathrm{C}$ NMR spectral peak of $\mathrm{C}(61)$ at $50.7 \mathrm{ppm}$ and bridgehead carbons at $79.3 \mathrm{ppm}$ are in accordance with the methanofullerene structure. The $s p^{3}$ carbon formally carrying two vinyl groups represents the basic structural moiety required for a photochemical di- $\pi$-methane rearrangement and the mechanism of rearrangement is a free radical one (figure 28). The reaction takes place from the triplet state due to the efficient intersystem crossing in $\mathrm{C}_{60}$. The diradical formed is stable due to the attachment of phenyl groups. This photochemical reaction is of great synthetic interest, because the thermal rearrangement of fullerene is not feasible otherwise due to product instability. 


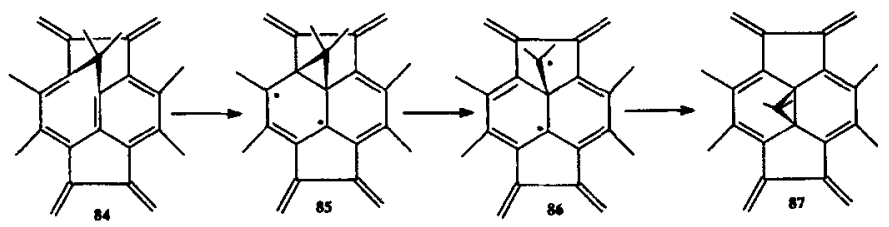

Figure 28. Photochemical di- $\pi$-methane rearrangement (Zimmerman) mechanism.
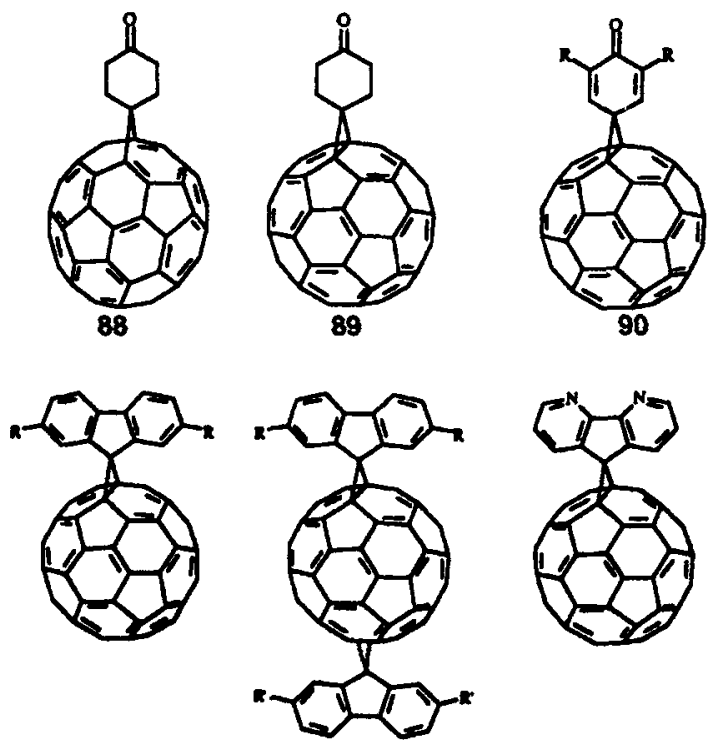

91

92

93

Figure 29. The influence of addends on the electronic properties of $\mathrm{C}_{60}$ (Eiermann et al 1995).

The 5,6- and 6,6-isomers of 1,1-(4-oxocyclohexano)-fullerene, 88 and 89 respectively (figure 29) are characterized by cyclic voltametry (CV) (Eiermann et al 1995), which is the most direct method for studying the influence of addends on the electronic properties of fullerenes. In 90, which has two double bonds in the cyclohexane ring, the reduction is facilitated by more than $70 \mathrm{mV}$ as compared to 89 . For a number of fluorenofullerenes (91-93) isolated exclusively as adducts on [6,6]-ring junctions, the CV spectra clearly demonstrate striking influence of electron-donating and electron-withdrawing groups of the fluorenyl group on the $\mathrm{C}_{60}$ moiety. Ohno et al (1996b), reported the synthesis and electrochemistry of quinone-type methanofullerene derivatives in which, depending upon the substitution pattern on the cyclohexanedienone moiety, the reduction potential could be tuned, leading to novel 
fullerene derivatives exhibiting better acceptor properties than $\mathrm{C}_{60}$. In addition to the monoadduct (95) (figure 30), the bis- as well as the tris-adducts of the corresponding 1,4-diazoanthrone are separated by chromatography. The methanofullerene structure is ascertained by the observation of bridgehead carbon in the $74-85 \mathrm{ppm}$ of ${ }^{13} \mathrm{C}$ NMR. The FTIR and FABMS results were also consistent with the assigned structure, and the ${ }^{1} \mathrm{H}$ NMR spectra show the typical resonance signals of the cyclohexanedione moiety. No evidence of the fulleroid $([5,6])$ isomer is observed. The better acceptor ability of the compounds (95-97) could be rationalized by the periconjugation of the $p_{z}-\pi$ orbitals of the cyclohexadienone moiety and the orbitals of the fullerene carbon atoms adjacent to the cyclopropane ring. The more negative reduction potential value found for the anthrone derivative (97) is attributed to the steric interaction of the aromatic peri-hydrogens with the spheroid, leading to a significant deviation from orthogonality, and, hence, the loss of periconjugation.

Ishida et al (1995) reported the synthesis of a [60]fullerene substituted TEMPO (2,2,6,6-tetramethylpiperidin-1-oxyl) radical (figure 31). The UV-VIS absorption spectra of 101 is very similar to that of $C_{60}$. The electronic structure of $C_{60}$ moiety is only slightly perturbed, strongly suggesting that [60]fullerene-TEMPO has an open $[5,6]$-structure with $C_{60}$ conjugation retained. To confirm this structure, these

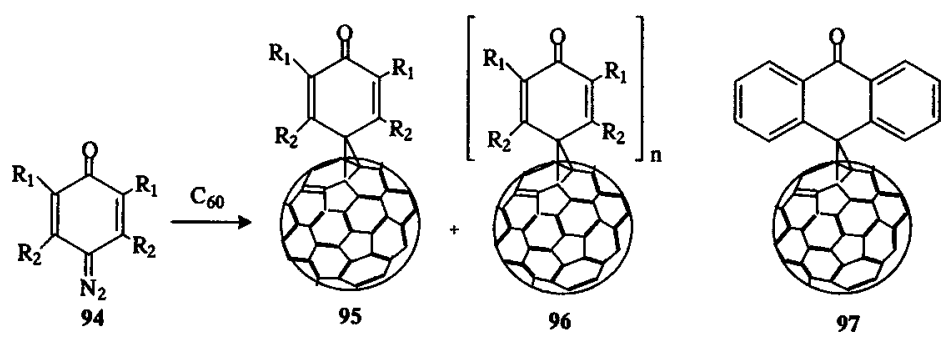

Figure 30. Quinone-type methanofullerenes in which, depending upon the substitution pattern on the cyclohexanedienone moiety, the reduction potential can be tuned (Ohno et al 1996b).

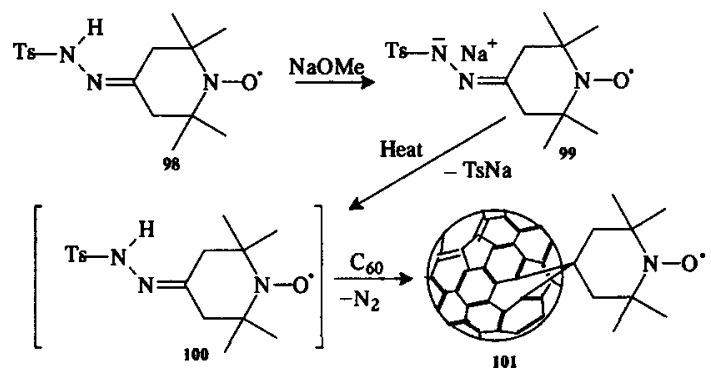

Figure 31. A [60]fullerene-substituted[2,2,6,6-tetramethylpiperidin-1-oxyl] radical (Ishida et al 1995). 

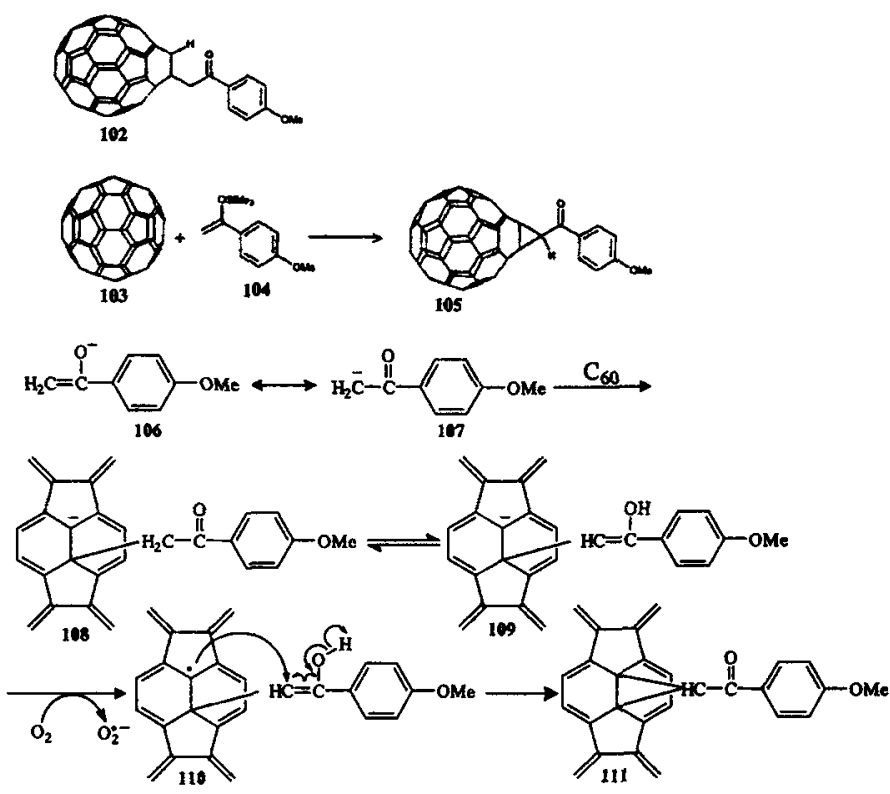

Figure 32. Reaction of [60]fullerene with 1-(4-methoxyphenyl)-1-(trimethylsilyloxy) ethylene and the reaction mechanism (Shu et al 1995).

workers synthesized $\mathrm{C}_{60}(\mathrm{CEt})_{2}$. The ${ }^{1} \mathrm{H}$ NMR analysis revealed that the two ethyl groups are inequivalent with a very large difference in chemical shifts. The synthetic method involved a 1,3-dipolar cycloaddition of diazocompounds to $\mathrm{C}_{60}$, followed by elimination of $\mathrm{N}_{2}$ is quite similar to the synthesis of $\mathrm{C}_{60}\left(\mathrm{CH}_{2}\right)$ by Suzuki et al (1991).

Aiming at the synthesis of $\mathbf{1 0 2}$, Shu et al (1995), identified the product to be $\mathbf{1 0 5}$ (figure 32). The mechanism was suggested to involve a free radical intermediate, oxygen available in the reaction atmosphere taking part in the reaction course. [60]Fullerene reacts with 1-(4-methoxyphenyl)-1-(trimethylsiloxy)ethylene in the presence of the complex of KF and 18-crown-6 to form a cyclopropane ring containing monoadduct (Shu et al 1995).

Tether-directed remote functionalization of $\mathrm{C}_{60}$, followed by a further addition step and subsequent removal of the tether-reactive group conjugate, led to the synthesis of the first regiospecific tetrakis-adduct (115) (figure 33) (Cardullo et al 1996). In the tetrakis adducts, all four methano-bridges lie on an equatorial belt and the array of cyclopropane rings divides the fullerene core into two equivalent tetrabenzopyracylene structures linked together by four biphenyl-type bonds(116).

Lamparth et al (1995) reported regioselective synthesis of $\mathrm{C}_{66}(\mathrm{COOEt})_{12}$ by successive cyclopropanation of equatorial 6-6 double bonds. Other hexaadducts with an analogous addition pattern were synthesized by Isaacs et al (1994) and by Kräutler et al (1995). Lamparth et al (1995) found that the reaction of $\mathrm{C}_{60}$ and 9,10dimethylanthracene (DMA) is reversible at room temperature (figure 34). The adduct $\mathrm{C}_{60}(\mathrm{DMA})_{n}$ being mixtures of regioisomers and the reaction shifting equili- 

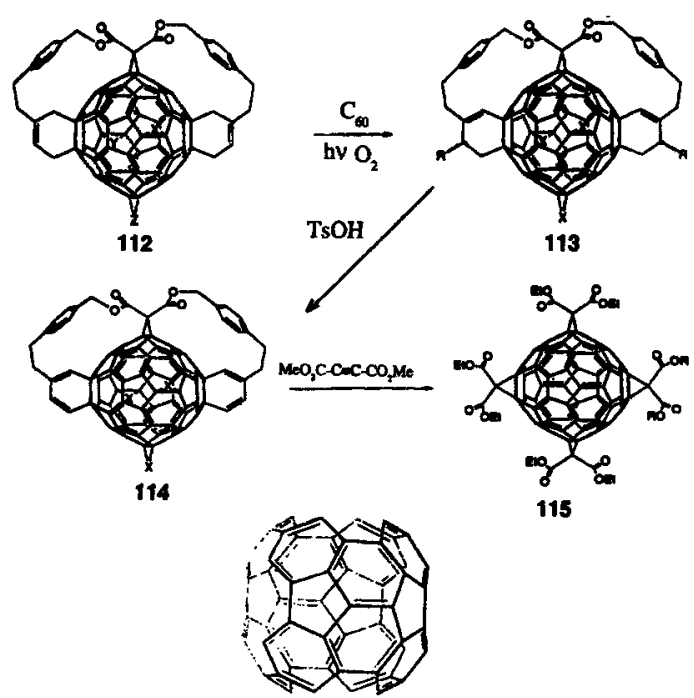

116

Figure 33. Regiospecific synthesis of a tetrakis adduct. 116 describes the adducts as composed of two biphenyl-type connected tetrabenzopyracylene substructures (Cardullo et al 1996).

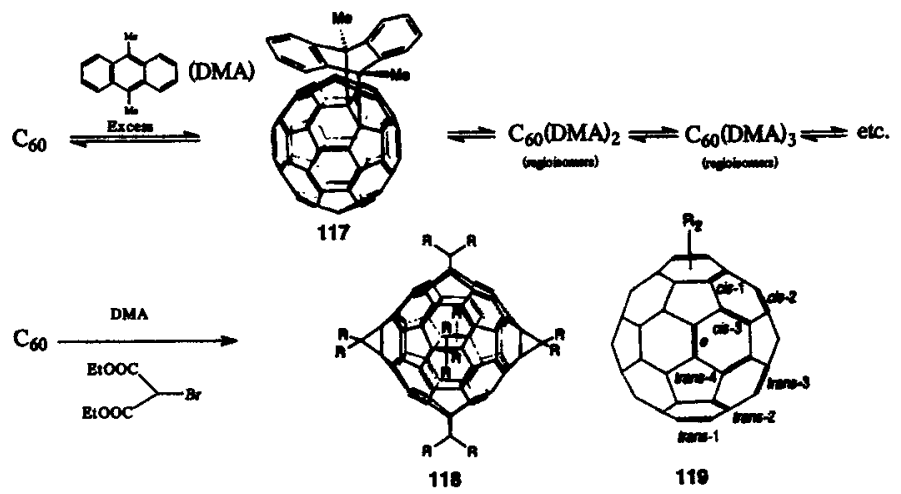

Figure 34. Reversible template-directed activation of equatorial double bonds of $\mathrm{C}_{60}$ : Regioselective direct synthesis of $\mathrm{C}_{66}(\mathrm{COOEt})_{12}$. Positional relationship of the eight different double bonds in a $\mathrm{C}_{60}$ monoadduct relative to the $6-6$ bond carrying the first addend is shown in 119 (Lamparth et al 1995).

brium towards unmodified $\mathrm{C}_{60}$. This reversibility is the basis of template activation for irreversible regioselective addition at 6-6 equatorial bonds by addend-substitution reaction. The synthesis of $\mathrm{C}_{66}(\mathrm{COOEt})_{12}$ after template activation with DMA was successful as a one-step process and as the only regiomeric hexaadduct. 


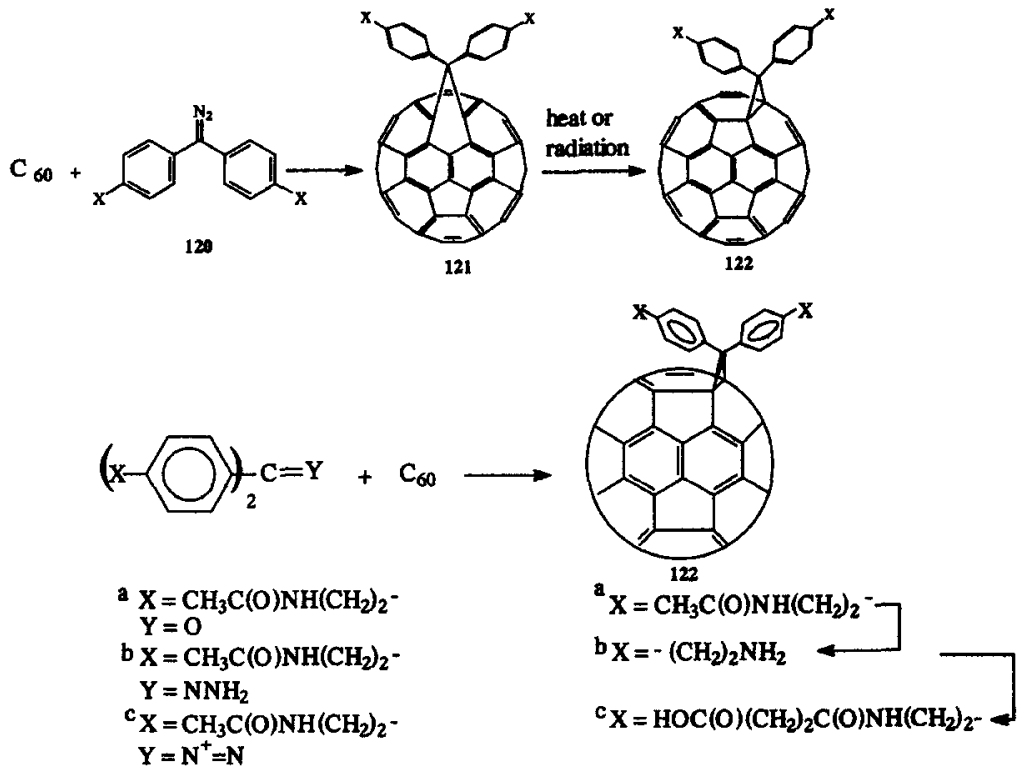

Figure 35. Synthesis of substituted diphenyl diazomethane derivative of $\mathrm{C}_{60}$ (Wudl et al 1993; Tomioka and Yamamoto 1995).

Two new methanofullerenes, $\mathrm{C}_{60}(\mathrm{CHCN})$ and $\mathrm{C}_{60}(\mathrm{CBr})_{2}$ were prepared by treating a mixture of $\mathrm{C}_{60}$ with either $\mathrm{CH}_{2} \mathrm{BrCN}$ or $\mathrm{CHBr}_{3}$, respectively (Benito et al 1996). The products were characterized by EI-MS and IR and shown by ${ }^{13} \mathrm{C}$ NMR to consist solely of $[6,6]$-ring junction adduct.

Synthesis of $\mathrm{C}_{60}$ derivatives bearing carboxy groups was reported by Tomioka and Yamamoto (1995). Bis (4-tert-butoxycarbonylphenyl) diazomethanes is treated with $\mathrm{C}_{60}$ to give the corresponding 1,2-methano derivatives, which upon hydrolysis with $\mathrm{CF}_{3} \mathrm{COOH}$ gave the carboxy bearing fullerene derivatives (figure 35). An important application of inflation of fullerene nucleus is the ability of $\mathrm{C}_{60}$ fullerene derivatives to interact with the active site of HIV -1 protease (HIVP) to inhibit an HIV enzyme (Friedman et al 1993). A diamido diacid diphenyl fulleroid derivative was designed to inhibit HIV enzyme. This compound was prepared in three steps from $\mathrm{C}_{60}$ via a suitably substituted diphenyldiazomethane. Compound 122 is soluble in water at $\mathrm{pH} \geqslant 7$, making it an ideal substrate for evaluation of physiological and pharmaceutical properties of methanofullerene. It was suggested that since $\mathrm{C}_{60}$ molecule has approximately the same radius as the cylinder that describes the active sites of HIVP and since $\mathrm{C}_{60}$ (and its derivatives) is primarily hydrophobic, there is an opportunity for strong hydrophobic interaction between the $\mathrm{C}_{60}$ derivative and the active site surfaces. This interaction makes $\mathrm{C}_{60}$ derivatives as inhibitors of HIVP. Kinetic analysis of HIVP in the presence of water soluble $\mathrm{C}_{60}$ derivatives suggests a competitive mode of inhibition. It was suggested through modelling that $\mathrm{C}_{60}$ derivatives should be inhibitors of HIVP due to their steric and chemical complementarity with the active sites. 


\subsection{Nitrogen bridging}

Two types of addition of organic azides to $\mathrm{C}_{60}$ are known. When alkyl azide is used, the addition reaction occurs at the $[5,6]$-ring junction to give an azafulleroid. On the other hand, when $\mathrm{N}_{3} \mathrm{COR}$ is employed, the adduct formed at the $[6,6]$-ring junction becomes the predominant product.

[(Trimethylsilyl)-ethoxy] methyl azide (SEM $\mathrm{N}_{3}$ ) and substituted benzyl azides add to $\mathrm{C}_{60}$ to give the corresponding fulleroids by the elimination of $\mathrm{N}_{2}$ upon heating (Prato et al 1993a) (figure 36). The addition is reported to take place across the 5,6-ring junction (i.e. open annulene structure), which is confirmed by the appearance of all the fullerene carbons in the $s p^{2}$ region of the spectrum. The azafulleroids (123) formed are found to be more electronegative than their carbon analogs.

The first example of a photochemical reaction between $\mathrm{C}_{60}$ and an N-hydroxysuccinimide functionalized perfluorophenyl azide was reported by Yan et al (1994). The reaction is believed to take place via the addition of the photogenerated, highly reactive nitrene intermediate to a $[6,6]$ double bond of $\mathrm{C}_{60}$. Only the aziridine monoadduct (125) (figure 37) is formed. There are sixteen peaks in the region

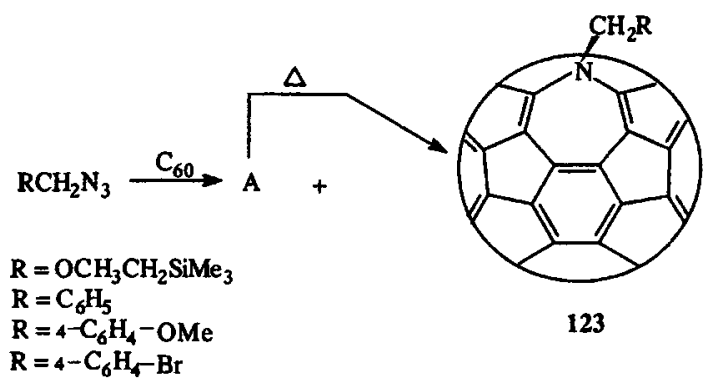

Figure 36. Synthesis of azafulleroids (Prato et al 1993a).

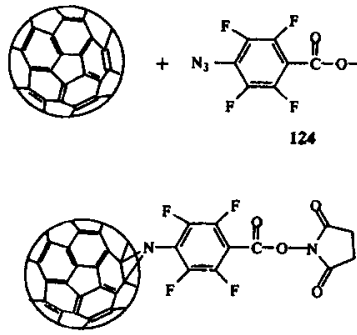

125

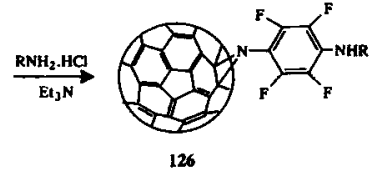

126

Figure 37. Photochemical reaction between $\mathrm{C}_{60}$ and N-hydroxysuccinimide-functionalized perfluorophenyl azide (Yan et al 1994). 


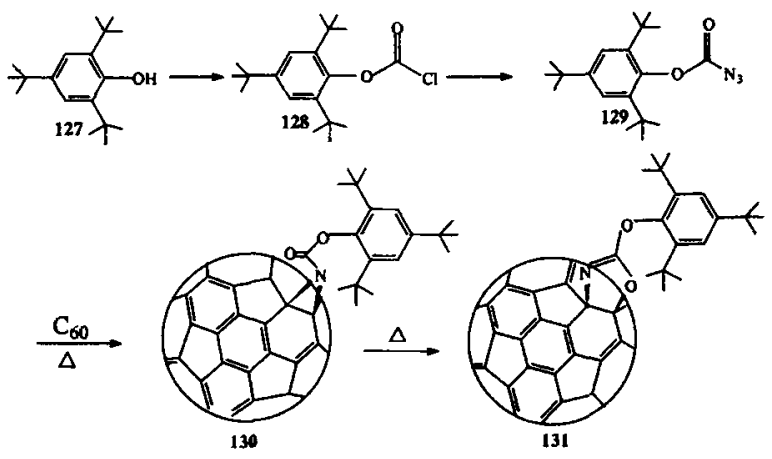

Figure 38. Reaction of $\mathrm{C}_{60}$ with azidoformate to form fullero aziridine (Banks et al 1994a).

$\delta 140-146$ in the ${ }^{13} \mathrm{C}$ NMR spectrum. The carbon atoms attached to a fluorine atom are not observed due to strong ${ }^{13} \mathrm{C}-{ }^{19} \mathrm{~F}$ coupling. The $\mathrm{C}_{60}$ skeleton of the product is thus of $\mathrm{C}_{2 v}$ symmetry. Hence the azamethanofullerene and azamethanoannulene $[5,6]$-ring structures are eliminated. The ${ }^{13} \mathrm{C}$ NMR spectra also showed a peak at $\delta 80.37$ which corresponds to a bridgehead carbon. These data indicated that 125 is an aziridine at $[6,6]$-ring junction of $\mathrm{C}_{60}$.

The isolation of nitrogen bridged fulleroaziridine (figure 38 ) with a $\sigma$-homoaromatic closed $[6,6]$-structure from the reaction of $\mathrm{C}_{60}$ with an azido formate (at elevated temperature) was reported by Banks et al (1994a). The fulleroaziridine rearranges on the fullerene surface upon further heating to fullerene having $O$ and $N$ heteroatoms vicinally bound to the [6,6]-ring fusion sites. Fulleroaziridines are formed in excellent yield by trapping of the appropriate nitrene at a $[6,6]$-ring junction of $\mathrm{C}_{60}$. Such compounds are thermally unstable and on heating result in an irreversible rearrangement to fullerooxazoles. Base-induced $\alpha$-elimination from substituted O-4-nitrophenyl sulphonylhydroxamic acid has been used as a mild source of nitrene for capture by [60]fullerene. Rearrangement of the resulting $[60]$ fullereno $\left[1^{\prime}, 2^{\prime}: 2,3\right]$ aziridine bearing a $\mathrm{N}$-ethoxy carbonyl grouping under the influence of chloromethylsilane results in the quantitative formation of $[60]$ fullereno[ $\left[1^{\prime}, 2^{\prime}: 4,5\right]$ oxazolidin-2-one, which can be cleaved to yield 1-hydroxy-2-N-methylamino [60]fullerene. Isolation of closed $[6,6]$-bridged aziridinofullerenes $\left(\mathrm{C}_{60} \mathrm{NCOOR}\right)$ by reaction of $\mathrm{C}_{60}$ with singlet oxycarbonylnitrenes is accompanied by small amount of previously undetected closed $[5,6]$ adducts, thought to arise by trapping of triplet nitrenes (Banks et al 1996). Isomerization of the $[6,6]$-bridged adducts to the corresponding oxazalo- $\left[4^{\prime}, 5^{\prime}: 1,2\right]$ [60]fullerene derivatives occurs upon heating with the exception of the tertbutoxycarbonyl adducts, which eliminates isobutene and carbon dioxide to yield the parent aziridinofullerene $\mathrm{C}_{60} \mathrm{NH}$. Addition of nitrenes to $\mathrm{C}_{60}$ furnished the fullerene derivative, the detailed spectroscopic analysis revealed that these products are $[5,6]$-open azaannulenes rather than the reportedly $[6,5]$-closed aziridines (Smith et al 1996). 
The reaction of $\mathrm{C}_{60}$ with aryl azides $\left(\mathrm{PhN}_{3}, 4-\mathrm{NC}-\mathrm{C}_{6} \mathrm{Hl}_{4} \mathrm{~N}_{3}\right)$ in dichlorobenzene at room temperature leads to isolable triazolinobenzene derivatives (Averdung and Mattay 1996) (figure 39). Photolysis of this derivative selectively yields aziridinofullerenes. Thermolysis, on the other hand, affords azafulleroids as main product next to $\mathrm{C}_{60}$. The first photochemical induced rearrangement of azafulleroid (1,6-azabridged isomers) to aziridinofullerenes (1,2-aza-bridged isomers) is described. Besides aziridines, the photochemical reaction of aryl azides with $\mathrm{C}_{60}$ predominantly yields one novel bisadduct. The synthesis of 1,2-(3,4-dihydro-2H-pyrralo)-[60]fullerenes by $[3+2]$ cycloaddition of nitrile ylides are reported.

The first example of $[6,6]$-open-bridged compounds by selective reduction of $\mathrm{C}-\mathrm{C}$ bond of $[6,6]$-closed-bridged aziridofullerene was reported by Banks et al (1996). The [6,6]-closed-bridged aziridofullerene (136) is reduced in acid medium to give the dihydroderivative (137) having a bridged ten-membered ring (figure 40). FAB-MS analysis of product confirmed that $\mathbf{1 3 6}$ has undergone reduction with
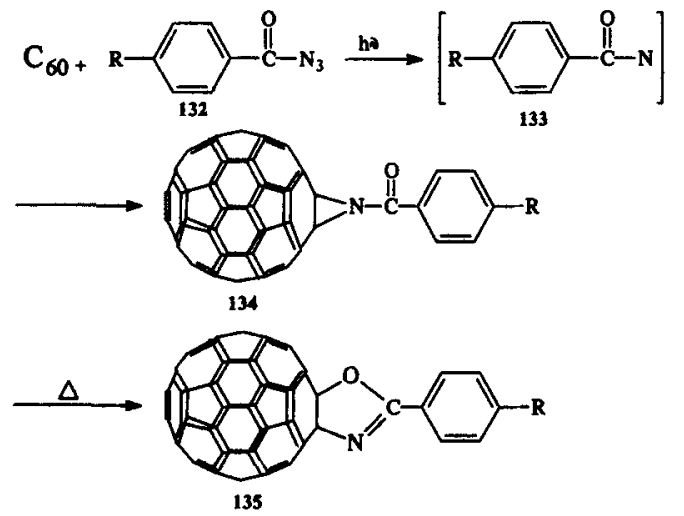

Figure 39. Formation of fulleroaziridine and thermal rearrangement to fullerooxazole (Averdung and Mattay 1995).

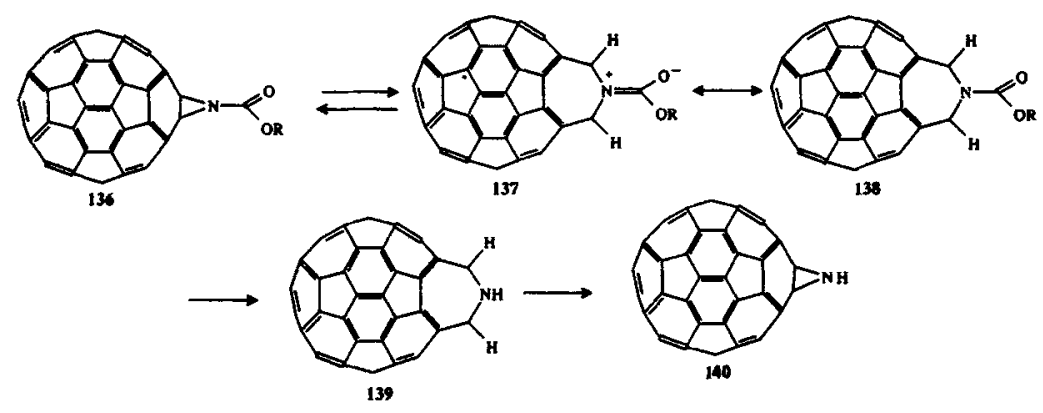

Figure 40. Incorporation of nitrogen at an open [6,6]-ring juncture (Banks et al 1996). 
incorporation of two hydrogen atoms. Evidence of addition of hydrogen atoms symmetrically across the aziridine moiety with ring expansion was provided by ${ }^{13} \mathrm{C}$ NMR data. Reaction of 2-azidobenzothiazole and 1-azido-4-(3',5'-dimethyl-1'-pyrazalyl)tetrafluorobenzene with [60]fullerene was reported by Jagerovic et al (1996). By FAB-MS and ${ }^{13} \mathrm{C}$ NMR spectroscopy the structure of three new imino[60]fullerenes were established. Two monoadducts, a $[6,6]$-closed $\sigma$-aziridinofullerene and a $[5,6]$ open $\pi$-azafulleroid and one $\pi$-bisazafulleroid were identified.

Grösser et al (1995) found that treatment of $\mathrm{C}_{60}$ with methyl azidoacetate yields triazoline 141 (figure 41), which when heated results in a mixture of nitrogen bridged monoadducts with $[5,6]$-open (142) and a $[6,6]$-closed (143) structures. In addition a bisadduct (144) is also formed, in which two neighbouring [5,6]-open bonds are imino bridged. The reaction of $\mathrm{C}_{60}$ with $\mathrm{N}_{3}\left(\mathrm{CH}_{2}\right)_{n} \mathrm{~N}_{3}(n=2$ or 3$)$ gives the corresponding bisazafulleroids (figure 42). The addition at the two [5,6]-ring junctions of the same five-membered ring (145) or at the two five-membered ring junctions of different five-membered rings (146) is possible. From the ${ }^{13} \mathrm{C}$ NMR and UV-VIS

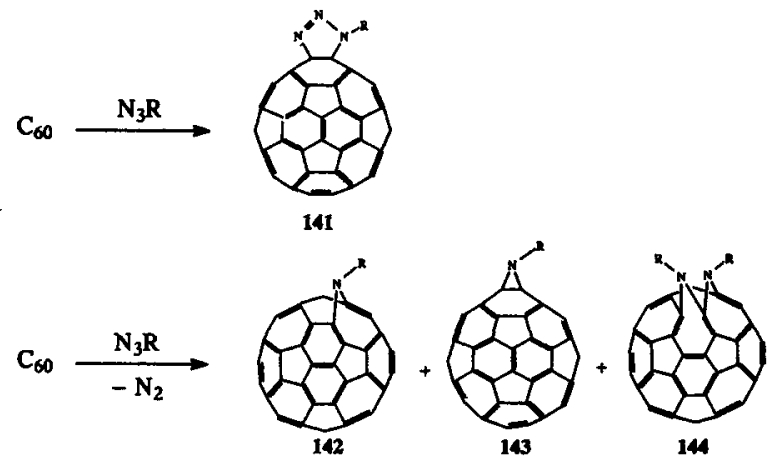

Figure 41. Ring expansion of the fullerene core by highly regioselective formation of diazafulleroids (Grösser et al 1995).
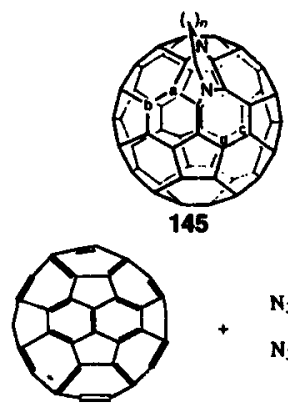

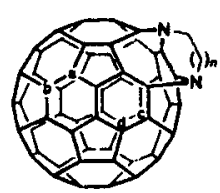

146

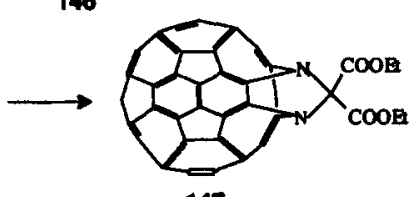

147

Figure 42. Bisazafulleroids (Shiu et al 1995; Dong et al 1995). 
studies the bisazafulleroid was assigned the structure 145 in which the addition is shown at the two $[5,6]$-ring junctions of the same five-membered ring. Dong et al (1995) reported a doubly bridged fulleroid 147 by reacting $C_{60}$ with diethyldiazidomalonate. Three structures corresponding to a double 5,6-insertion, a double 6,6-insertion and a 5, 6/6,6-insertion were considered. The ${ }^{1} \mathrm{H}$ NMR study of 147 showed two sets of ethoxy groups. From this observation and that addition of mono-azido compounds to $\mathrm{C}_{60}$ is established to be 5,6-insertion, the authors proposed the double bridged fulleroid as a double 5,6-insertion.

The first report of the synthesis and characterization of a $\mathrm{C}_{60}$ bearing triple-chain lipid (148) (figure 43) was reported by Murakami et al (1996). Spectral evidence suggested the lipid to exist as a closed aziridine structure at a $[6,6]$-ring junction of $\mathrm{C}_{60}$.

\subsection{Oxygen bridging}

Ultraviolet irradiation of $\mathrm{C}_{60}$ in presence of oxygen in hexane gives rise to the corresponding epoxides (Taylor et al 1991) (figure 44). When these epoxides are heated the corresponding ethers are formed. Ethers are also formed by the UV irradiation of fullerene. Extensive irradiation degrades the epoxides to the carbonyl containing compounds. The addition of oxygen takes place across the $[6,6]$-central bond of pyracylene unit of $\mathrm{C}_{60}$. The electrochemical oxidation of $\mathrm{C}_{60}$ led to the generation of $\mathrm{C}_{60} \mathrm{O}_{n}(n=1-4)$ (Kalsbeck and Thorp 1991). The photooxidation of $\mathrm{C}_{60}$ in benzene furnished a single mono oxide $\mathrm{C}_{60} \mathrm{O}$ as the sole isolable product. Spectroscopic analysis strongly supports the epoxide structure (150) and not the

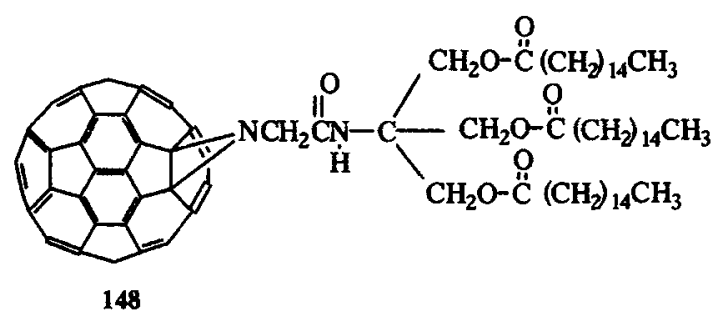

Figure 43. A $_{60}$ bearing lipid (Murakami et al 1996).
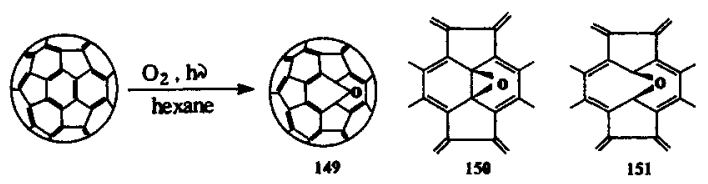

Figure 44. Epoxide formation at the [6,6]-bond of pyracylene unit. 

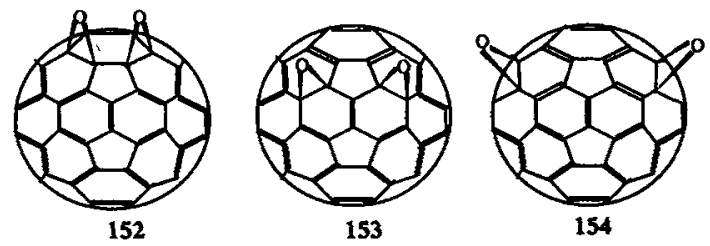

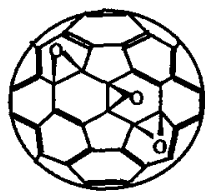

155

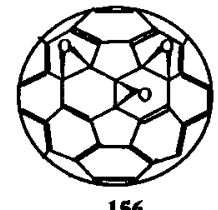

156

Figure 45. Diepoxy- and triepoxy[60]fullerenes (Hamano et al 1995).

isomeric 1,6-oxido [10] annulene (151) (Creegan et al 1992). Juha et al (1994) observed that $\mathrm{C}_{60}$ in its ground state does not react with excited molecular oxygen, chemically generated externally. It is suggested that the fullerene cage must itself be excited to be able to react with singlet oxygen.

In applying cytochrome P450 chemical model to studies on drug metabolism, Hamano et al (1995) synthesized 1,2-diepoxy[60]fullerene as a step in the analysis of the metabolic transformation of $\mathrm{C}_{60}$. From the spectroscopic data, out of the three possible symmetrical structures (152-154) the diepoxide was identified as the $1,2,3,4-$ diepoxy[60]fullerene (figure 45). In addition to the diepoxide, two triepoxides $(155,156)$ were also isolated and identified as 1,$2 ; 3,4 ; 9,10$-triepoxy[60]fullerene and 1,$2 ; 3,4 ; 11,12$-triepoxy[60]fullerene.

The eight symmetry non-equivalent bonds in $\mathrm{C}_{70}$ would yield as many as eight isomeric epoxides and an equal number of oxidoannulenes. Diederich et al (1991) reported the isolation of $\mathrm{C}_{70} \mathrm{O}$ and based on UV and mass spectra, the compound was formulated as an annulene with the oxygen atom bridging an unspecified $[6,6]$ ring fusion. Smith et al (1996) reported the synthesis of two isomeric epoxides and confirmed the structure to be $[6,6]$-closed $(157,158)$ (figure 46 ).

$\mathrm{C}_{60}$ contains 30 formal double bonds. Its spherical nature places stringent steric constraints on the conversion of the molozonide intermediate (161) to the ozonide. In presence of toluene 161 rearranges to 1,2-diketone (163) accompanied by formation of isomeric cresols (figure 47). The products are 2,5-xylol and 2,4-xylol. The oxidation occurs at the various double bonds of $\mathrm{C}_{60}$ ball, generating a mixture of oxidized product having ketonic, ester and epoxide functionalities.

\subsection{Other nonmetal and metal bridging}

Wudl et al (1993) reported the addition of bis(2,6-diisopropylphenyl)silylene with $\mathrm{C}_{60}$ to give an adduct by the addition across the $[6,6]$-ring fusion to give silirane 


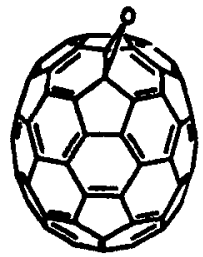

157

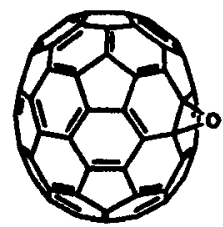

159

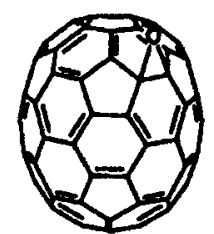

158

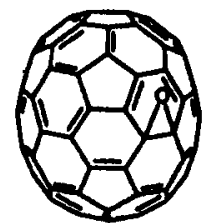

160

Figure 46. Four possible $[6,6] \mathrm{C}_{70} \mathrm{O}$ epoxides (Smith et al 1996).

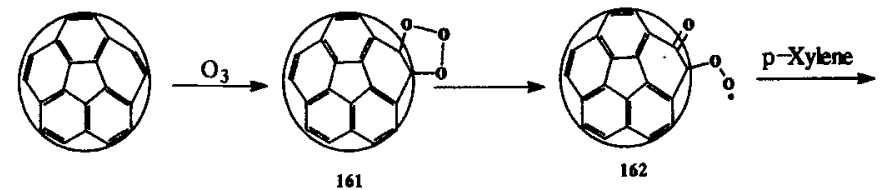

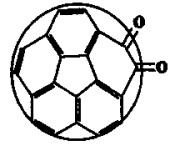

163<smiles>[M]C12C=CC(C)=CC1O2</smiles><smiles>Cc1ccc(C)c(O)c1</smiles><smiles>Cc1ccc(O)c(C)c1</smiles>

Figure 47. Steric constraints prevent conversion of molozonide intermediate to the ozonide (Malhotra et al 1994b).

(figure 48) with exothermicity of $61 \cdot 3 \mathrm{kcal} / \mathrm{mol}$. The ${ }^{13} \mathrm{C}$ NMR signal at $\delta=71.12$ supports the structure 167 for the above adduct rather than 168 .

In reaction with metal derivatives, $\mathrm{C}_{60}$ also behaves as an alkene (giving $\eta^{2}$ coordination) rather than an aromatic ( $\eta^{6}$-coordination). The first structurally characterized $\mathrm{C}_{60}$ derivative is an osmate ester with $\mathrm{C}-\mathrm{O}-\mathrm{Os}$ bonds, $\left(t-\mathrm{Bu} \mathrm{C}_{5} \mathrm{H}_{5} \mathrm{~N}_{2}\right)_{2}$ $\mathrm{Os}(=\mathrm{O})_{2} \mathrm{O}_{2} \mathrm{C}_{60}$ (Hawkins et al 1990). Two of the above adducts can be added to $\mathrm{C}_{60}$. Hawkins et al (1993) reported the formation of adducts of $\mathrm{C}_{60}$ with $\mathrm{OsO}_{4}$ (4-t$\mathrm{Bu} \mathrm{Py}$ ) and its analogs. The $\mathrm{X}$-ray analysis of the crystals of osmium complex indicated the elimination of free rotation of $\mathrm{C}_{60}$ spheroids in the solid state. Osmylation of $\mathrm{C}_{60}$ yields $1: 1$ and 2:1 adducts with cup and band shaped $\pi$-systems respectively (figure 49). Five regioisomers of 2:1 adduct $\mathrm{C}_{60}\left(\mathrm{OsO}_{4} \mathrm{~L}_{2}\right)_{2}$ are formed including two chiral isomers, which are formed due to the substitution pattern in the 


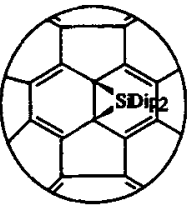

167

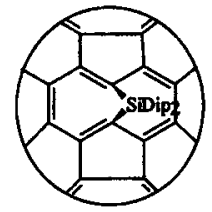

168

$\mathrm{Dip}{ }_{2} \mathrm{Si}_{\left(\mathrm{SiMe}_{3}\right)_{2}} \underset{\mathrm{Me}_{3} \mathrm{SiSiMe}_{3}}{\longrightarrow}\left[\mathrm{Dip}{ }_{2} \mathrm{Si}\right] \stackrel{\mathrm{C}_{60}}{\longrightarrow} \mathrm{Dip}_{2} \mathrm{C}_{60}$

Figure 48. Synthesis of siliranes (Wudl et al 1995).

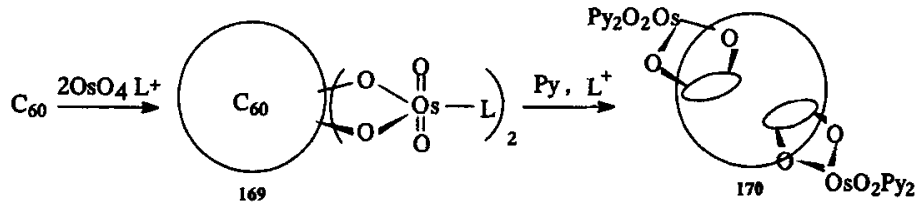

Figure 49. Osmylation of $\mathrm{C}_{60}$ (Hawkins et al 1993).

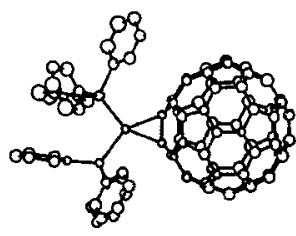

171

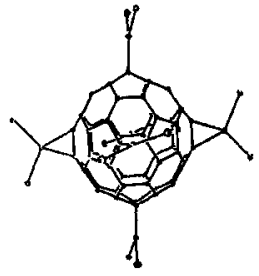

172

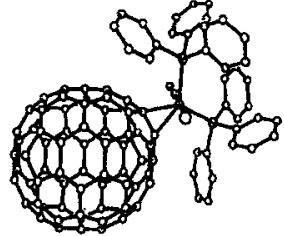

173

Figure 50. Platinum and iridium functionalized complexes of $\mathrm{C}_{60}$ (Balch et al 1991a; Fagan et al 1991a).

icosahedral carbon cluster (Hawkins et al 1993). Osmylation of $C_{70}$ with 0.75 equiv. of $\mathrm{OsO}_{4}$ in pyridine/toluene at $0^{\circ} \mathrm{C}$ yielded two isomers of $\mathrm{C}_{70}\left(\mathrm{OsO}_{4} \mathrm{Py}_{2}\right)$. Osmylation occurs at the double bonds and not at the single or intermediate (aromatic) bonds. Greater reactivity at more pyramidalized carbons corresponds to greater strain relief as the fullerene carbons become four coordinate.

The synthesis of the first optically active organometallic fullerene derivative by $\eta^{2}$-functionalization of $\mathrm{C}_{60}$ by $\mathrm{Pd}^{0}$ complex was reported by Bashilov et al (1993). Reactions of $\mathrm{C}_{60}$ with organometallic ruthenium and platinum reagents were thoroughly studied in which metals can be directly attached to the carbon framework by dihapto bonding and $\mathrm{X}$-ray diffraction analysis of platinum complex $\left[\mathrm{Ph}_{3} \mathrm{P}\right]_{2} \mathrm{Pt}$ $\left(\eta^{2}-\mathrm{C}_{60}\right)-\mathrm{C}_{4} \mathrm{H}_{8} \mathrm{O}$ showed that the structure is similar to the $\left[\mathrm{Ph}_{3} \mathrm{P}\right]_{2} \mathrm{Pt}\left(\eta^{2}\right.$ ethylene) (Fagan et al 1991).

$\left[\mathrm{Ph}_{3} \mathrm{P}\right]_{2} \mathrm{Pt}\left(\eta^{2}-\mathrm{C}_{60}\right)$ can be prepared by the addition of $\mathrm{C}_{60}$ with $\left[\mathrm{Ph}_{3} \mathrm{P}\right]_{2} \mathrm{Pt}\left(\eta^{2}-\right.$ ethylene) in toluene under nitrogen atmosphere. From the ${ }^{31} \mathrm{P}$ NMR spectral data of the above compound (171) (figure 50) it was indicated that, coupling constants 
and chemical shifts were similar for both $\mathrm{C}_{60}$ and ethylene complex. From this it was suggested that coordination sphere about platinum was nearly identical in both the cases i.e. addition takes place across two fused six-membered rings rather than at the junction of five- and six-membered rings. Spectroscopic data also reveals that the organometallic derivative in contrast to diazomethane adduct has a open ring (i.e. fulleroid) structure. Fagan et al (1992) in another report showed that either one, two or six groups can be added, the latter giving an octahedral array. In this process only one isomer was obtained and in hexasubstituted platinum derivative $\left\{\left[\left(\mathrm{C}_{2} \mathrm{H}_{5}\right)_{3} \mathrm{P}\right]_{2} \mathrm{Pt}\right\}_{6} \mathrm{C}_{60},(172)$, the phosphorous, platinum and $\mathrm{C}_{60}$ atoms exhibit $T_{\mathrm{h}}$ point group symmetry. Monoadducts of $\mathrm{C}_{60}$ have also been formed with nickel and palladium. Iridium complex-alkene adduct can also add to $C_{60}$ across 6,6-ring fusion in dihapto fashion to form a crystalline derivative (Balch et al 1991). Two iridium adducts can be added to $C_{60}$. Shapley et al (1992) reported the addition of complex $\left(\eta^{5}-\mathrm{C}_{9} \mathrm{H}_{7}\right) \operatorname{Ir}(\mathrm{CO})$ to $\mathrm{C}_{60}$ in dihapto fashion to form $\left(\eta^{5}-\mathrm{C}_{9} \mathrm{H}_{7}\right) \operatorname{Ir}(\mathrm{CO})\left(\eta^{2}-\right.$ $\left.\mathrm{C}_{60}\right)$. The complex formed is air stable. Ir $(\mathrm{CO}) \mathrm{Cl}\left(\mathrm{PPh}_{3}\right)_{2}$ can also add to $\mathrm{C}_{70}$ to give $\left(\eta^{2}-\mathrm{C}_{70}\right) \operatorname{Ir}(\mathrm{CO}) \mathrm{Cl}\left(\mathrm{PPh}_{3}\right)_{2}(\mathbf{1 7 3})$ by addition across one of the high order $\pi$ bonds adjacent to the pentagonal cap (Balch et al 1991). Iridium ion is bound to an $\mathbf{a}-\mathbf{b}$ edge of $\mathrm{C}_{70}$. The symmetry around the iridium atom is similar to that of $\left(\eta^{2}-\mathrm{C}_{60}\right) \operatorname{Ir}(\mathrm{CO}) \mathrm{Cl}\left(\mathrm{PPh}_{3}\right)_{2}$ and two iridium adducts can be added. $\mathrm{Ir}(\mathrm{CO}) \mathrm{Cl}\left(\mathrm{PMe}_{2} \mathrm{Ph}\right)_{2}$ can also form diadduct with $\mathrm{C}_{70}\left[\mathrm{Ir}(\mathrm{CO}) \mathrm{Cl}\left(\mathrm{PMe}_{2} \mathrm{Ph}\right)_{2}\right]_{2}$ (Balch et al 1992).

\section{Cycloaddition reaction}

Fullerenes undergo various types of cycloaddition reactions such as $[2+2]$, $[2+3],[2+4],[4+4],[2+2+2]$ and other higher electron count reactions. These reactions provide efficient means of attaching functional groups, imparting useful properties to the parent molecule.

In $[2+4]$ cycloaddition reaction, fullerene nucleus acts as a dienophile (Wudl 1992). This is due to the fact that inter five-membered ring bonds are fulvenoid and also electrophilic in nature. In case of both $\mathrm{C}_{60}$ and $\mathrm{C}_{70}$, up to six molecules of diene can be added to $\mathrm{C}_{60}$ nucleus across the six pyracylene units.

$\mathrm{C}_{60}$ undergoes $[2+4]$ cycloaddition reaction with various reagents such as anthracene, furan, cyclopentadiene, nitrile oxide, isobenzofuran, $o$-quinodimethanes etc to give the corresponding cycloadduct. In all the reactions, the addition takes place across the junction of two six-membered rings rather than at the junction of fiveand six-membered rings. Rubin et al (1993) reported the reaction between anthracene and $\mathrm{C}_{60}$, but the adducts could not be isolated and characterized. A $\mathrm{C}_{60}$-cyclopentadiene adduct was isolated from a low pressure benzene flame by Rotello et al (1993). The ${ }^{1} \mathrm{H}$ and ${ }^{13} \mathrm{C}$ NMR spectra of the cycloadduct correspond to the expected $\mathrm{Cs}$ symmetry of the molecule formed by addition across the $\mathrm{C}_{6}-\mathrm{C}_{6}$ ring fusion. Wudl et al (1993) reported the multiple addition product formed by the addition of excess cyclopentadiene or anthracene to $\mathrm{C}_{60}$ and obtained the polyadduct (figure 51). In this reaction, up to six molecules of cyclopentadiene or anthracene could be added to $\mathrm{C}_{60}$ moiety. Komatsu et al (1993) used naphthalene as 


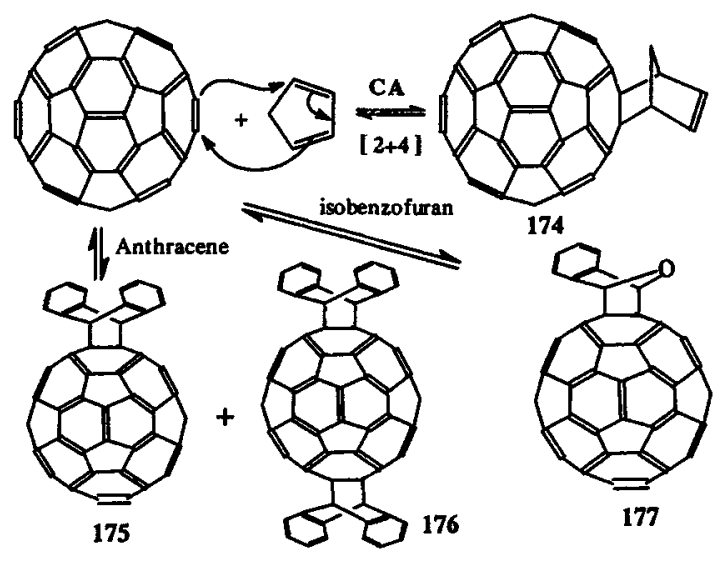

Figure 51. $[2+4]$ cycloaddition reaction. Up to six molecules of diene add at the $[6,6]$ ring junction.

a high boiling solvent and isolated selectively the 1:1 adduct. Tsuda et al (1993) reported the synthesis of several cycloadducts of $\mathrm{C}_{60}$ with anthracene, cyclopentadiene, 1,3-diphenylisobenzofuran and 1,3-dimethyl butadiene. The adducts are characterized by means of negative ion FAB mass and ${ }^{1} \mathrm{H}$ and ${ }^{13} \mathrm{C}$ NMR spectroscopy. For anthracene, both mono- and di-adducts $(175,176)$ are isolated and characterized. Schlueter et al (1993) characterized the $C_{60}$-anthracene 1:1 adduct by NMR, UV-vis, IR, mass spectroscopies and thermogravimetric analysis. The TGA indicated a $19.97 \%$ weight loss, the onset of transition occurring at $120^{\circ} \mathrm{C}$, which is expected for the removal of a single anthracene unit. Klemt et al (1995) studied the reaction between $\mathrm{C}_{60}$ and anthracene and observed EPR-active adducts of ${ }^{3} \mathrm{C}_{60}$ to anthracene.

In all the above reactions, the cycloadduct formed revert back to $\mathrm{C}_{60}$, which was detected by X-ray crystallographic studies and mass spectral analysis. To overcome this difficulty, Prato et al (1993) reported that when $C_{60}$ reacts with isobenzofuran generated in situ from 1,4-dihydro-1,4-epoxy-3-phenylisoquinoline in refluxing benzene, the corresponding cycloadduct obtained by fusion at the $[6,6]$-ring junction did not undergo cycloreversion. Rubin et al (1993) synthesized the adduct (178) by $[2+4]$ cycloaddition of $\mathrm{C}_{60}$ with 5,6-dimethylene-1,4-dimethyl-2,3-diphenyl norboran-2-en-7-one, which by elimination of $\mathrm{CO}$ finally gave a stable adduct (179) (figure 52). This adduct does not undergo retro-Diels-Alder reaction due to the stability imparted by the aromatic ring, and this must be overcome to give cycloreversion product $\mathrm{C}_{60}$ and $o$-quinodimethane intermediate. The reaction of $\mathrm{C}_{60}$ with in situ generated $6 \mathrm{~b}, 10 \mathrm{a}$-dihydrofluoranthene affords a stable $[4+2]$ cycloadduct (Averdung and Mattay 1994). Diels-Alder reaction of 4-amino-o-quinodimethane with $\mathrm{C}_{60}$ affords a thermally stable and chemically reactive adduct (Walter et al 1996). The nucleophilic amino group is well suited for the covalent attachment of different molecules to the [60]fullerene core by further chemical reaction. 

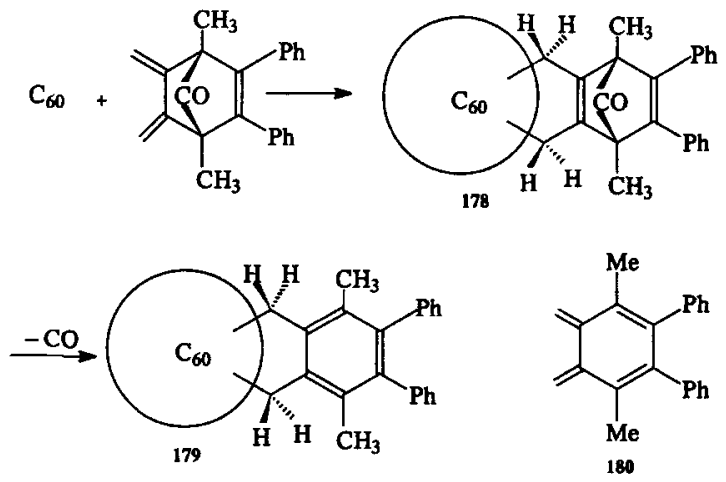

Figure 52. Synthesis of stable cycloadducts by $[2+4]$ cycloaddition followed by elimination (Rubin et al 1993).

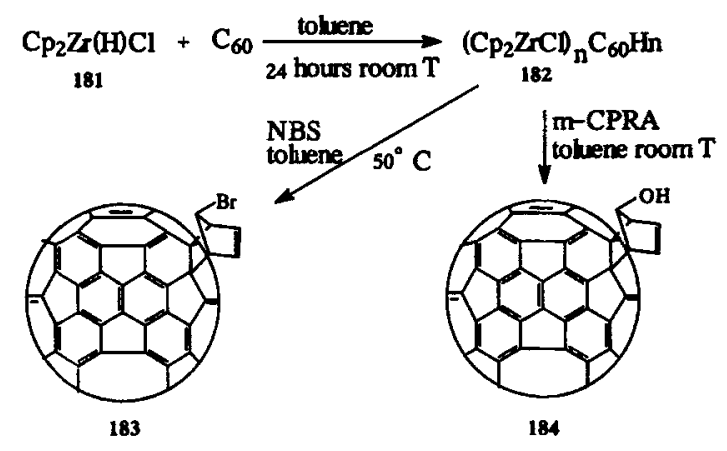

Figure 53. Cycloaddition of metallofullerene (Ballenweg et al 1994).

Metallofullerene undergoes cycloaddition reaction with various reagents. $C_{60}$ hydrozirconation adduct (182) reacts with NBS and $m$-chloroperbenzoic acid, leading to Diels-Alder adduct with bromo- and hydroxycyclopentadiene respectively (figure 53) (Ballenweg et al 1994). Both exo- and endo-isomers are possible. Endo isomer is more stable with respect to the double bond in the norbornene position. A three-step mechanism to explain this unusual reaction is proposed (Ballenweg et al 1996).

Wilson and $\mathrm{Lu}(1993)$ reported the results of $\mathrm{C}_{60}$ - Diels-Alder reaction with a relatively unreactive crown ether diene 185 (figure 54), and followed the reaction course by electrospray MS method. The reaction is not reversible. $\mathrm{C}_{60}$ also reacts with 'Danishefsky Diene' (187) to produce annealed ketone 188, which could be useful for preparation of the functionalized fullerenes. The synthesis of the fullerene derivatives of quinones was first reported by Iyoda et al (1994). The compound 190 (figure 54a) was of interest because of a potential donor-acceptor interaction between fullerene and $p$-benzoquinone parts, and because of the opposite acceptordonor interaction between $\mathrm{C}_{60}$ semiquinone radical or hydroquinone dianion 191 

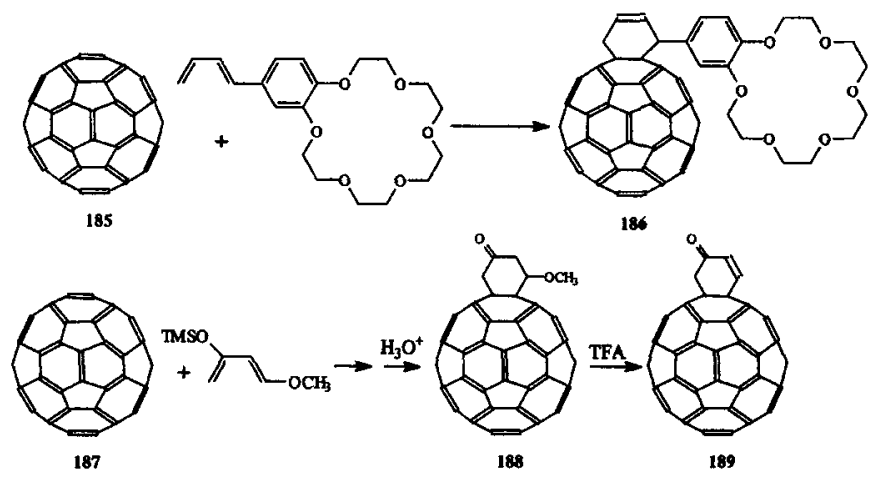

Figure 54. Cycloaddition of a crown ether diene and Danishefsky diene (1-methoxy-3(trimethylsiloxyl)-1,3-butadiene) to [60]fullerene (Wilson and Lu 1993).

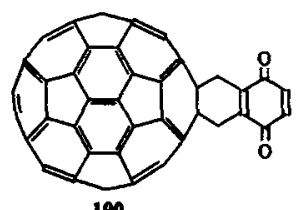

190

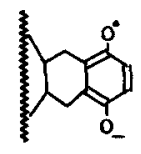

191

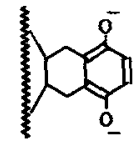

192

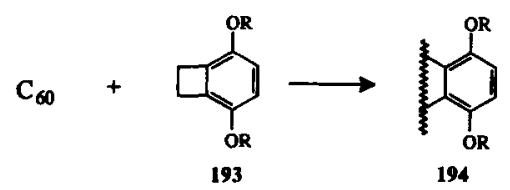

Figure 54a. Redox system containing fullerene and p-benzoquinone (Iyoda et al 1994).

and 192. To construct the novel redox system, $C_{60}$ was allowed to react with 3,6-dimethoxybenzocyclobutane 193 to give the monoadduct 194. The removal of methyl group resulted in the desired compound. In order to estimate the $\pi-\pi$ interaction between fullerene and quinone parts, the redox potential of 190, 194 and $\mathrm{C}_{60}$ were measured by cyclic voltametry.

The high-pressure Diels-Alder reaction of $\mathrm{C}_{60}$ with substituted tropone derivatives gives stable $[2+4]$ cycloadducts (Liu et al 1995). The selectivity is controlled by the steric environment. The Diels-Alder reaction between $\mathrm{C}_{60}$ and 2,3-dimethylene-1,4-dioxane or 4, 5-dimethylene-2,2-dimethyldioxolane are reported by TorresGaricia and Mattay (1996). The regioselective functionalization of $\mathrm{C}_{60}$ by way of $[2+4]$ cycloaddition reactions give synthetic access to exohedrally derivatized fullerenes, with either flexible or rigidly bound addends. The binding of the addends to the central carbon sphere is made effectively irreversible by subsequent addition reactions at the double bond of the addends (Kräeutler and Maynollo 1996).

An et al (1995) reported the reaction of $\mathrm{C}_{60}$ with 1,3-dienes to afford substituted 1,2-(4'-cyclohexeno)buckminsterfullerenes. These cyclohexenones are sensitive to 
ambient light and air, easily undergoing ${ }^{1} \mathrm{O}_{2}$ ene reaction to form the corresponding hydroperoxides. The reaction is used advantageously in the preparation of allylic alcohols. Kräutler and Maynollo (1995b) reported a remarkably regioselective sixfold $[2+4]$ cycloaddition of $\mathrm{C}_{60}$ with 2,3-dimethyl-1,3-butadiene. The six-fold Diels-Alder reaction of 1,3-diene takes place at the six symmetry-equivalent "6-6 bonds' located between the six-membered rings of fullerene. The Diels-Alder strategy was found suitable for the functionalization of $\mathrm{C}_{60}$ using 1,3-butadienes substituted with an electron withdrawing group as well as an electron donating group. This gives cyclohexene-fused $\mathrm{C}_{60}$ derivatives (Ohno et al 1996a), having ethoxycarbonyl, acetyl, cyano, phenylsulphonyl and nitro substituents. These cycloadducts are stabilized by conjugation with the substituent and no cycloreversion takes place.
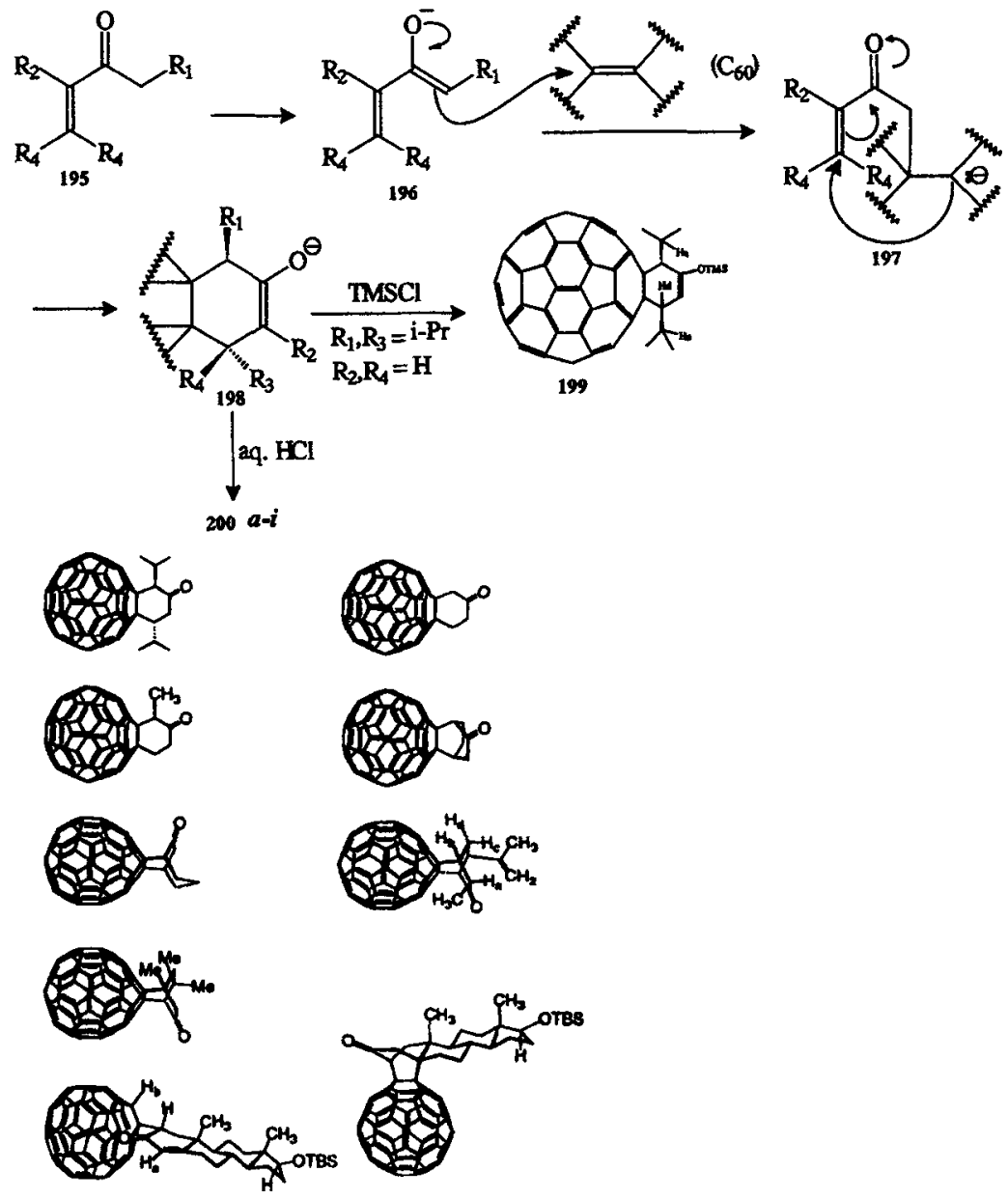

$200 a-i$

Figure 55. Synthesis of sterically congested $\mathrm{C}_{60}$ derivatives with defined stereochemistry (Ganapathi et al 1995). 
<smiles>CC1CCCCC1</smiles>
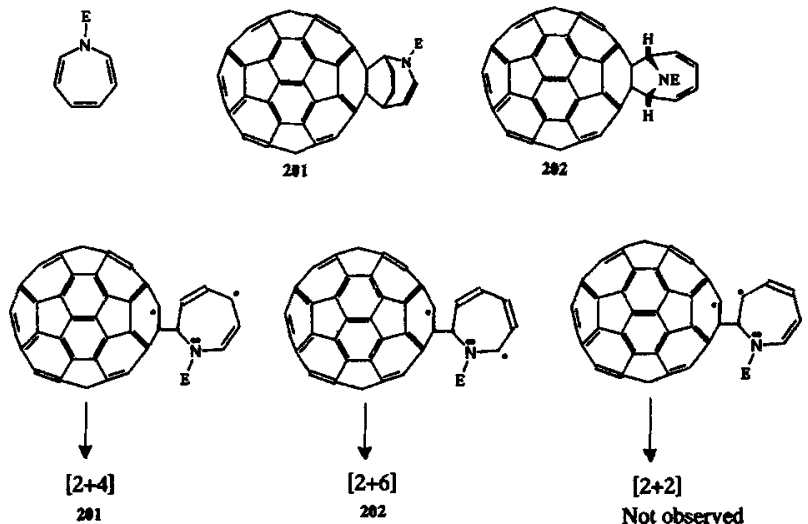

Figure 56. Competing pathways in the photolytic cycloaddition reactions of N-ethoxycarbonylazepine to [60] fullerene (Banks et al 1995).
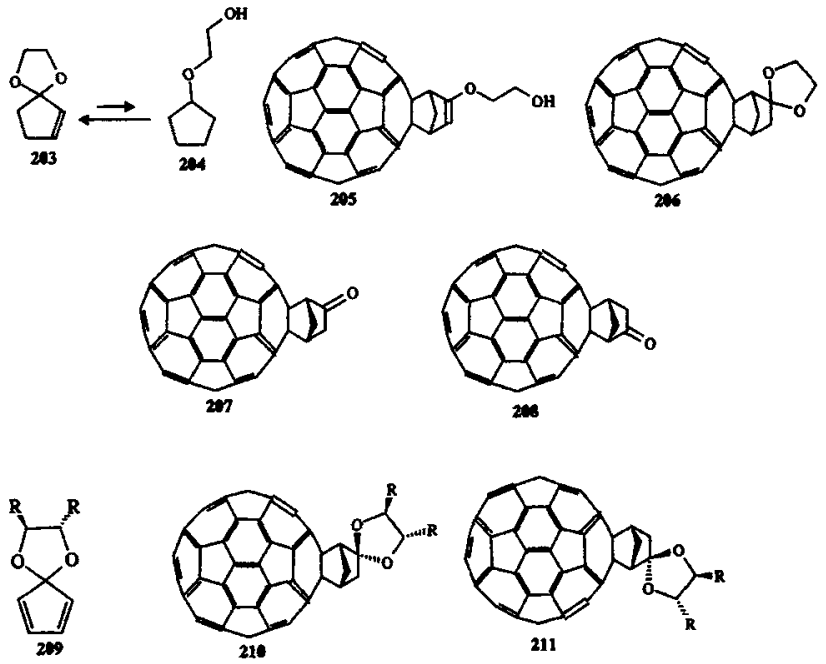

Figure 57. Reaction of $\mathrm{C}_{60}$ with cyclopent-2-enone acetals: a convenient access to chiral $\mathrm{C}_{60}$ derivatives (Ohkita et al 1995).

Attaching a cyclohexane ring with a sterically crowded 1,4-position to $\mathrm{C}_{60}$ was accomplished by Ganapathi et al (1995). The reaction involved a 'double Michael' addition of a dienolate anion to $\mathrm{C}_{60}$ (figure 55). Protonation of 198 resulted in the desired cyclohexyl moiety attached to $C_{60}(200 a-i)$. Either of the two diasteromers might be formed and both were predicted to show significant increase in apolar binding to HIV-protease. HIV-1 protease is an important target for antiviral therapy since it has vital function in the maturation of the AIDS-inducing virus. Banks et al (1995) in a course of further investigation of their reported work on synthesis of closed [6,6]fulleroaziridines observed the formation of 201 and 202 (figure 56). 


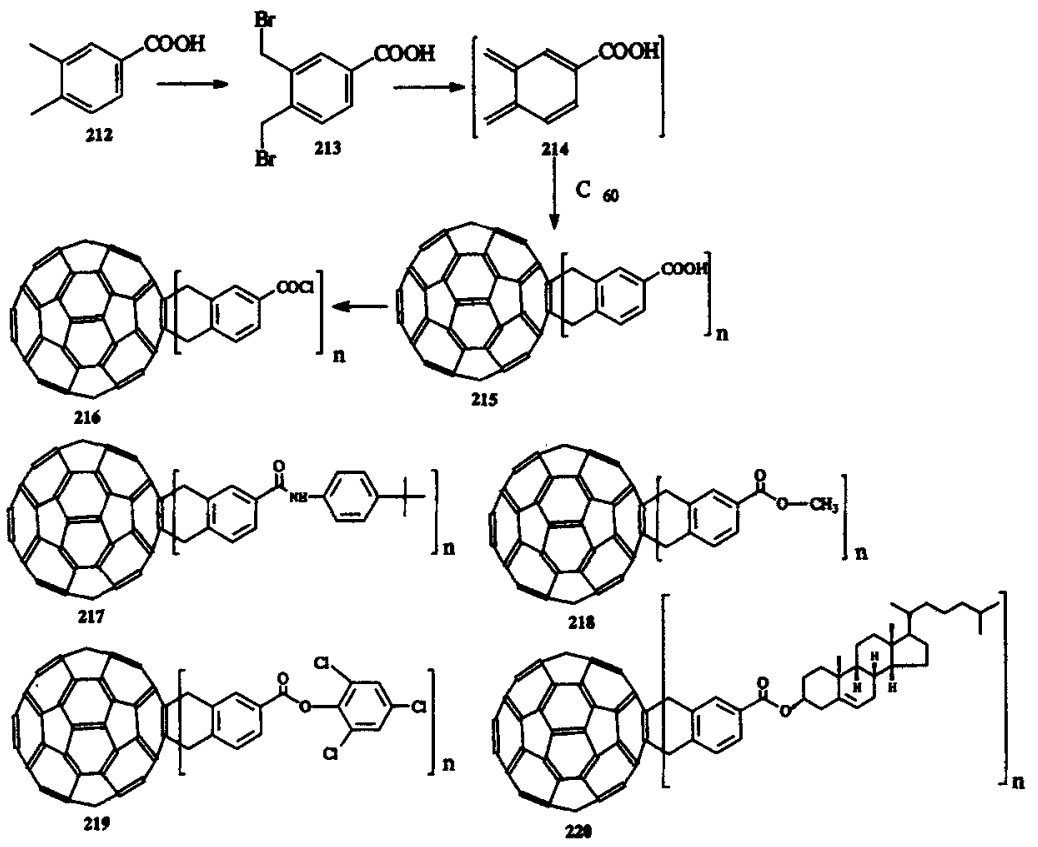

Figure 58. Diels-Alder adduct of $\mathrm{C}_{60}$ and 4-carboxy-o-quinodimethane: Synthesis and chemical transformation (Belik et al 1995).

Benzene, used as the solvent, captured the photolytically generated nitrene to produce $N$-ethoxycarbonylazepine, which then underwent further photoreaction with $\mathrm{C}_{60}$ giving [2+4] and [2+6] cycloadducts. Formation of $[2+2]$ photoadduct was not detected. Reaction of cyclopent-2-enone acetal 204 with $\mathrm{C}_{60}$ at $[6,6]$ ring junction via its ring opened form 205 is reported by Ohkita et al (1995). The primary cycloadduct 205 (figure 57) is promptly converted to the acetal 206, thereby effectively preventing the reversion of the adduct to the reactants. Hydrolysis of $\mathbf{2 0 6}$ afforded the corresponding $( \pm)$ ketone 207,208 in quantitative yields. The authors also investigated the reaction of $\mathrm{C}_{60}$ with acetal 209 , bearing a chiral auxillary and derived from L-tartaric acid. Two diastereomeric monoadducts 210 and 211 were isolated in nearly equal amounts, indicating insignificant asymmetric induction in the process.

$\mathrm{C}_{60}$ undergoes a smooth irreversible hetero-Diels-Alder reaction with an $\alpha, \beta$ unsaturated thiocarbonyl compound, prepared in situ from thioacrylamide and acyl chloride, to give dihydrothiopyran-fused $C_{60}$ cycloadducts (Ohno et al 1995). This is the first example of a sulphur-bonded $\mathrm{C}_{60}$ derivative.

The $[2+4]$ cycloaddition reaction of $o$-quinodimethane with $\mathrm{C}_{60}$ is a method of choice for the synthesis of physically stable and chemically reactive $C_{60}$ adducts. $A$ multitude of reactive functional groups can be introduced in the process. Belik et al (1995) reported the synthesis of carboxy-substituted adducts of $\mathrm{C}_{60}$ and $o$ quinodimethane, and subsequent reaction of the adducts with alcohols and amines. The chlorides (216) are transformed to amides and esters with 4-tert-butylaniline, methanol, 2, 4, 6-trichlorophenol and chloresterol (217-220) (figure 58). 


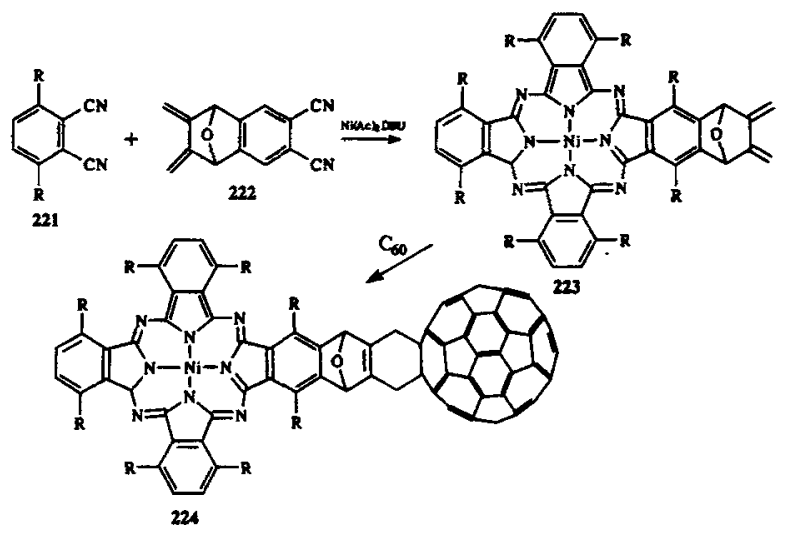

Figure 59. A Dieis-Alder adduct of [60] fullerene with a phthalocyanine-a green fullerene (Linssen et al 1995).

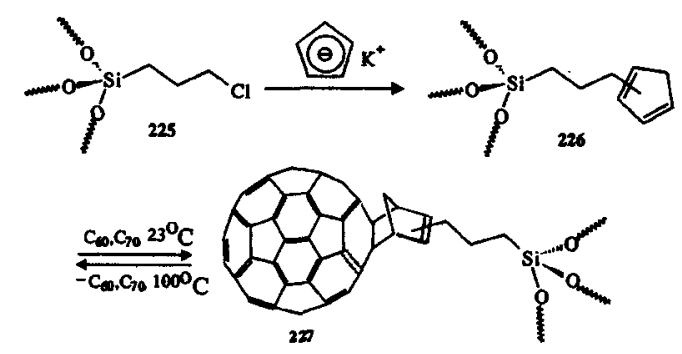

Figure 60. Nonchromatographic purification of fullerenes via reversible addition to silicasupported dienes (Nie and Rotello 1996).

The synthesis and electrochemistry of a Diels-Alder adduct of $\mathrm{C}_{60}$ with nickel phthalocyanine (223) resulted in a 'green fullerene' (224) (figure 59). The nickel phthalocyanine was synthesized from 3,6-diheptylphthalodinitrile (221) and 1, 2, 3,4tetrahydro-2,3-dimethylene-1,4-epoxynaphthalene-6,7-dicarbonitrile (222) to react with nickel acetate in the presence of a catalytic amount of 1,8-diazabicyclo[5.4.0] undec-7-ene (DBU). The $\mathrm{C}_{60}$ adduct of 223 was formed at the $[6,6]-$ ring junction providing the 'green fullerene'.

The property of reversible cycloaddition of free (Rotello et al 1993) and polymer supported (Guhr et al 1995) dienes to $C_{60}$ led Nie and Rotello (1996) to devise a simple method for the purification of fullerenes. Reaction of chloropropyl functionalized silica gel 225 with potassium cyclopentadienylide provided the cyclopentadiene-functionalized silica gel 226 (figure 60). This material reacted readily with $\mathrm{C}_{60}$ and $\mathrm{C}_{70}$ to yield mixed $\mathrm{C}_{60} / \mathrm{C}_{70}$ conjugate 227 , which on heating released $93.7 \%$ of bound $C_{60}$ and $41.1 \%$ of bound $C_{70}$. The process was fully reproducible, with fullerenes being completely reabsorbed upon cooling. The difference in release provided fullerenes significantly enriched in $C_{60}$ : the initial $C_{60} / C_{70}$ ratio was 90:10, the final ratio was $96: 4$. 
Paquette and Trego (1996) condensed bifunctional dienes with $\mathrm{C}_{60}$, the products were dumbbell-like systems 230 and 231 (figure 61). When hericene (232), a trifunctional diene $(2,3,5,6,7,8$-hexamethylidene bicyclo $[2 \cdot 2 \cdot 2]$ octane) was treated with $\mathrm{C}_{60}$, cycloaddition takes place in a three-dimensional format, resulting in the adduct 233. This is the first example of a 'radiafullerene' with three carbon spheres radiating out symmetrically from the staging framework.

Exceptions to the dienophilic character to $C_{60}$ are known. Cooks et al (1992) reported both 1,4- and 1,2-type addition of $\mathrm{C}_{60}$ to benzene giving a mixture of two products. In the 1,4-addition reaction, addition preferentially takes place across the

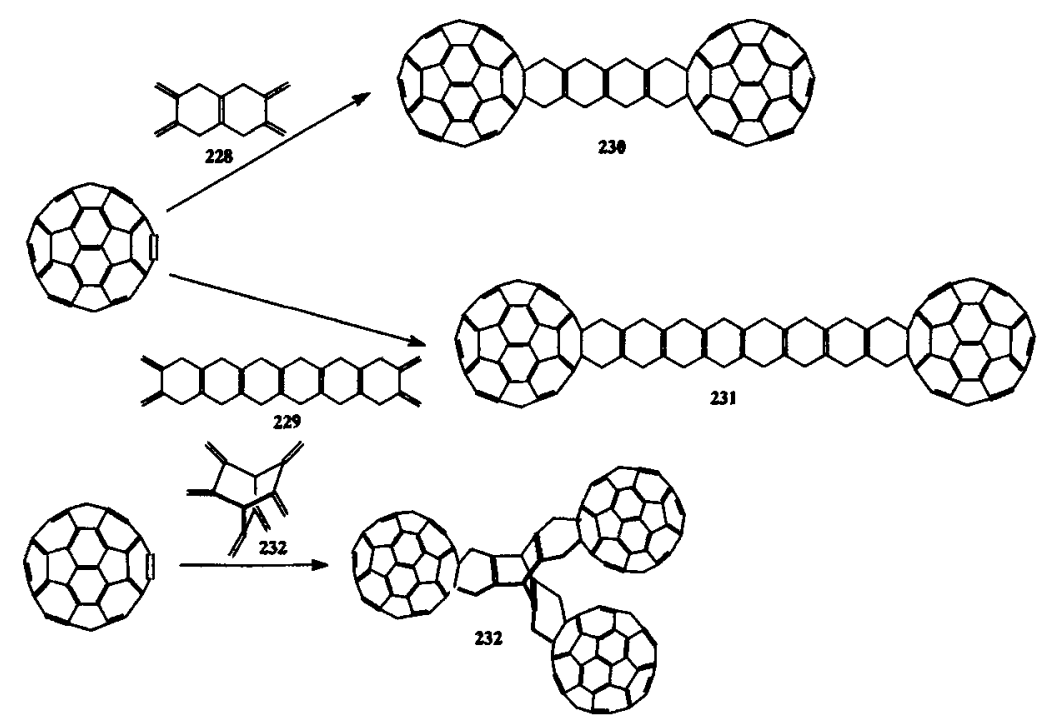

Figure 61. Extended projection of $\mathrm{C}_{60}$ spheres into three dimensional space-three-fold cycloaddition of $[60]$ fullerene to hericene (Paquette and Trego 1996).

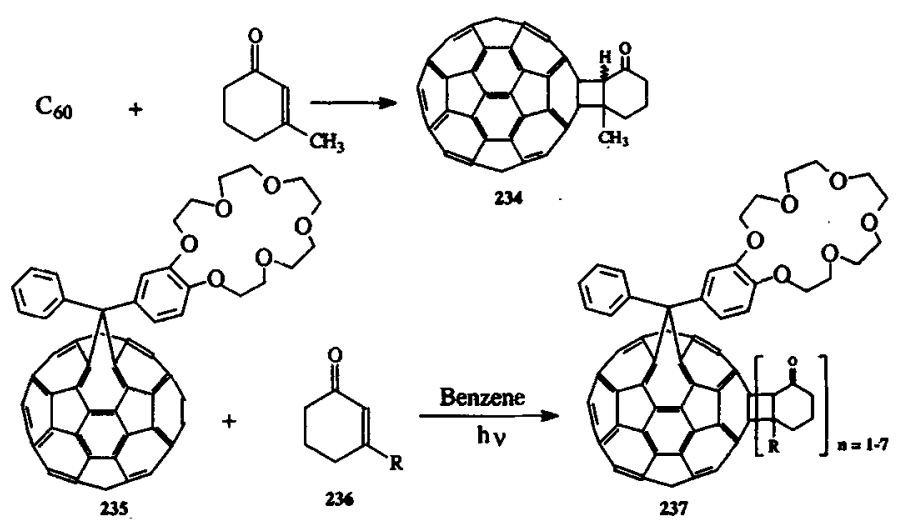

Figure 62. $\mathrm{C}_{60}$-enone $[2+2]$ photoadducts. Addition of enones to crown ether fulleroid is followed by ESI-MS studies (Wilson et al 1993b). 

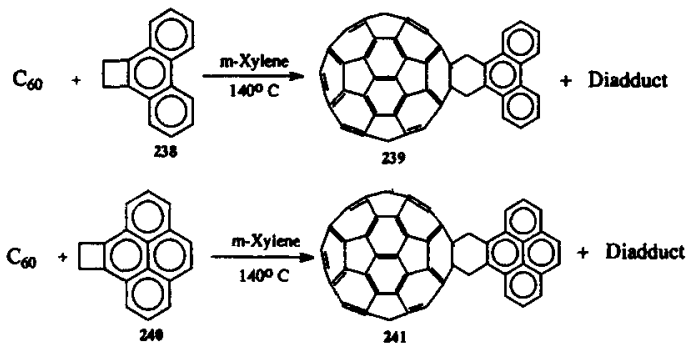

Figure 63. Reaction of fullerene with benzocyclobutene homologs (Tago et al 1993).

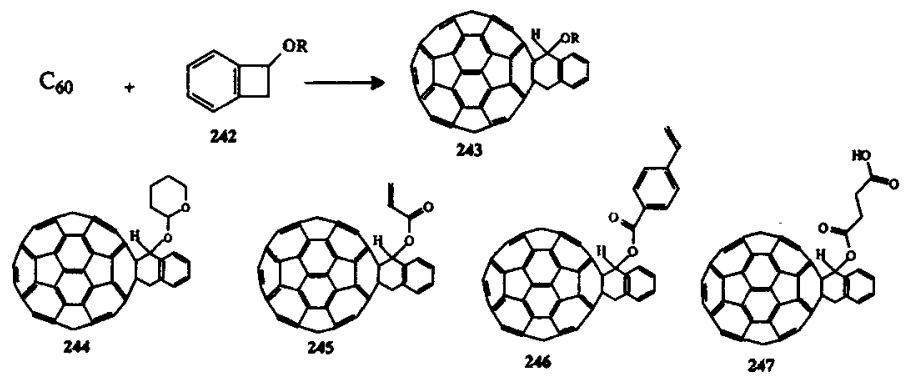

Figure 64. An expeditious route to fullerene adducts by reaction of [60] fullerene with benzocyclobutenol (Zhang and Foote 1994).

1,4-position within a ring and not between two. Up to four molecules of benzene can add to $\mathrm{C}_{60}$ from which monoaddition product is preferentially formed which is characterized by ${ }^{1} \mathrm{H}$ and ${ }^{13} \mathrm{C}$ NMR spectroscopy. $\mathrm{C}_{70}$ also reacts with benzene in a similar fashion as $C_{60}$ and the probable addition site is along 1,9-bonds (Darwish et al 1994). Addition along 7,8-bonds is also possible, but less probable. $C_{70}$ can add up to 10 benzene molecules, which was confirmed by mass spectroscopy.

$\mathrm{C}_{60}$ is readily functionalized by photocycloaddition with cyclohexenones in a reaction that involves the attack of enone triplet excited states on the fullerene. Wilson et al (1993b) reported the preparation of [2+2] photocycloadducts of $\mathrm{C}_{60}$ and cyclic enones (figure 62). Photocycloaddition of 3-methylcyclohexenone to $C_{60}$ formed chiral cis- and trans-fused adducts which are separated by HPLC. A variety of substituted cyclohexenones as well as cycloheptenones are used (Schuster et al 1994). The course of reaction upon UV-irradiation of crown ether fulleroid 235 and 3-methylcyclohexene-2-one in benzene solution was followed by ESI-MS, which was seen as a uniquely suitable tool for studying such reactions.

$\mathrm{C}_{60}$ was easily converted to its derivatives by treatment with benzocyclobutene homologs using the thermally allowed conrotatory $\left[\sigma_{2}+\pi_{2}\right]$ electrocyclic ring opening of the benzocyclobutene homologs (figure 63) (Tago et al 1993). Reaction of $\mathrm{C}_{60}$ with benzocyclobutenol 242 and its methoxy ether gave 1,9-dihydrofullerene cycloadduct 243 in high yields (figure 64). The alcohol was converted to pyranyl ether 244, acrylate 245, p-vinyl benzoate 246 and acid succinate esters 247 (Zhang and Foote 1994). 

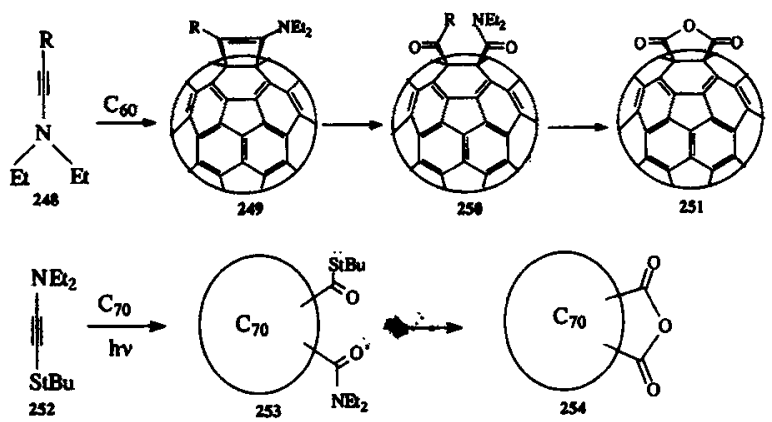

Figure 65. Synthesis of $\mathrm{C}_{62} \mathrm{O}_{3}$ and $\mathrm{C}_{72} \mathrm{O}_{3}$ (Zhang and Foote 1995).

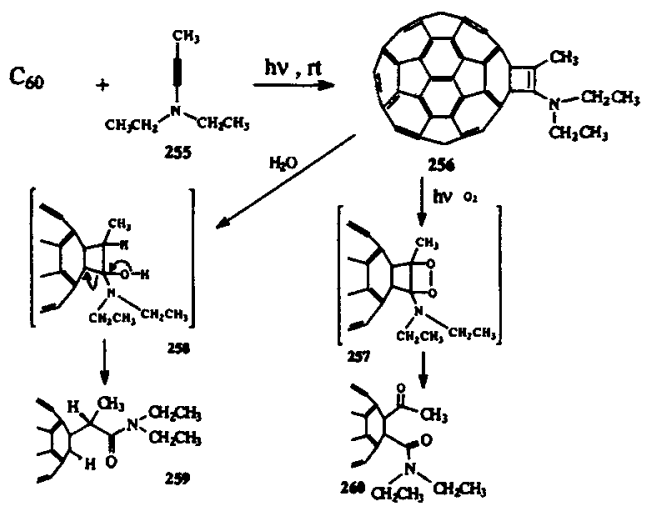

Figure 66. Photochemical $[2+2]$ cycloaddition of $N, N^{\prime}$-diethylpropynyl amine to $C_{60}$ (Zhang et al 1993a).

Zhang and Foote (1995) synthesized the first fullerene anhydrides, $\mathrm{C}_{62} \mathrm{O}_{3}$ and $\mathrm{C}_{72} \mathrm{O}_{3}$ by $[2+2]$ photochemical addition of $\mathrm{C}_{60}$ and $\mathrm{C}_{70}$ to both yndiamine and thioynamines and latter upon self-sensitized photooxidation of the adducts (figure 65). $\mathrm{C}_{60}$ reacts with both $\mathrm{N}, \mathrm{N}, \mathrm{N}^{\prime}, \mathrm{N}^{\prime}$-tetraethylene diamine and $\mathrm{N}, \mathrm{N}$-diethyl-2-ethyl thioethyne diamine to give the corresponding cyclobutene intermediate (249), which upon self-sensitized photooxygenation in toluene gives diamide (250). This on treatment with $p$-toluene sulphonic acid gives finally 1,2-dihydrofullerene [60]-1,2-dicarboxylic acid anhydride (251). $\mathrm{C}_{70}$ reacts $\sim 4$ times faster than $\mathrm{C}_{60}$ in which addition takes place across the 1,9-bond of $\mathrm{C}_{70}$, while in the case of $\mathrm{C}_{60}$ the addition site is $[6,6]$-ring junction. Due to the electron rich characteristic of ynamine and the electron deficient characteristic of fullerenes, it was suggested that ground state electrontransfer or charge-transfer mechanism takes place during the addition process.

Zhang et al (1993a) studied the photochemical [2+2] cycloaddition of $\mathrm{N}, \mathrm{N}$ diethylpropynylamine (255) to $C_{60}$ (figure 66). The cyclobutanamine 256 is unique in that it has a photosensitizer (the dihydrofullerene) and a photooxidizable group (the enamine) in the same molecule. Brief exposure to air at room light cleaves the enamine double bond producing the ketoamide 260. Tokuyama et al (1994) reported 


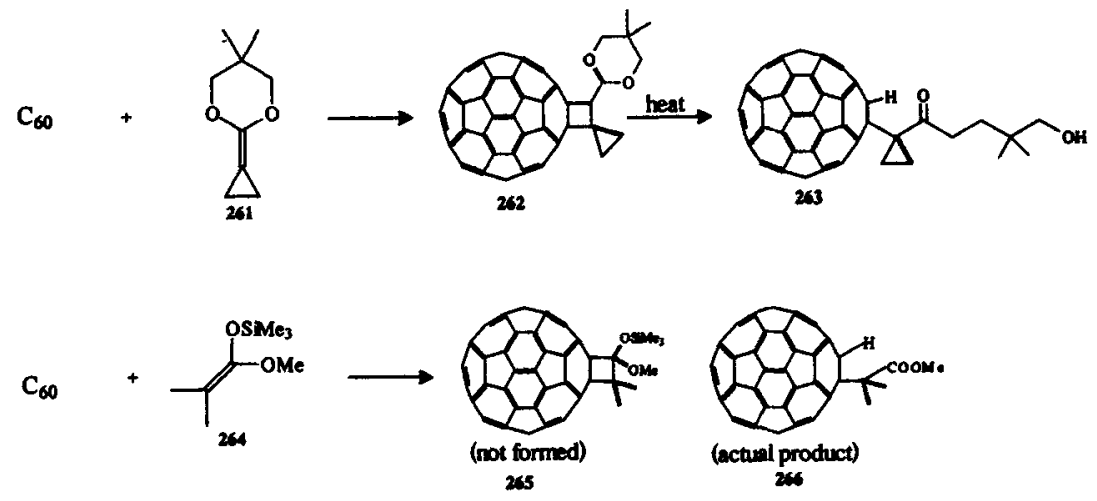

Figure 67. Photoaddition of silyl ketene acetal to [60] fullerene (Tokuyama et al 1994).

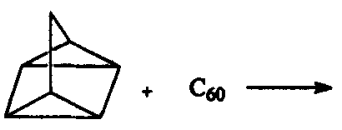

287

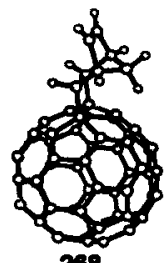

268

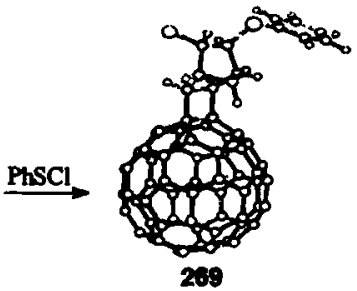

Figure 68. Addition of quadricyclane to $\mathrm{C}_{60}$ : Easy access to fullerene derivatives bearing a reactive double bond in the side chain (Prato et al 1993d).

that a highly strained ketene acetal (261) (figure 67) undergoes stepwise [2+2] cycloaddition to give 262, whose $\mathrm{C}-\mathrm{C}$ bond was cleaved upon heating in aqueous $\mathrm{H}_{2} \mathrm{SO}_{4}$ to give the ester 263. Photoaddition of an unstrained silyl ketene acetal (264) to $\mathrm{C}_{60}$ took place at room temperature in wet toluene to afford a fullerene substituted carboxylic ester (266) instead of the expected [2+2] cycloadduct. Themechanism was suggested to involve a zwitterion formed through a radical ion-pair (Tokuyama et al 1994).

Reaction of $\mathrm{C}_{60}$ with quadricylene gives a stable $[6,6]$ adduct (268) (figure 68), a derivative of $\mathrm{C}_{60}$ bearing a reactive double bond in the side chain (Prato et al 1993). The double bond reacts readily with electrophiles such as $\mathrm{PhSCI}$. Single cycloaddition reactions have been utilized to attach prefunctionalized dienes to $\mathrm{C}_{60}$, the 'ball and chain' adduct (270) (figure 69), reported by Khan et al (1993), is an example of the complex product available by this approach. The chemistry of cycloaddition onto $\pi$-centres already attached by $\sigma$-bonds to $C_{60}$ is little explored. Warrener et al (1995) reported the cycloaddition of norbornene-containing enes (271 and 274) with 3,6-di(2'-pyridyl) pyridazine providing powerful chelating sites.

Prato et al (1993b) reported [2+3] cycloaddition of $\mathrm{C}_{60}$ with trimethylene methane (TMM), the latter reacting as a nonpolar or polar intermediate (figure 70). The TMM precursor, which gave the best results in terms of isolation and characterization, was the methylenecyclopropanone ketal 277 which was heated overnight at $70^{\circ} \mathrm{C}$ in the presence of equimolar $\mathrm{C}_{60}$. The reaction resulted in the isolation of two 


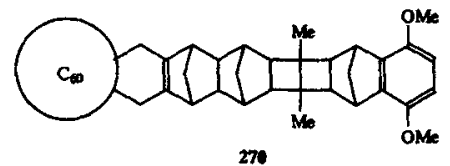

270

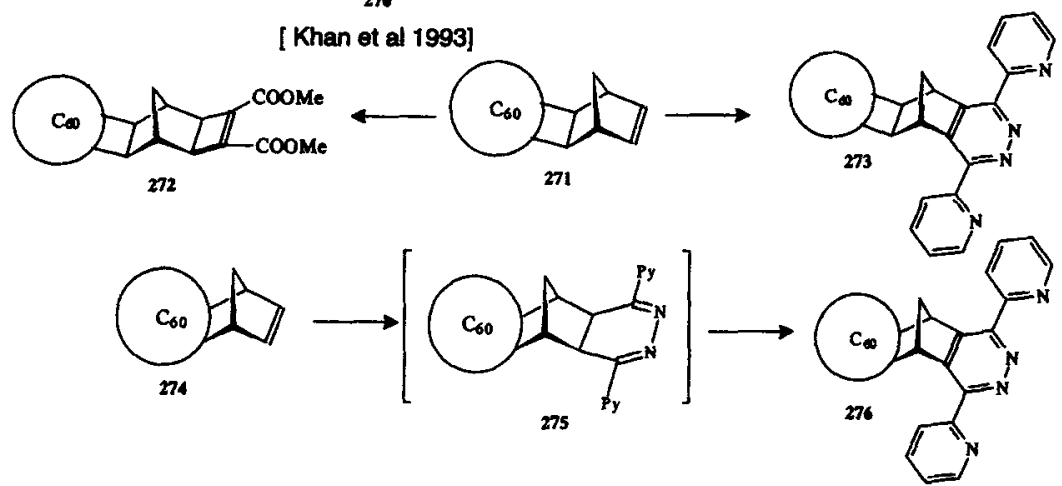

Figure 69. Attaching chelating capacity to [60] fullerene via short rigid rods (Warrener et al 1995).

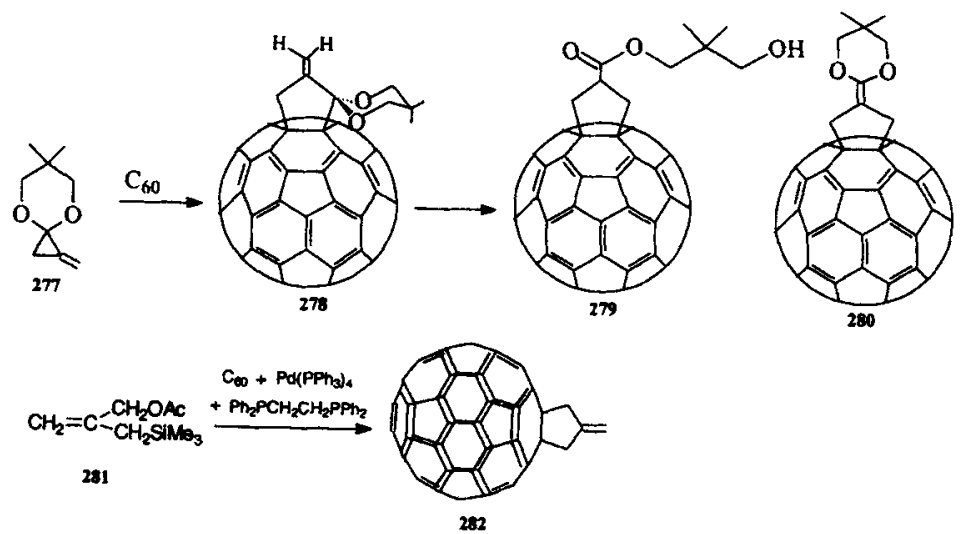

Figure 70. $[3+2]$ cycloaddition of $\mathrm{C}_{60}$ with trimethylene methane (Prato et al 1993). Synthesis of parent TMM-C 60 (282) (Shiu et al 1994).

products 278 and 279 , the ester 279 could be the silica gel catalyzed hydrolysis of the ketene acetal 280 . The product is stabilized by the irreversible addition of TMM. The first synthesis of the parent TMM- $\mathrm{C}_{60}$ adduct 282 was achieved by means of palladium-catalyzed [2+3] cycloaddition (Shiu et al 1994). $\mathrm{C}_{60}$ was first mixed with a stoichiometric amount of $\left[\mathrm{Pd}\left(\mathrm{PPh}_{3}\right)_{4}\right]$ and $\mathrm{Ph}_{2} \mathrm{PCH}_{2} \mathrm{CH}_{2} \mathrm{PPh}_{2}$ in benzene, which resulted in the palladium- $\mathrm{C}_{60}$ complex. Addition of a benzene solution of the TMM precursor 281 resulted in the adduct 282.

$\mathrm{C}_{60}$ can add in 1,3-dipolar fashion to azomethine ylides such as $\mathrm{H}_{2} \mathrm{C}=\mathrm{N}^{+}\left(\mathrm{CH}_{3}\right)-\mathrm{CH}_{2}^{-}$(283) (Maggini et al 1993) giving the substituted pyrrolidines (284) in which the ring opening of the azomethine ylides takes place (figure 71). Azomethine ylide is conveniently generated from a mixture of $\mathrm{N}$-methylglycine 


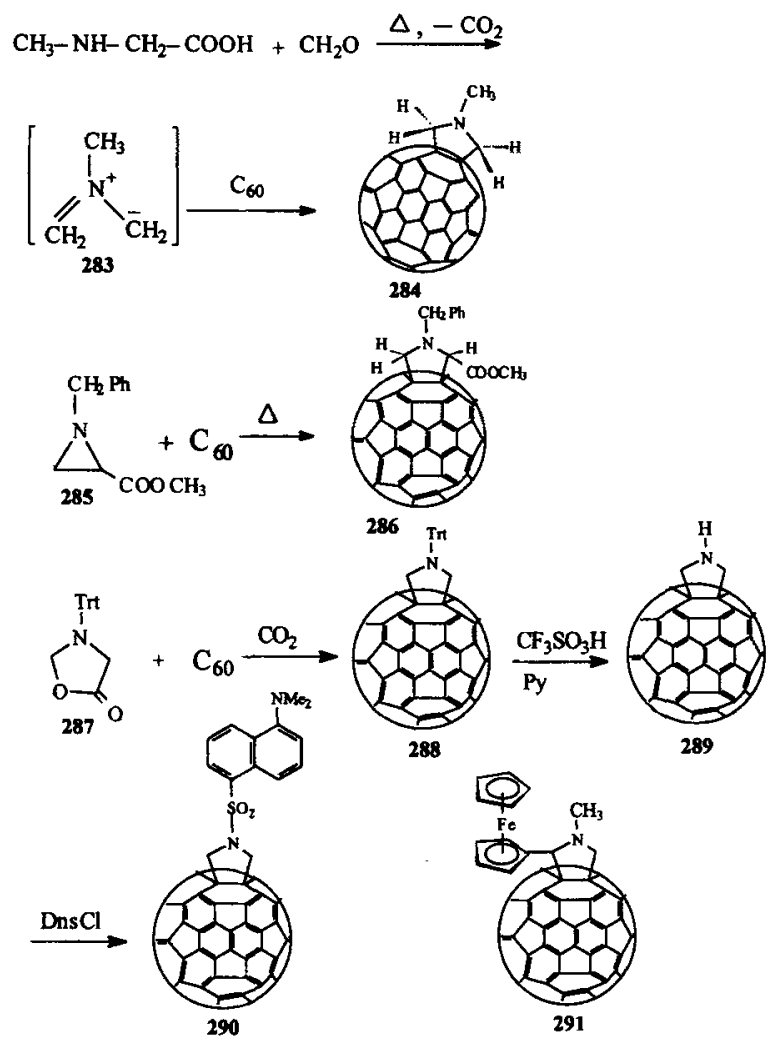

Figure 71. 1,3-Dipolar addition of azomethine ylides (Maggini et al 1993).

and paraformaldehyde. From the spectroscopic data it was concluded that the symmetry of the substituted pyrrolidine is $C_{2 v}$ which accounts for the addition at $[6,6]$ ring fusion. Another approach to azomethine ylides is the thermal ring opening of the aziridines. Thus heating 285 with $\mathrm{C}_{60}$ in toluene, led to the pyrrolidine 286 . Yet another method involves heating 3-triphenylmethyl-5-oxazolidinone with $\mathrm{C}_{60}$ which provides 288. Addition of pyridine and dansyl chloride to 288 brought about the isolation of dansyl pyrrolidine derivative 290. The possibility of further reacting 289 with a series of electrophiles provides an extremely versatile approach to many functionalized fullerenes. The combination of two electroactive species, ferrocene and $\mathrm{C}_{60}$, could be achieved by this method. By heating a mixture of ferrocene aldehyde, sarcosine, and $\mathrm{C}_{60}$ in toluene at reflux, compound 291 was isolated, exhibiting the reduction and oxidation pattern of both $\mathrm{C}_{60}$ and ferrocene moieties.

Maggini et al (1994) described the preparation of $\mathrm{N}$-acetyl derivatives of fullero3,4-prolines. Fulleroproline tert-butyl ester 292 , prepared by reacting glycine tertbutyl ester, paraformaldehyde and $\mathrm{C}_{60}$ in refluxing toluene was found to be unstable, probably owing to the reactivity of amines with fullerenes (figure 72). Functionalization of nitrogen by treating the reaction mixture directly with acetic anhydride resulted in stable acetamido derivative 293. When 292 was treated with 
trifluoromethanosulphonic acid, the protonated amino acid was obtained, which reacts with acetic anhydride to give the $\mathrm{N}$-acetyl derivative 295. This water-soluble compound is a potential candidate for synthesis of peptides containing $\mathrm{C}_{60}$ that may have HIV protease inhibitory properties. 1,3-Dipolar cycloaddition of chiral azomethine ylides to $\mathrm{C}_{60}$ afforded a mixture of diastereomeric fulleropyrrolidines which could be separated by flash chromatography (Novello et al 1996). The stereoselectivity is most probably due to steric reasons. In all the three cases of addition of azomethine ylides (figure 73 showing one such case) to $\mathrm{C}_{60}$, the chiral 1,3-dipole has a bulky group that directs the addition, the hindered bulkier site being oriented away from the $\mathrm{C}_{60}$ frame. $\mathrm{N}$-benzyl azomethine ylide was generated in situ by desilylation of $\mathrm{N}$-benzyl- $\mathrm{N}$-(methoxymethyl)- $\mathrm{N}$-[(trimethylsilyl)methyl]amine catalyzed by trifluoroacetic acid (Laborde 1992). Zhang et al (1993b) used this method to synthesize a $\mathrm{C}_{60}$-fused $\mathrm{N}$-benzylpyrrolidine (figure 74 ). New cycloadducts

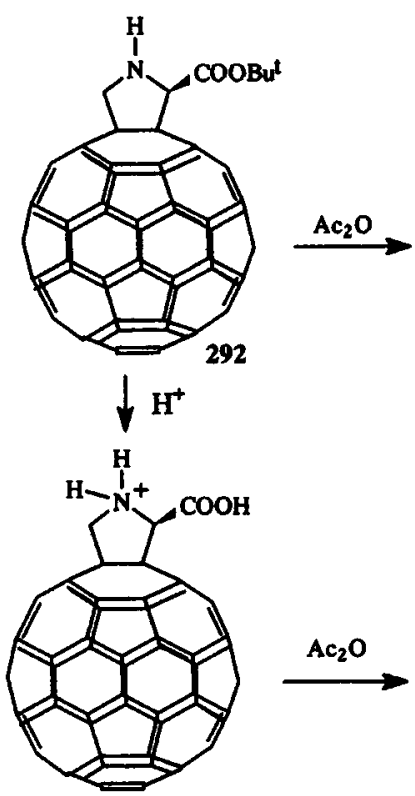

294

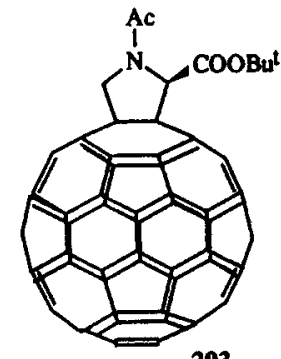

293

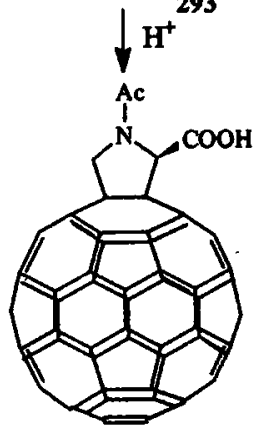

295

Figure 72. Synthesis of fulleroproline with an amino acid directly linked to fullerene (Maggini et al 1994).

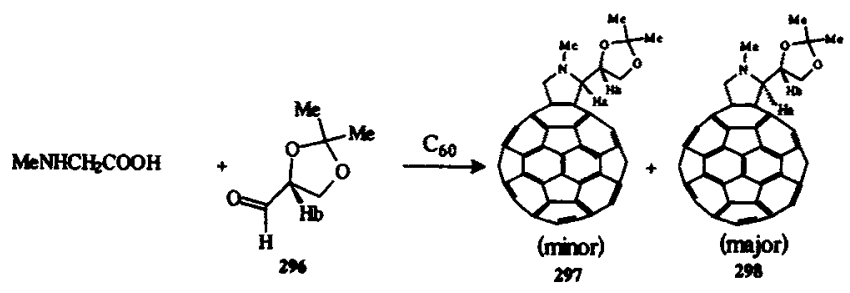

Figure 73. Stereoselective addition to [60] fullerene (Novello et al 1996). 


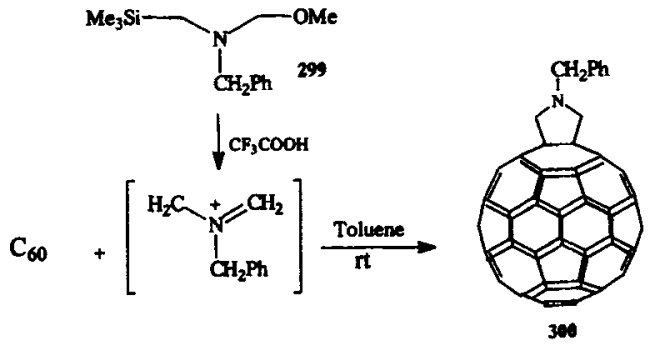

Figure 74. Generation of azomethine ylide by desilylation and formation of $\mathrm{C}_{60}$-fused N-benzylpyrrolidine (Zhang et al 1993b).
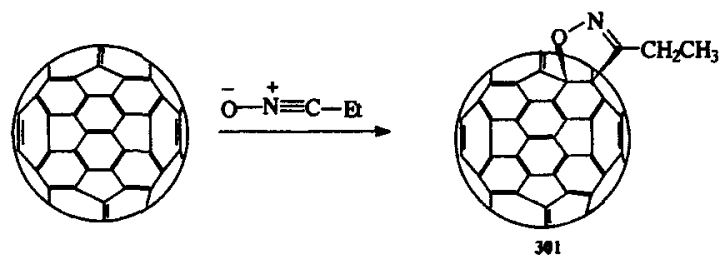

Figure 75. 1,3-Dipolar addition to fullerene with nitrile oxide (Meier and Poplawska 1993).

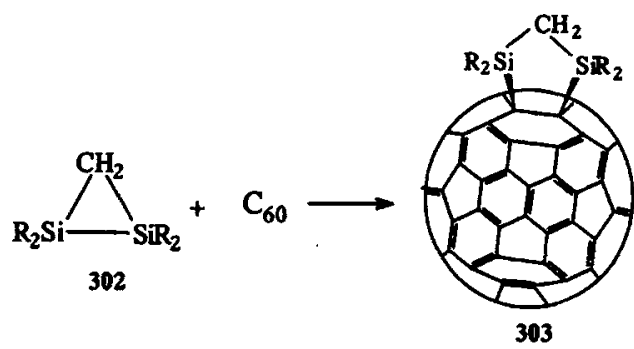

Figure 76. $[2+3]$ photoadduct formation of $\mathrm{C}_{60}$ with disilirane (Akasaka et al 1993).

are obtained by the reaction of $\mathrm{C}_{60}$ with pyrazalidinium ylides and 4-aryl-5arylimino-2-pheynyl-1,2, 4-thiadiazolidin-3-ones respectively (Bartoszek et al 1996).

1,3-Dipolar addition of $\mathrm{C}_{60}$ with nitrile oxide reported by Meier and Poplawska (1993) giving the corresponding cycloadduct of $\mathrm{C}_{\mathrm{s}}$ symmetry, which was confirmed by ${ }^{13} \mathrm{C}$ NMR spectroscopy, resulting from addition across $[6,6]$-ring junction (figure 75). The addition of acetonitrile oxide to $C_{60}$ also takes place in similar 1,3-dipolar fashion to give the corresponding isoxazoline of $\mathrm{C}_{\mathrm{s}}$ symmetry.

Akasaka et al (1993) reported the first photochemical [2+3] cycloaddition of $\mathrm{C}_{60}$ with disilirane (figure 76 ). The reaction proceeds via a charge-transfer interaction. The addition of disilirane to $\mathrm{C}_{70}$ also leads to the formation of a photoadduct with the addition occurring at the equatorial belt (e-e) (Akasaka et al 1994). 


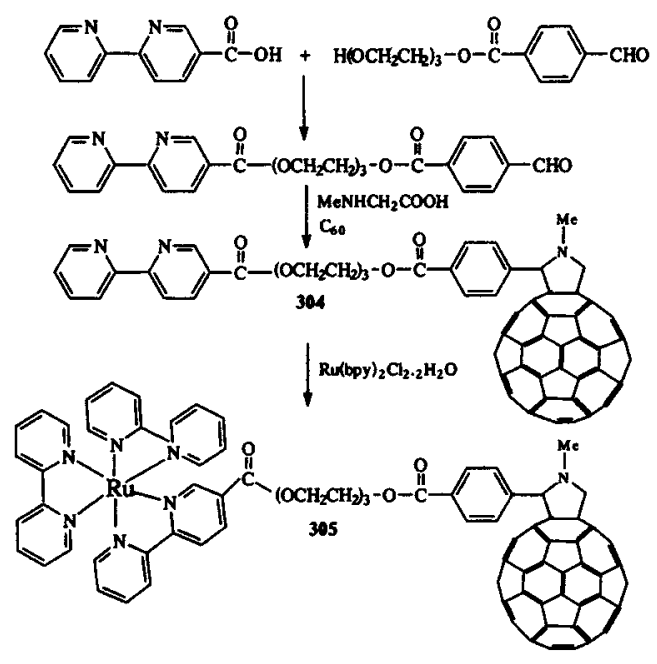

Figure 77. A $\mathrm{C}_{60}$ derivative covalently linked to a ruthenium(II)tris(bipyridine) complex (Maggini et al 1995b).

$\mathrm{Ru}(b p y)_{3}^{2+}$ complexes constitute a class of photoactive compounds, known to give energy transfers in the excited states. $\mathrm{C}_{60}$ is known to accept reversibly up to six electrons. The coupling of the two was reported by Maggini et al (1995b). Such compounds are appealing as on-off components in molecular switches. $\mathrm{C}_{60}$ was functionalized via azomethine ylide cycloaddition (Maggini et al 1993) to give fulleropyrrolidine 304 (figure 77), which has a bipyridyl group. It was then allowed to react with $\mathrm{Ru}(b p y)_{2} \mathrm{Cl}_{2} \cdot 2 \mathrm{H}_{2} \mathrm{O}$ to yield a $\mathrm{C}_{60}$ derivative covalently linked to $\mathrm{Ru}(\mathrm{II})$ tris (bipyridine) complex (305). A fullerene-porphyrin conjugate, covalently linked via a pyrrolidine linkage was prepared by treating $b$-formyltetraphenyl porphyrin with fullerene $\mathrm{C}_{60}$ and $\mathrm{MeNHCH}_{2} \mathrm{COOH}$ (Drovetskaya et al 1995). The Ni(II) complex was similarly prepared from the $\mathrm{Ni}(\mathrm{II})$ complex of the porphyrin. A porphyrin-linked fullerene where a $\mathrm{C}_{60}$ moiety is covalently linked to the meso position of 5,15-diarylporphyrin with a pyrrolidine spacer was prepared (Imahori and Sukata 1996). N-Methyl glycine, 10,20-bis (3,5-di-tert-butylphenyl)-5-formyl porphyrinatonickel(II) and $\mathrm{C}_{60}$ were refluxed in toluene to give the porphyrin-linked fullerene.

Gan et al (1996) reported the direct reaction between amino acid esters and $\mathrm{C}_{60} . \mathrm{A}$ novel air-assisted radical reaction mechanism is proposed. Thermal reaction between glycine ethyl ester and $\mathrm{C}_{60}$ resulted in an unexpected product 306 (figure 78). It was suggested that acetone present in ethanol solvent reacts with glycine ester to form a 1,3-dipolar intermediate, which adds on to $\mathrm{C}_{60}$ giving 306 . When the same reaction was carried out through a photochemical route, the isolated product was 307. Photochemical addition of sarcosine provided 308, the reaction is twice as fast as the glycine ester reaction. So the methyl group on the nitrogen had a more positive than a negative effect on the reaction rate. The hydrolysis of $\mathbf{3 0 7}$ and $\mathbf{3 0 8}$ to result in the corresponding carboxylic acids is not possible as $\mathrm{C}_{60}$ reacts with 


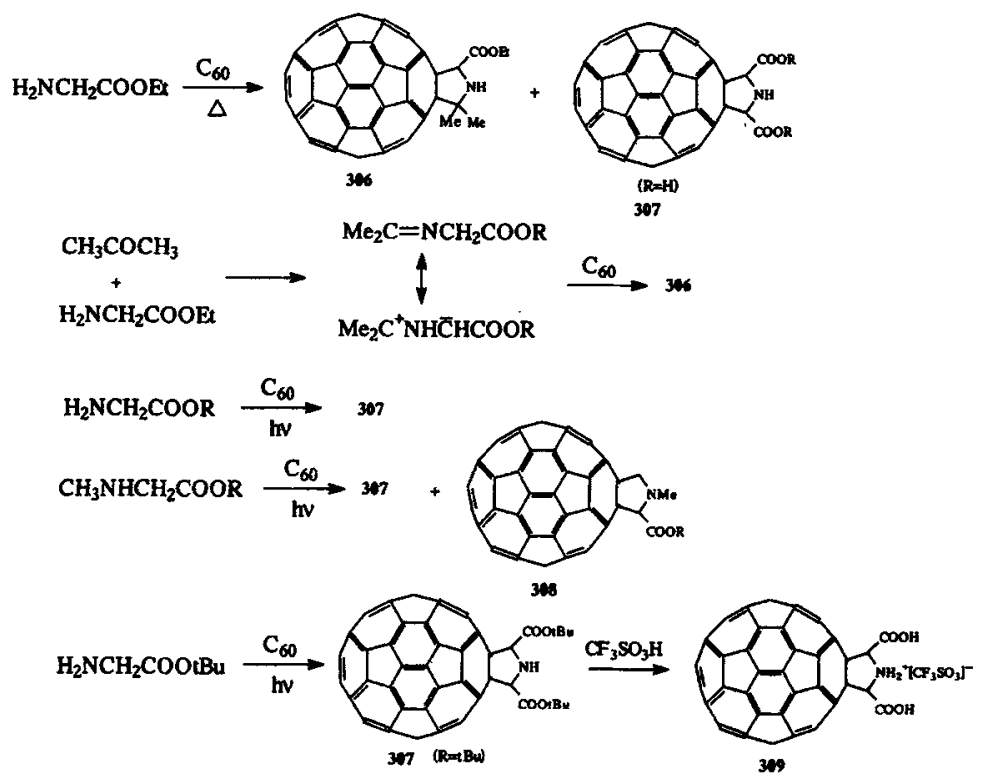

Figure 78. Fullerene amino acid derivatives (Gan et al 1996).

hydroxides to give fullerols. The $t$-butyl ester analog of $\mathbf{3 0 7}$ is hydrolysed by trifluoromethane sulphonic acid to yield the dicarboxylic acid 309, which are of great interest in the investigation of the biologically active fullerenes.

The reversible cycloaddition of $\mathrm{Rh}(\mathrm{II})$ catalyzed diazoimides to $\mathrm{C}_{60}$ was studied by Gonzalez et al (1994). The adducts were found to undergo ready thermal cycloreversion. To generate and determine if the isomunchone (312) (figure 79) dipole remained intact in the process, the adduct 311 was heated in toluene in the presence of $\mathrm{N}$-phenylmaleimide. Besides $\mathrm{C}_{60}$, the reaction mixture contained the known adduct 313.

Arce et al (1996) reported the synthesis of a stable bridged bisfulleroid 315, which originated from a facile photochemically promoted rearrangement of 314 (figure 80 ). The bridged bisfulleroid formed a Co(III) complex readily. An alternate route to synthesis of 315 in higher yields was reported by these workers. Addition of a 2-fold excess of 1-(trimethylsilyl)-1,3-butadiene to $\mathrm{C}_{60}$ afforded the silyl ether, which on acidification furnished the allylic alcohol in up to gram quantities. Photolysis of the latter afforded good yields of the bisfulleroid.

Slow addition of ethyl propiolate to a toluene solution of $\mathrm{C}_{60}$ in tricyclohexylphosphine $\left[\mathrm{P}(\mathrm{Cy})_{3}\right]$ at ambient temperature afforded a $[2+2+2]$ cycloaddition product 320 (figure 81). In the absence of $\mathrm{P}(\mathrm{Cy})_{3}$, no product was formed (Liou and Cheng 1995). The spectral data strongly support a head-to-tail addition of two propiolate units to $\mathrm{C}_{60} . \mathrm{P}(\mathrm{Cy})_{3}$ acts as a nucleophile and a leaving group. The mechanism of the reaction is discussed. 
<smiles>COC(=O)C(=N)C(=O)N(C)C(=O)c1ccccc1</smiles>

310

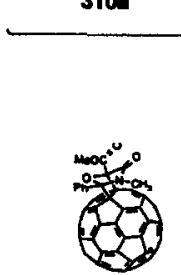

311a

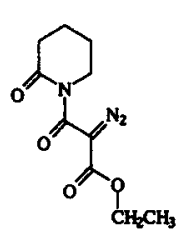

$310 b$<smiles>N#CC(C(=O)O)C(=O)NC(=O)CC1Cc2ccccc2N1C(=O)c1ccccc1</smiles>

$310 \mathrm{C} \mathrm{CH}_{3}$<smiles>CC(=O)OC(=O)C(=N)C(=O)N(CCc1ccccc1)C(C)=O</smiles>

$310 d$

$\int_{\text {Rhab }}^{C_{\infty}}$

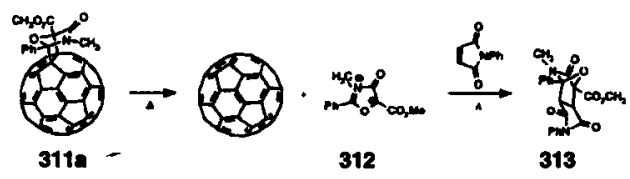

Figure 79. The reversible cycloaddition of isomünchones to $C_{60}$ (González et al 1994).

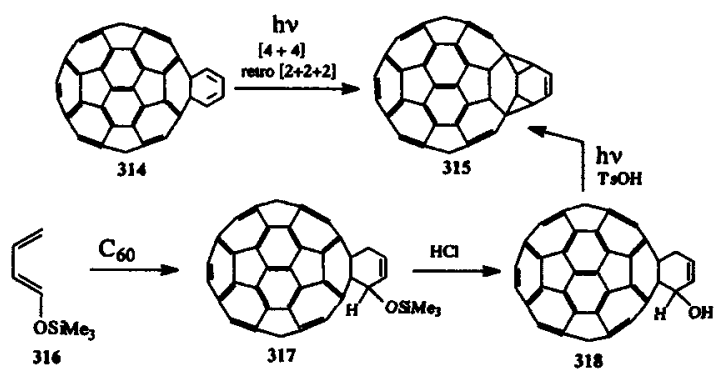

Figure 80. Triple scission of a six-membered ring on the surface of $\mathrm{C}_{60}$ via consecutive pericyclic reactions (Arce et al 1996).

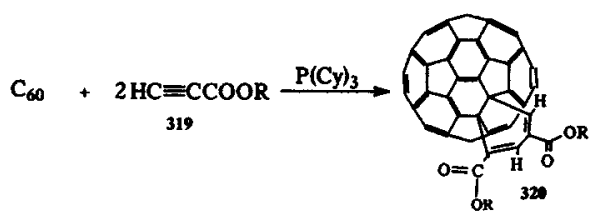

Figure 81. Cyclotrimerization of alkynes with [60] fullerene (Liou and Cheng 1995). 


\section{Nucleophilic addition reactions}

The observed high electron affinity of $\mathrm{C}_{60}$ to its electron donating ability leads to the prediction that this class of materials are susceptible to nucleophilic addition. $\mathrm{C}_{60}$ reacts with both neutral and charged nucleophiles to give a variety of adducts. Neutral nucleophiles such as amines can be added to $C_{60}$ (Wudl et al 1991c) to form the corresponding adduct. In this process a maximum of 12 amine molecules can be added to $\mathrm{C}_{60}$ nucleus but the most stable one is the adduct which contains six amino groups. The addition takes place across the 6,6-ring junction of the pyracylene unit, resulting in an octahedral array. Six morpholine units can add to $C_{60}$ to give $\mathrm{C}_{60} \mathrm{H}_{6}$ (morpholine) $)_{6}$. The reaction of $\mathrm{C}_{60}$ with an excess of morpholine or piperidine in benzene in the presence of oxygen led to the isolation of hydrogenated aminoadducts 321, 322 (figure 82) with a preferred 1,4-addition (Schick et al 1995). The first aminated fullerene dimer (323) with a single inter-fullerene connection was also a major reaction product. The dimer is insoluble in most organic solvents and only slightly soluble in $o$-dichlorobenzene.

$\mathrm{C}_{60}$ adds on to 1,2-diamines, the addition proceeds with an apparent loss of two hydrogen atoms to form a variety of products (Kampe et al 1993; Kampe and Egger 1995; Maggini et al 1995c). Balch et al $(1995,1996)$ carried out X-ray studies of $\mathrm{C}_{60} \mathrm{~N}_{2}\left(\mathrm{C}_{2} \mathrm{H}_{4}\right)_{2} 324$ and one isomer of $\mathrm{C}_{60}\left[\mathrm{~N}_{2}\left(\mathrm{C}_{2} \mathrm{H}_{4}\right)_{2}\right]_{2}(325)$. The structure of 325 (figure 83 ) reveals that the diamine has added across a $[6,6]$-ring junction as ex-

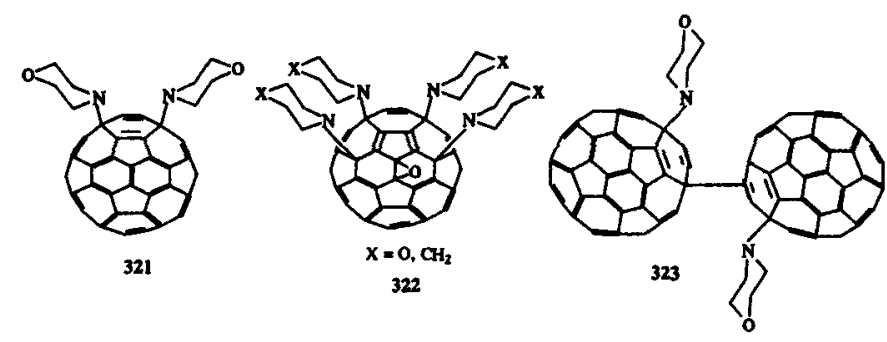

Figure 82. Reaction of $\mathrm{C}_{60}$ with morpholine and piperidine: preferred 1,4-addition and fullerene dimer formation (Schick et al 1995).

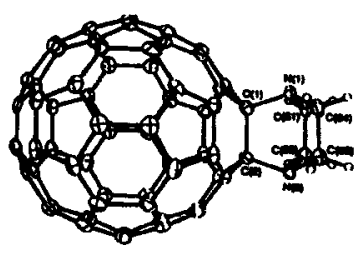

324

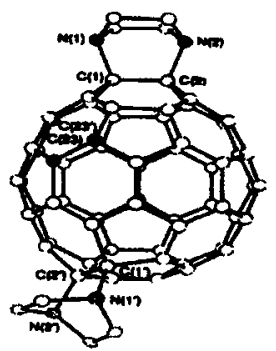

325

Figure 83. Prospective views of $\mathrm{C}_{60} \mathrm{~N}_{2}\left(\mathrm{C}_{2} \mathrm{H}_{4}\right)_{2}$ and $\mathrm{C}_{60}\left[\mathrm{~N}_{2}\left(\mathrm{C}_{2} \mathrm{H}_{4}\right)_{2}\right]_{2}$ (Balch et al 1995). 
pected and a local distortion of the fullerene is produced. This distortion is manifest in the displacement of $\mathrm{C}(1)$ and $\mathrm{C}(2)$ away from their normal positions as the fullerene surface, and an elongation of $\mathrm{C}(1)-\mathrm{C}(2)$ bond, the length of which is $1.624(8) \AA$. In comparison, the length of a normal $\mathrm{C}-\mathrm{C}$ bond at a $[6,6]$ ring junction of an undistorted fullerene is $1.383(4) \AA$. The double addition product has $\mathrm{C}_{2}$ symmetry, with the $C_{2}$ axis bisecting the bond between $C(23)$ and $C\left(23^{\prime}\right)$, and, hence, is chiral. However each individual crystal is achiral and contains a racemic mixture of the double addition product. $\mathrm{C}_{60}$ and triethylamine (TEA) undergo characteristic photoinduced electron transfer-proton transfer reaction at a room temperature toluene solution (Lawson et al 1995). The $C_{60}$-TEA ion-pair intermediate in a nonpolar but polarizable solvent is formed, which gets transformed to the cycloadduct 326 (figure 84). However, it is not clear how the two methine hydrogens on the cage are eliminated for the final product. Leigh et al (1992) reported that the family of fullerene azacrown ethers (327) (figure 85) formed by the addition of azacrown ethers in toluene to $\mathrm{C}_{60}$ at room temperature, resulted in the monoamine derivative of fullerenes. Both 1,2- and 1,4-addition products are possible, but the 1,2-addition product is most stable.

Charged nucleophiles can add to $\mathrm{C}_{60}$ as alkylation by either Grignard or organolithium reagents followed by reaction with alkyl iodide. In this process many mono and polyadduct of $\mathrm{C}_{60}$ are formed e.g. $\mathrm{C}_{60} \mathrm{H} \mathrm{t}$-Bu, $\mathrm{C}_{60} \mathrm{HEt}, \mathrm{C}_{60} \mathrm{Me}_{10} \mathrm{Ph}_{10}$,

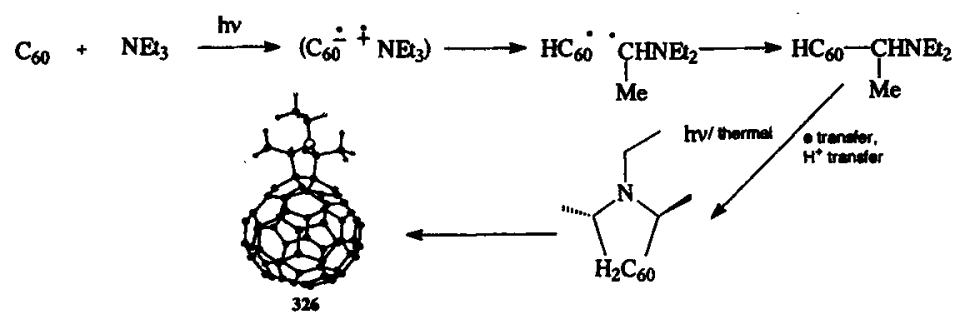

Figure 84. Photochemical inter- and intra-molecular electron transfer reactions of $\mathrm{C}_{60}$ and a tertiary amine (Lawson et al 1995).

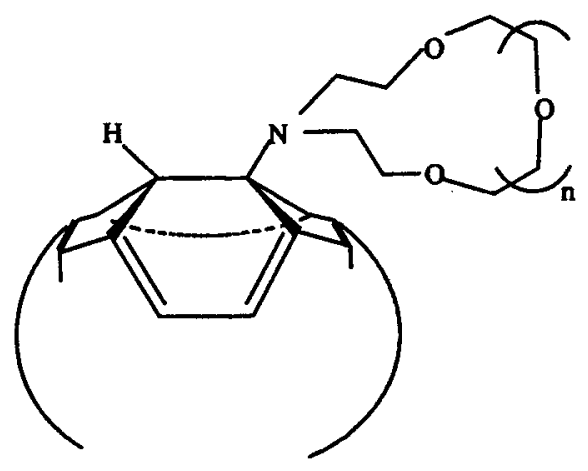

327

Figure 85. Addition of azacrown ethers to fullerene (Leigh et al 1992). 
$\mathrm{C}_{60} \mathrm{Me}_{3} \mathrm{Ph}_{2}$ and $\mathrm{C}_{60} \mathrm{Me} t$ - $\mathrm{Bu}$. Nucleophilic reactions led to the synthesis of $\mathrm{C}_{60} \mathrm{H}\left(\mathrm{CH}_{2} \mathrm{CMe}_{\mathrm{CH}} \mathrm{CH}_{2}\right), \mathrm{C}_{60} \mathrm{H} \backslash\left(\mathrm{CH}_{2} \mathrm{CMe}: \mathrm{CH}_{2}\right)_{8}, \mathrm{C}_{60} \mathrm{H}_{8}\left(\mathrm{C}_{9} \mathrm{H}_{7}\right)_{8}$ by treating $\mathrm{C}_{60}$ with 2-methylallyl magnesium chloride and sodium indenide in THF (Huang et al 1994). Addition of ortho-quinodimethanes to $C_{60}$ leads to stable easily soluble derivatives (Belik et al 1994). Substituents like carboxy, hydroxy and amino groups have been in positions more or less close to $C_{60}$ and these groups allow further reactions. The adduct of 4-fluoro-3-nitrobenzoyl benzocyclobutene and $\mathrm{C}_{60}$ shows a high affinity for nucleophilic substitution by amines. Dodecylated $\mathrm{C}_{60^{-}}$ $\left[(\mathrm{Do})_{n} \mathrm{C}_{60}(\mathrm{H})_{n}\right]$ and butylated $\mathrm{C}_{60}-\left[(\mathrm{Bu})_{n} \mathrm{C}_{60}(\mathrm{H})_{n}\right]$ were synthesized by Levon et al (1994). XRD results reveal that the structure of $C_{60}$ expands to a primitive hexagonal structure upon butylation and to a layered structure upon dodecylation.

$\mathrm{C}_{60}$ reacts with $\mathrm{PhCH}_{2} \mathrm{ONa}-\mathrm{PhCH}_{2} \mathrm{OH}$ in the presence of air to afford a 1,3dioxolane derivative of $\mathrm{C}_{60}$ (328) (Wang et al 1995). The mechanism of the reaction is discussed (figure 86). Komatsu et al (1994b) reported the first alkyne $\mathrm{C}_{60}$ derivatives, which would be a versatile precursor to a variety of new molecules. The ethynyl handle was provided by [(trimethylsilyl)-ethynyl]lithium. Both mono- and bis-adducts (figure 87 ) were isolated. The product yields were highly dependent on reaction conditions.

Schneider et al (1994) reported that hydroxy groups can be added to $\mathrm{C}_{60}$ by reaction with $\mathrm{BH}_{3}$-THF complex followed by hydrolysis with either glacial acetic acid, $\mathrm{NaOH} / \mathrm{H}_{2} \mathrm{O}_{2}$ or $\mathrm{NaOH}$. This gives water soluble fullerols. A very convenient

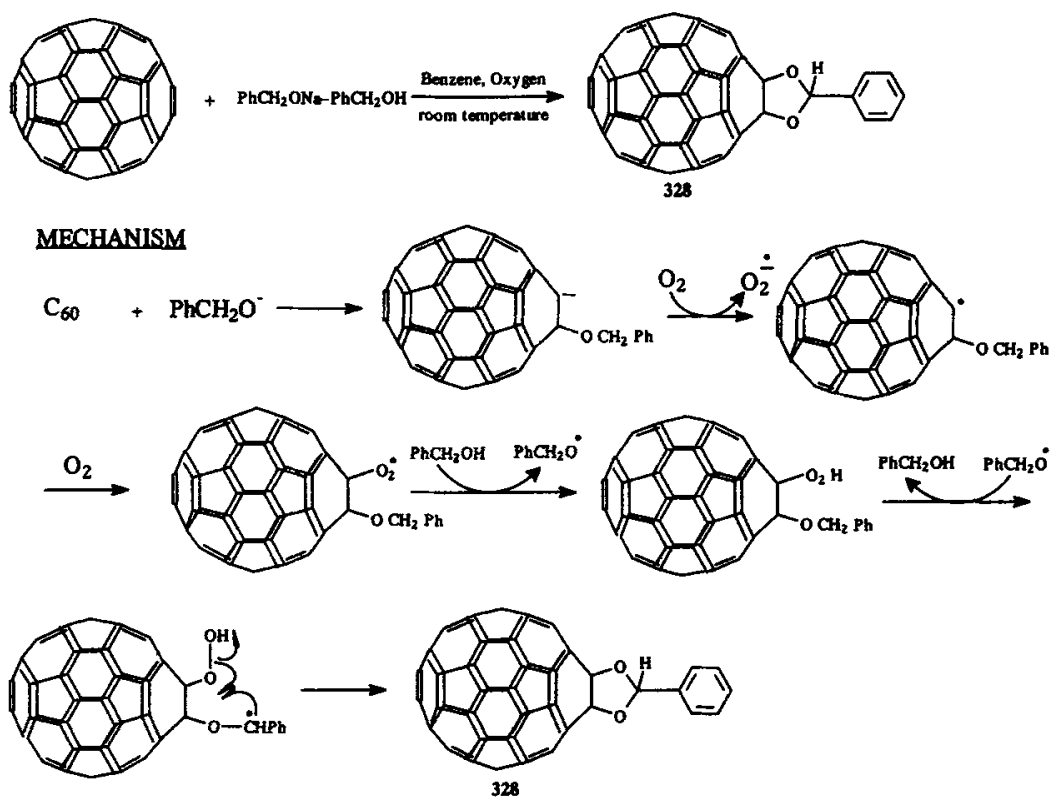

Figure 86. Formation of a 1,3-dioxane derivative and involvement of oxygen in a nucleophilic addition reaction of $\mathrm{C}_{60}$ with sodium alkoxide (Wang et al 1995). 
method for the synthesis of $\mathrm{C}_{60}(\mathrm{OH})_{x}$ was reported by Sun et al (1996). $\mathrm{C}_{60}$ in toluene is reacted with potassium and hydrolysis of the product provides fullerols.

Di-addended and tetra-addended $\mathrm{C}_{60}$ were synthesized through the use of novel organoborane intermediates. The $\mathrm{C}_{60}, \mathrm{C}_{70}$ or higher fullerene is reacted with a borane such as $\mathrm{BH}_{3}$ in toluene to form an organoborane intermediate which on hydrolysis with water or alcohol results in the di-addended or tetra-addended product. The reaction of lithiated phosphine-borane or a phosphinite-borane with $\mathrm{C}_{60}$, followed by removal of the $\mathrm{BH}_{3}$ group, affords a fullerene substituent, which undergoes complexation with $\mathrm{BH}_{3}$ and $\mathrm{PtCl}_{2}$ selectively on the phosphorus atom with a 1:1 and 2:1 stoichiometry (Yamago et al 1994b). Two types of isopropoxysilyl compounds, $\mathrm{C}_{60}(\mathrm{H})\left[\mathrm{CH}_{2} \mathrm{Si}\left(\mathrm{O}^{i} \mathrm{Pr}\right) \mathrm{Me}_{2}\right] 332$ and $\mathrm{C}_{60}\left[\mathrm{CH}_{2} \mathrm{Si}\left(\mathrm{O}^{i} \mathrm{Pr}\right) \mathrm{Me}_{2}\right]_{2} 333$ are isolated from $\mathrm{C}_{60}$ and $\mathrm{ClMgCH}_{2} \mathrm{SiMe}_{2}\left(\mathrm{O}^{i} \mathrm{Pr}\right.$ ) (Nagashima et al 1995). The conversion of the isopropoxy groups of $\mathbf{3 3 2}$ and $\mathbf{3 3 3}$ to the corresponding chlorides and triflates is reported by Nagashima et al (1995) (figure 88). The high oxophilicity of the silicon atoms of the chlorides and triflates in turn resulted in an expeditious way to link alcohols, phenols, and even silica to $C_{60}$ moieties.

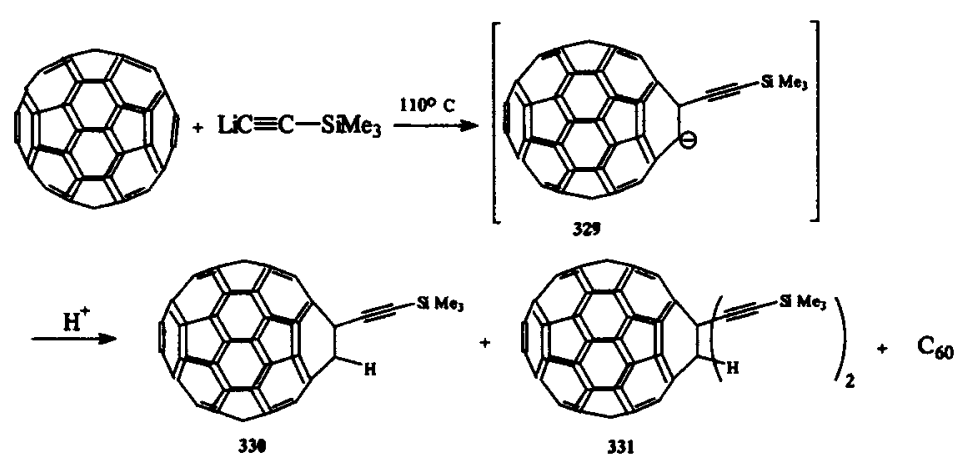

Figure 87. Acetylene derivatives of $\mathrm{C}_{60}$ (Komatsu et al 1994).
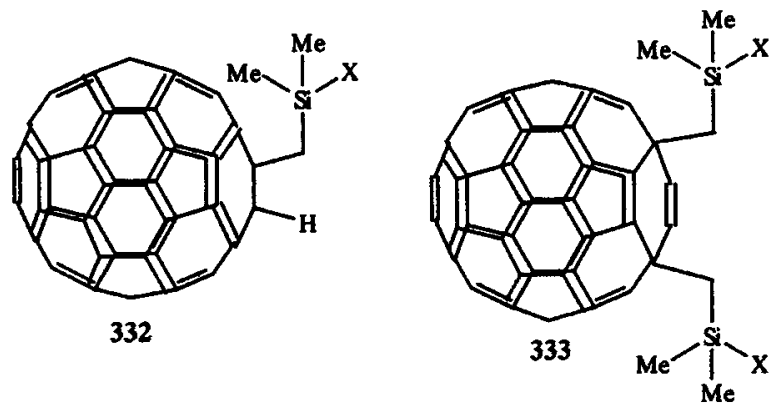

Figure 88. Chlorosilanes and silyl triflates containing $\mathrm{C}_{60}$ : a versatile synthetic route linking $\mathrm{C}_{60}$ moieties with alcohols, phenols, and silica (Nagashima et al 1995). 


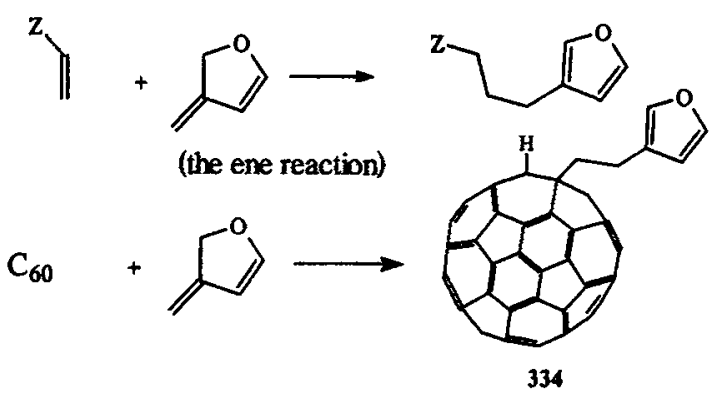

Figure 89. Ene reaction of $\mathrm{C}_{60}$ and 3-methylene-2,3-dihydrofuran (Miles and Smiley 1996).

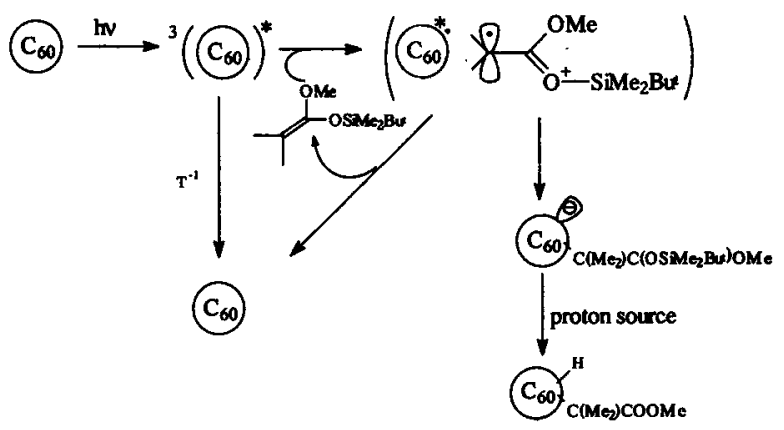

Figure 90. Photo-induced electron transfer from ketene silyl acetals to the triplet excited state of $\mathrm{C}_{60}$ leading to fullerene acetates (Mikami et al 1995).

The reaction of $\mathrm{C}_{60}$ with 1-heptene and 4-allylanisole (Wu et al 1994), and 3,5di-t-butyl-4-[(trimethylsiloxyl)allyl]benzene (Komatsu et al 1994) were the first published report of an ene reaction (figure 89 ) with a fullerene. 4-Alkylanisole reacts with $\mathrm{C}_{60}$ at $200-220^{\circ} \mathrm{C}$ to form an ene reaction adduct (Wu et al 1994). Miles and Smiley (1996) reported the ene reaction of $\mathrm{C}_{60}$ and 3-methylene-2,3-dihydrofuran and isolated fullerene addition product 334 in good yields. The chemical manipulation of furan ring provides a means of obtaining a whole host of new fullerene compounds, including water soluble fullerenes. Analogous to 'prototropic ene reaction', Mikami et al (1995) reported 'silatropic ene reaction' of $\mathrm{C}_{60}$ with esters derived from ketene silyl acetals (KSA), to provide fullerene acetates. The addition of KSAs to the triplet excited state of $\mathrm{C}_{60}$ takes place via photoinduced electron transfer (figure 90). The reaction is useful for further elaboration to fullerene amide and peptide of biological importance.

1,9-(4-Hydroxycyclohexano)buckminsterfullerene 338 is a versatile alcohol that permits further functionalization of $\mathrm{C}_{60}$ which permits the preparation of a variety of $\mathrm{C}_{60}$-derivatives. An et al (1993) reported the preparation of first $\alpha$-amino acid derivatives $(339,340)$ (figure 91 ). The de-protected amino acids are water soluble and retain the unusual redox and photophysical properties of $\mathrm{C}_{60}$. The Diels-Alder 


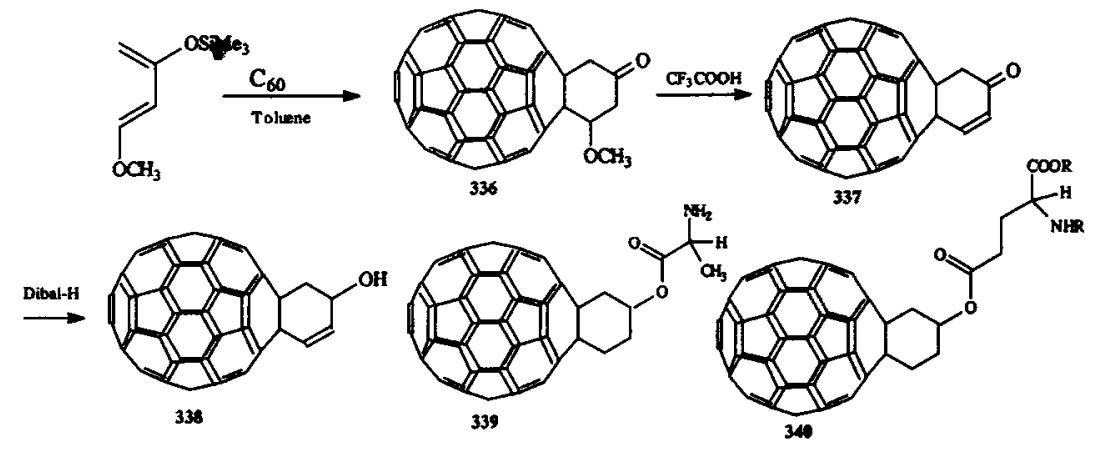

Figure 91. A methodology for the reversible solubilization of fullerenes and synthesis of $\alpha$-amino acid derivatives (An et al 1993, 1995a).

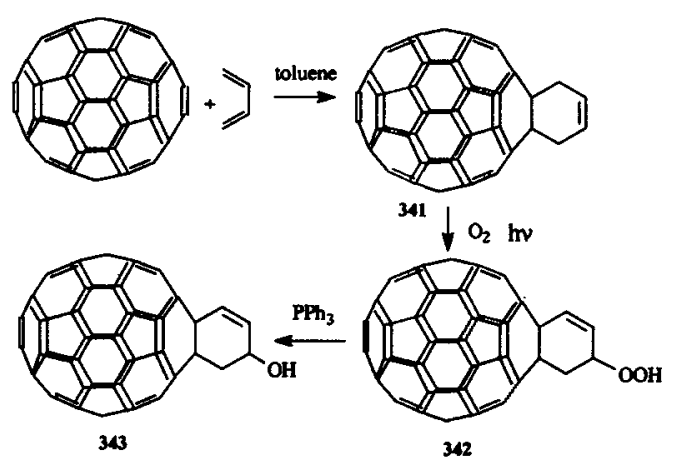

Figure 92. Singlet oxygen ene reaction of cyclohexenobuckminsterfullerene (An et al 1995a).

reaction of 1,3-butadiene and $\mathrm{C}_{60}$ is noted for its instability towards air and light, affording hydroperoxide 342 (figure 92). Reaction of $\mathrm{C}_{60}$ with ${ }^{1} \mathrm{O}_{2}$ afforded the allylic alcohol 343 after reduction with $\mathrm{PPh}_{3}$ (An et al 1995). The dihydrofullerene moiety plays the role of ${ }^{1} \mathrm{O}_{2}$-sensitizer, and the cyclohexene moiety that of an unavoidable reaction center. The alcohol 344 available from the $[2+3]$ cycloaddition of a dipolar trimethylenemethane was treated with benzoyl chloride and pyridine to yield the benzoate (figure 93) (Yamago et al 1993). By this method fullerene bearing olefins, aldehydes, alcohol, sugar and amino acid groups are synthesized by oxidation, reduction and $\mathrm{C}-\mathrm{O}$ and $\mathrm{C}-\mathrm{C}$ forming reactions.

\section{Electrophilic addition reactions}

Fullerene is unreactive towards the electrophilic reagents because of its electron withdrawing nature. This obstacle is overcome by the formation of their anions which act as potent reactant. Methyl iodide reacts with $\mathrm{C}_{60}$ to form methylated derivative and this is confirmed by ${ }^{1} \mathrm{H}$ and ${ }^{13} \mathrm{C}$ NMR spectrum $\delta\left({ }^{1} \mathrm{H}\right) \sim 0 \cdot 06$, 


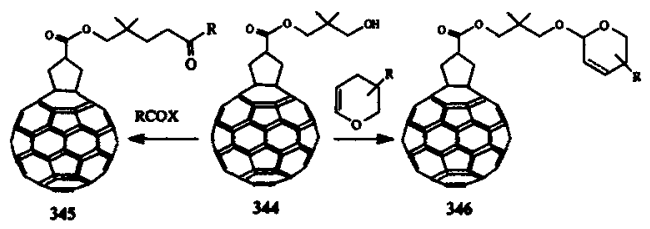

Figure 93. Derivatization of organofullerenes (Yamago et al 1993).

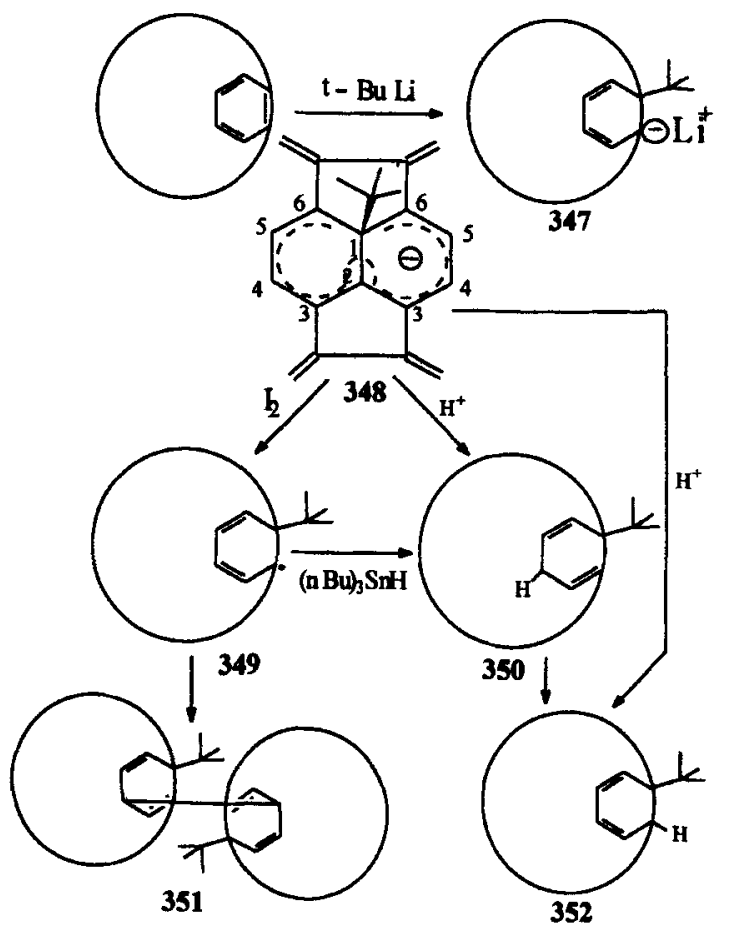

Figure 94. Reaction of $\mathrm{C}_{60}$ with $t-\mathrm{BuLi}$ and synthesis of $t-\mathrm{BuHC}_{60}$ (Fagan et al 1992).

$\delta\left({ }^{13} \mathrm{C}\right) \sim 1 .\left(\mathrm{CH}_{3}\right)_{6}$ and $\left(\mathrm{CH}_{3}\right)_{8}$ fullerene derivatives predominate in the products, which contained up to 24 methyl groups (Bausch et al 1991). More controlled anion formation has been achieved in the reaction of $\mathrm{C}_{60}$ with $t$ - $\mathrm{Bu} \mathrm{Li}$ (347) (figure 94) (Fagan et al 1992). It forms $t-\mathrm{BuC}_{60}$ with small amounts of $(t-\mathrm{Bu})_{n} \mathrm{C}_{60}{ }^{n-1}(n=2-6)$. $t$-BuHC ${ }_{60}$ exists in two forms with the $\mathrm{H}$ and $t$-Bu groups in either 1,2 - or 1,11 positions $(350,352)$. The latter rearranges to the former, which is more stable. The high electron withdrawal by the cage makes $t-\mathrm{BuHC}_{60}$ a strong carbon acid $\left(\mathrm{pK}_{\mathrm{a}}=5 \cdot 7\right)$ with a weak $\mathrm{C}-\mathrm{H}$ bond dissociation energy $(71 \mathrm{kcal} / \mathrm{mol})$.

Pure $\mathrm{C}_{60}$ and $\mathrm{C}_{60} / \mathrm{C}_{70}$ mixtures undergo $\mathrm{AlCl}_{3}$ or $\mathrm{FeCl}_{3}$-catalyzed reaction with aromatics such as benzene and toluene to polyarene units by initial protonation of the cage by the $\mathrm{HAlCl}_{3} \mathrm{OH}$ super acid (Olah et al 1991). Since $\mathrm{Ar}$ and $\mathrm{H}$ are added across fullerene double bonds, the reaction can be characterized as fullerenation of 
aromatics the products $\mathrm{C}_{60} \mathrm{H}_{n} \mathrm{Ar}_{n}$, the species with $n=12$ and 16 are especially obtained when aromatic group is $\mathrm{Ph}$. The results support the direct fullerenation of the aromatic ring by initial protonation of fullerene to the corresponding fullerene cation and subsequent Friedel-Crafts alkylation. FAB mass spectrometry indicated a strong mass peak $\left(\mathrm{M}^{+}, 1656\right)$, supporting the formation of $\mathrm{C}_{60}\left(\mathrm{C}_{6} \mathrm{H}_{6}\right)_{12}$ and also formation of $\mathrm{C}_{60}\left(\mathrm{C}_{6} \mathrm{H}_{6}\right)_{16}\left(\mathrm{M}^{+}, 1968\right)$. There is no evidence of phenylation of $\mathrm{C}_{70}$ in fullerene mixture.

$\mathrm{C}_{60} \mathrm{Cl}_{6}$ can be phenylated and arylated to give derivatives of the type $\mathrm{C}_{60} \mathrm{Ar}_{5} \mathrm{Cl}$, which may be readily converted to $\mathrm{C}_{60} \mathrm{Ar}_{5} \mathrm{H}$ (Taylor et al 1994). The compounds $\mathrm{C}_{60} \mathrm{Ph}_{5} \mathrm{H}$ and various other phenylated derivatives are isolated from the product of reaction of $\mathrm{C}_{60}$ with bromine, $\mathrm{FeCl}_{3}$ /benzene. In the presence of $\mathrm{FeCl}_{3}$, benzene readily undergoes electrophilic substitution by $\mathrm{C}_{70} \mathrm{Cl}_{10}$ to give both yellow $\mathrm{C}_{70} \mathrm{Ph}_{10}$ and orange-red $\mathrm{C}_{70} \mathrm{Ph}_{8}$ each of which is luminescent (Avent et al 1996). $\mathrm{C}_{70} \mathrm{Ph}_{10}$ is not formed directly from $\mathrm{C}_{70} \mathrm{Cl}_{10}$, but rather by further phenylation of the intermediate $\mathrm{C}_{70} \mathrm{Ph}_{8}$. The adjacent $\mathrm{Ph}$ groups of $\mathrm{C}_{70} \mathrm{Ph}_{10}$ are sterically prevented from rotating at room temperature. $\mathrm{C}_{70} \mathrm{Ph}_{8}$ spontaneously oxidizes in air to form a bis-lactone $\mathrm{C}_{70} \mathrm{Ph}_{8} \mathrm{O}_{4}$, having an eleven-membered whole in the fullerene cage (Birkett et al 1995b). The reaction is believed to proceed via insertion of oxygen into $[5,6]$-bonds followed by oxidative cleavage of the adjacent double bond.

Chiang et al (1992) reported initial electrophilic attack of nitronium ion to $\mathrm{C}_{60}$ to form an intermediate $\mathrm{C}_{60}\left(\mathrm{NO}^{2+}\right)_{x}$ and nucleophilic 1,3- or 1,5-substitution followed by hydrolysis to finally give polyhydroxy organocarboxylate derivative consisting of average 13-15 hydroxyl substituents and 4-5 p-bromobenzoate moieties per $\mathrm{C}_{60}$ molecule. This upon hydrolysis gives the corresponding water soluble fullerols consisting of 18-20 hydroxyl groups per $\mathrm{C}_{60}$ molecule.

$$
\begin{aligned}
& \mathrm{NO}_{2} \mathrm{BF}_{4}+\mathrm{RCOOH} \rightarrow \mathrm{RCOO}^{-} \mathrm{NO}_{2}^{+}+\mathrm{HBF}_{4} \\
& \mathrm{C}_{60} \stackrel{\stackrel{1) \mathrm{RCOO}^{-} \mathrm{NO}_{2}^{+}}{\longrightarrow} \mathrm{C}_{60}\left(-\mathrm{H}_{2} \mathrm{O}\right.}{\longrightarrow} \mathrm{OCOR}_{x}(\mathrm{OH})_{y} \\
& \quad\left(\mathrm{R}=-\mathrm{C}_{6} \mathrm{H}_{5}, p-\mathrm{C}_{6} \mathrm{H}_{4} \mathrm{Br}, x=13-15, y=4-5\right) \\
& \mathrm{C}_{60}(-\mathrm{OCOR})_{x}(\mathrm{OH})_{y} \stackrel{\mathrm{NaOH} / \mathrm{H}_{2} \mathrm{O}}{\longrightarrow} \mathrm{C}_{60}(\mathrm{OH})_{x+y}, \quad x+y=18-20
\end{aligned}
$$

$\mathrm{C}_{60}$ nitroderivatives were also prepared by reacting $\mathrm{C}_{60}$ in the inert $\mathrm{CCl}_{4}$ solution with conc. $\mathrm{HNO}_{3}$ and $\mathrm{NO}_{2}$ gas (Huang et al 1996). The product had the composition $\mathrm{C}_{60}\left(\mathrm{NO}_{2}\right)_{x}(\mathrm{OH})_{y}, \mathrm{C}_{60}$ is sulphonated in fuming sulphuric acid and chlorinated in chlorosulphonic acid (Miller et al 1994). Both reactions involve initial oxidation of $\mathrm{C}_{60}$ followed by in situ trapping of electrophilic $\mathrm{C}_{60}$ cation.

\section{Radical (neutral, anion, and cation) addition to $\mathbf{C}_{60}$}

The radicals such as $\mathrm{Me}, \mathrm{Ph}, \mathrm{PhS} \cdot \mathrm{PhCH}_{2}, \mathrm{CBr}_{3}, \mathrm{CF}_{3}$, and $\mathrm{Me}_{3} \mathrm{CO} \cdot$ react with $\mathrm{C}_{60}$ forming either mono or poly or both types of adducts (Krusic et al 1991a; Morton et al 1992b), although in some cases rapid reversion to $\mathrm{C}_{60}$ occurs. There are thirty double bonds in $\mathrm{C}_{60}$ to which free radicals can add to give radical 


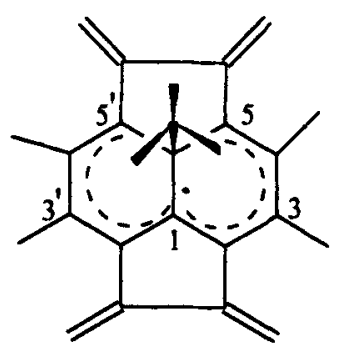

Figure 95. Radical addition of $\mathrm{C}_{60}$ and preferred orientation of alkyl substituent (Krusic et al 1993).

adducts. Normally the addition takes place across the $[6,6]$-double bond of pyracylene unit. In case of monoadduct the radical is located on one of the ring fusion site of $[6,6]$-double bond and substitution on the other side. Each half of the radical structure is of $\mathrm{C}_{\mathrm{s}}$ symmetry. As reported by Krusic et al (1991) up to 11 phenyl groups, 15 benzyl groups and 35 methyl groups can be added to $C_{60}$ in the course of reaction.

Alkyl radicals can readily add to $\mathrm{C}_{60}$ to give the product $\mathrm{R}_{n} \mathrm{C}_{60}$, which can be detected by mass spectrometry for even $n$ and by ESR spectroscopy for odd $n$. The dependence of signal intensity on temperature and dilution (Krusic et al 1993) established the fact that the radical adduct of $\mathrm{C}_{60}$ exists in equilibrium with their dimers: $\mathrm{RC}_{60} \mathrm{C}_{60} \mathrm{R} \rightleftharpoons 2 \mathrm{RC}_{60}$. There exists substantial rotational barrier about $\mathrm{R}-\mathrm{C}_{60}$ bond $\left(C_{6}-C_{9}\right)$ (figure 95), so that substituents adopt preferred equilibrium conformation relative to $\mathrm{C}_{60}$ framework. For $t-\mathrm{Bu}-\mathrm{C}_{60}$, activation energy for internal rotation is $8.2 \mathrm{kcal} / \mathrm{mol}$.

Photochemically generated benzylic radical adds to give $\left(\mathrm{C}_{6} \mathrm{H}_{5} \mathrm{CH}_{2}\right)_{n} \mathrm{C}_{60}$ where $n=1$ to 15 (Krusic et al 1991a). Mass and ESR spectra of the above adduct show two intense signals for $n=3$ and 5 and these two were found to be most stable having allylic and pentadienyl structure respectively (figure 96):

$$
\begin{aligned}
& \left(\mathrm{CH}_{3}\right)_{3} \mathrm{CO}-\mathrm{OC}\left(\mathrm{CH}_{3}\right)_{3} \longrightarrow 2\left(\mathrm{CH}_{3}\right)_{3} \mathrm{CO} \cdot \\
& \mathrm{C}_{6} \mathrm{H}_{5} \mathrm{CH}_{3}+\left(\mathrm{CH}_{3}\right)_{3} \mathrm{CO} \longrightarrow \mathrm{C}_{6} \mathrm{H}_{5} \mathrm{CH}_{2} \cdot\left(\mathrm{CH}_{3}\right)_{3} \mathrm{COH} \\
& n\left(\mathrm{C}_{6} \mathrm{H}_{5} \mathrm{CH}_{2} \cdot+\mathrm{C}_{60} \longrightarrow\left(\mathrm{C}_{6} \mathrm{H}_{5} \mathrm{CH}_{2}\right)_{n} \mathrm{C}_{60^{\circ}} \quad[n=3 \text { and 5] }\right.
\end{aligned}
$$

In all the above cases of radical adduct, the radicals formed are not allowed for delocalization because delocalization placed double bond in the pentagonal rings. So the radicals formed are unstable leading to dimerization. ESR spectra confirms that $\mathrm{C}_{60} t$-Bu radical (349) forms a dimer (351) (figure 94) and steric constraints suggest that dimerization must take place at para position.

Alkoxy radicals (RO) generated photochemically from peroxides add to $\mathrm{C}_{60}$ yielding the $\mathrm{RO}-\mathrm{C}_{60}$ radical adduct which is detected by $\mathrm{ESR}$ spectroscopy (Cremonini et al 1993). A more convenient photolytic source of alkoxy radicals for addition to fullerenes is dialkoxy disulphide ROSSOR. Borghi et al (1996) studied the radical adduct $\mathrm{RO}-\mathrm{C}_{60} \cdot(\mathrm{R}=\mathrm{Me}, \mathrm{Et}, i-\mathrm{Pr}$, and $t-\mathrm{Bu})$ obtained by photolysis of the corresponding ROSSOR derivatives in the presence of $\mathrm{C}_{60}$. 


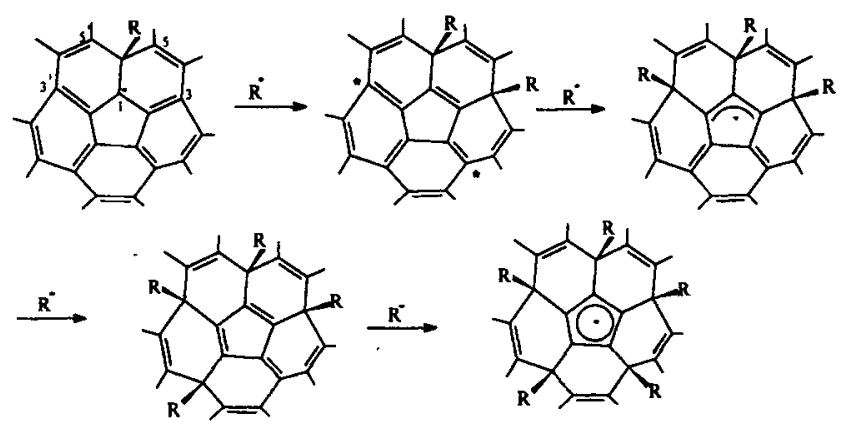

Figure 96. Addition of photochemically generated benzylic radical to $\mathrm{C}_{60}$ (Krusic et al 1991a).

The rotation about the intercage bond of singly bonded $\mathrm{C}_{60}$ dimers $\mathrm{RC}_{60} \mathrm{C}_{60} \mathrm{R}(\mathrm{R}=\mathrm{H}, \mathrm{Me}$, and $t-\mathrm{Bu}$ attached at ortho or para positions from pivot carbon atoms) obtained by dimerization of $\mathrm{RC}_{60}$. radicals, has been studied by molecular mechanics (Osawa et al 1996). The predicted rotational barriers are high ranging from $15 \mathrm{kcal} / \mathrm{mol}$ for the least hindered $p, p^{\prime}-\left(\mathrm{HC}_{60}\right)_{2}$ to the almost forbidding values for those carrying tert-butyl groups. Contrary to the expectation, rotamers with $\mathbf{R}$ groups close to each other like the gauche form are predicted to be consistently more stable than with maximally separated substituents, by as much as $10 \mathrm{kcal} / \mathrm{mol}$ in case of $\mathrm{R}=$ tert-butyl.

The reaction of $\left(\eta^{3}-\mathrm{Ph}_{3} \mathrm{C}\right) \operatorname{Re}(\mathrm{CO})_{4}$ with $\mathrm{CO}$ is known to produce $\operatorname{Re}(\mathrm{CO})_{5}$, via homolysis of a weak $\mathrm{Re}-\mathrm{C}$ bond in a $\left(\eta^{1}-\mathrm{Ph}_{3} \mathrm{C}\right) \operatorname{Re}(\mathrm{CO})_{5}$ intermediate. The reaction with $\mathrm{C}_{60}$ in the presence of $\mathrm{CO}$ results in colour change in the solution with the formation of $\mathrm{C}_{60}\left[\operatorname{Re}(\mathrm{CO})_{5}\right]_{2}$ by either thermal or photochemical process (Zhang et al 1993). The photolysis of $\mathrm{C}_{60}$ in the presence of donor molecules such as dimethyl aniline, tetramethylphenylene diamine, hexamethyl benzene etc in toluene/2-Me THF solutions to produce radical anion of $\mathrm{C}_{60}$. With benzyltrialkyl tin derivative, the photolysis of $\mathrm{C}_{60}$ in toluene/2Me THF solution is also reported and confirmed by ESR spectroscopy.

Olah et al (1991a) carried out oxidation studies on $\mathrm{C}_{60}$ and $\mathrm{C}_{70}$ using $\mathrm{SbF}_{5}$ in $\mathrm{SO}_{2}$ CIF solution, a system found highly efficient for oxidation of polycyclic aromatic to their dications. Green coloured solution is obtained that gave extremely broad ${ }^{13} \mathrm{C}$ NMR spectra at all temperatures employed. The results indicated the generation of diradical cations instead of diamagnetic di- or polycations. A novel synthetic route for the formation of the biphenyl anion from benzene using fullerene anion was reported by Eastman et al (1994). 18-Crown-6-assisted potassium metal reduction of $\mathrm{C}_{60}$ in benzene at room temperature gave coupling of benzene and ultimately the biphenyl anion, identified by ESR studies. Stable 1-octynyl- $\mathrm{C}_{60^{-}}$ carbanion was generated by the reaction of 1 -octynyl- $\mathrm{C}_{60}-\mathrm{H}$ with $t-\mathrm{BuOK}$ in THF and its structure was confirmed by ${ }^{1} \mathrm{H}$ and ${ }^{13} \mathrm{C}$ NMR spectra (Murata et al 1996). The redox properties are studied by cyclic voltametry and involve a one electron oxidation process affording a dimer of the corresponding radical. The reaction of 
dianion species with various carbon electrophiles afforded the 1,2- or 1,4-disubstituted dihydrofullerenes.

\section{Polymerization reactions}

Zhu et al (1994) observed the phenomena of electrical fusion of fullerenes in a laser desorption mass spectrometric study of adduct compounds of $\mathrm{R}_{n} \mathrm{C}_{60}\left(\mathrm{R}=\mathrm{C}_{6} \mathrm{H}_{5} \mathrm{CH}_{2}\right.$ or $\mathrm{C}_{9} \mathrm{H}_{7}$ ) in the negative ion channel. The nature of $\mathrm{R}$ is believed to play a key role in the formation of stable higher mass fullerenes and doubly charged negative ions of $\mathrm{C}_{60}$ in the gas phase. Yang and Yuan (1995) treated sublimed $\mathrm{C}_{60}$ thin films by direct current discharge plasma. The UV-visible spectra of the treated $C_{60}$ films show the plasma polymerization of $\mathrm{C}_{60}$ film surface. Ultraviolet irradiation of $\mathrm{C}_{60}$ in the absence of oxygen formed a polymeric product $\left(\mathrm{C}_{60}\right)_{n}$, where $n \sim 20$ and this again undergoes ring opening reaction to finally give 1,2 -addition products (Taylor and Walton 1993).

$\mathrm{C}_{60}$ and $\mathrm{C}_{70}$ initiate the polymerization of the monomer 1,3-butadiene in the gas phase (Wang et al 1992a). While $\mathrm{C}_{60}^{+}$and $\mathrm{C}_{70}^{+}$were found to be unreactive towards 1,3-butadiene, both $\mathrm{C}_{60}^{2+}$ and $\mathrm{C}_{70}^{2+}$ were observed to react readily. In the process of polymerization, the coulombic repulsion between the positive charges is relaxed as more butadiene monomers are added. There are two ways in which a polymer chain can be propagated. One is the propagation of polymer chain on one side of the cage in a tadpole-like fashion and the second is on both sides of the cage in a spindle-like fashion. From the above it was concluded that the fullerene cage may become a pendant on or be blocked in the polybutadiene chain (figure 97). Reaction of $\mathrm{C}_{60}^{+}$, $\mathrm{C}_{60}^{2+}$ and $\mathrm{C}_{60}^{3+}$ were investigated with $\mathrm{C}_{2} \mathrm{H}_{2}$ and $\mathrm{C}_{2} \mathrm{H}_{4}$ in the gas phase (Wang et al 1996a). The $\mathrm{C}_{60}^{+}$is unreactive and $\mathrm{C}_{60}^{2+}$ reacts only slowly by adduct formation. However $\mathrm{C}_{60}^{3+}$ reacts rapidly with $\mathrm{C}_{2} \mathrm{H}_{2}$ by adduct formation and electron transfer. A mechanism is proposed for the polymerization without and with hydride shift in the derivatized fullerene cation.

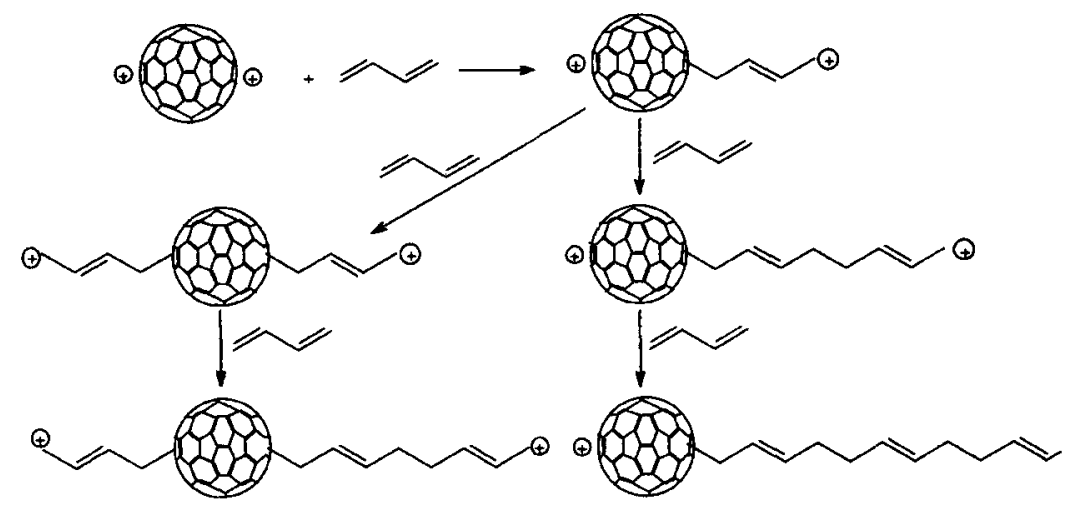

Figure 97. Attachment of polybutadiene chain to fullerene cage (Wang et al 1992). 


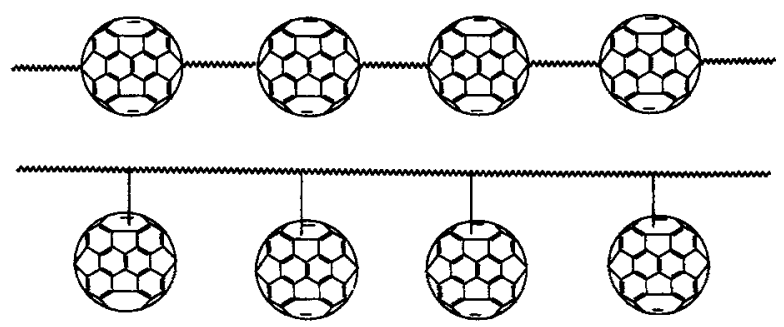

Figure 98. 'Pearl necklace' and 'charm-bracelet' type polymers of fullerene.
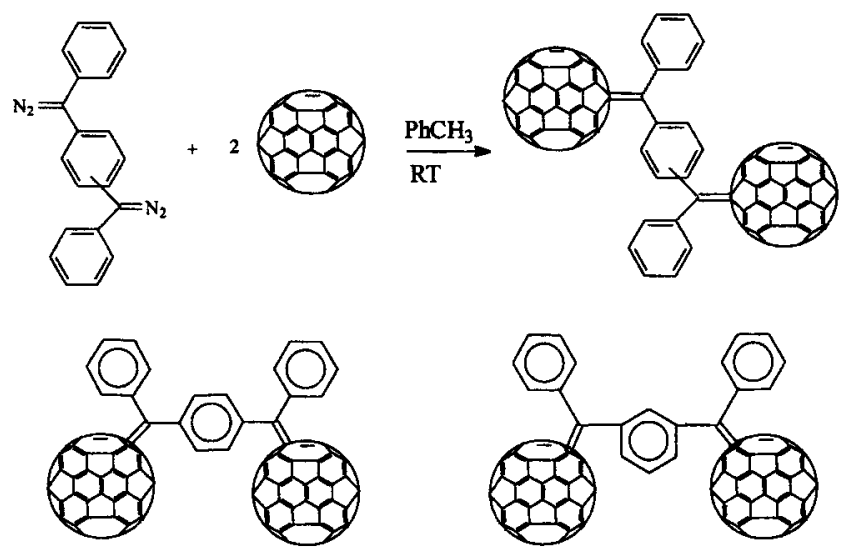

Figure 99. Synthesis of a basic unit for 'pearl necklace' polymers (Suzuki et al 1992).

Fulleroid formation has opened the way for the synthesis of two types of polymerization i.e. 'pearl necklace' and 'charm bracelet' (figure 98) (Amato 1991). The former is the hypothetical one in which $\mathrm{C}_{60}$ framework is the part of a backbone and the latter is a polymer in which $\mathrm{C}_{60}$ is attached to the side chain of a traditional polymer. The third variety of polymer also exists in which a necklace variant with a direct link between the cages is apparently formed on polymerization of $\mathrm{C}_{60}$ by UV radiation in the absence of oxygen (Wudl et al 1992). A basic unit for 'pearl necklace' polymer is the diphenyl fulleroid (figure 99) (Suzuki et al 1992). Fullerene inflation reaction can yield molecules which are the basic unit of pearl necklace polymers in which the fulleroid becomes part of the polymer backbone. Nigam et al (1995b) investigated the addition of 2-methylaziridine to $\mathrm{C}_{60}$. The adduct was suggested to have ten aziridine rings per molecule of $\mathrm{C}_{60}$. This $\mathrm{C}_{60}$-methylaziridine reacts readily with phenolic and epoxy monomers via aziridine ring opening to produce polymers with good thermal stability. The first 'charm bracelet' conjugated polymers-an electroconducting polythiophene with covalently bound fullerene was reported by Benincori et al (1996). The polymer is prepared by electrochemical polymerization of a cyclopenta[2,1-b:3,4- $\left.b^{\prime}\right]$ dithiophen-4-ylidene fullerene- $C_{60}$ adduct. The electrical properties of the polymers are reported. 


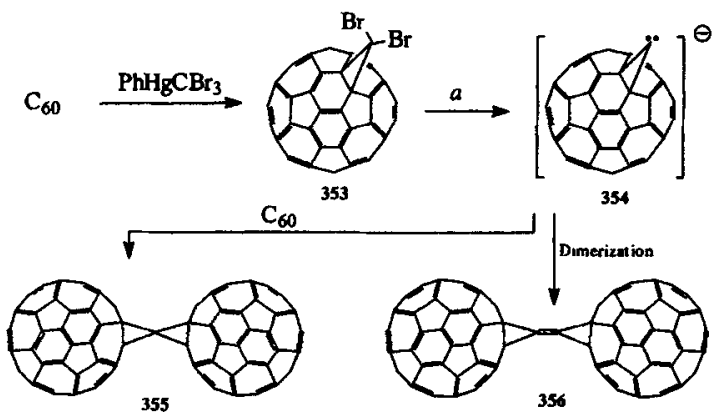

Figure 100. Evidence of the carbon allotropes $\mathrm{C}_{121}$ and $\mathrm{C}_{122} a-\mathrm{i}$. toluene, $\mathrm{Fe}(\mathrm{CO})_{5}, 0^{\circ} \mathrm{C}$ reflux, ii. toluene, $\mathrm{hv}, 330 \mathrm{~nm}, 25^{\circ} \mathrm{C}$, iii. toluene, $\mathrm{Cu}$, reflux and iv. toluene or $\mathrm{THF}, \mathrm{BrLi}$, $-90^{\circ} \mathrm{C}$, reflux (Osterodt and Vögtle 1996).

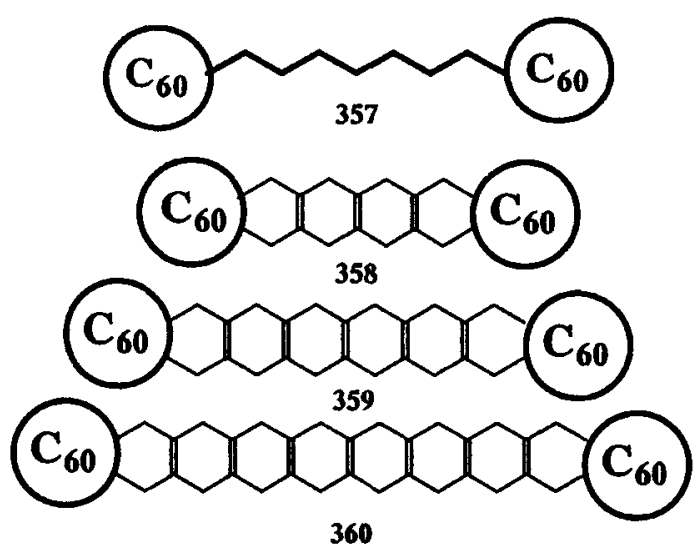

Figure 101. Controlled spacing of $\mathrm{C}_{60}$ carbon spheres (Paquette and Graham 1995).

$\mathrm{C}_{60}$ dimerizes into various forms, and there are several reports of singly bonded dimers (Morton et al 1992a; Keizer et al 1993; Yoshida et al 1994). The rotation about the intercage bond of singly bonded $C_{60}$ dimers $R_{60} C_{60} R$ obtained by dimerization of $\mathrm{RC}_{60}{ }^{\circ}$ radicals has been studied by molecular mechanics (Osawa et al 1996). The first indication of a double-bonded dimer is reported by Osterodt et al (1996). The addition of methanofullerenecarbene, $\mathrm{C}_{60} \mathrm{C}$ :, to $\mathrm{C}_{60}$ and its dimerization would provide $355\left(C_{121}\right)$ and $356\left(C_{122}\right)$ (figure 100) which have been detected by mass spectroscopy. There is a possibility that 355 and 356 are formed under mass spectrometric conditions. The ${ }^{1} \mathrm{H}$ NMR spectra of the dimer shows a very broad band, indicating the presence of a number of isomers.

Controlled spacing of $\mathrm{C}_{60}$-carbon spheres with 1,4-cyclohexadienyl ladders by pairwise Diels-Alder cycloaddition to $\mathrm{C}_{60}$ was reported by Paquette and Graham (1995) (figure 101). A number of dumbbell-like structures could be designed. Diederich et al (1995) reported the synthesis of a rotaxane 363 (figure 102) assembled via the copper(I) templated approach, bearing two $\mathrm{C}_{60}$ units as chemical stoppers. The syn- 

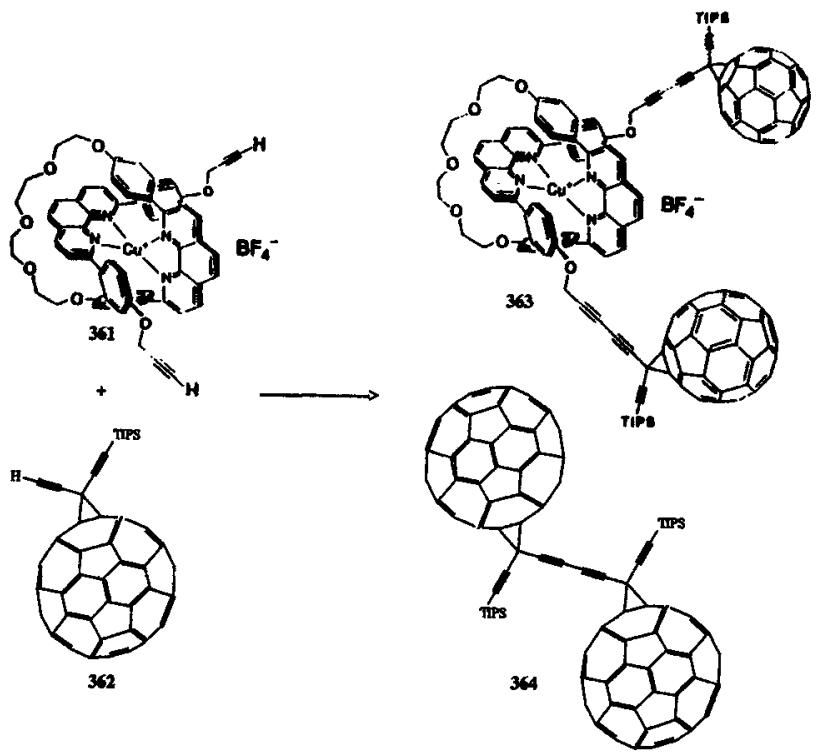

Figure 102. A copper(I)-complexed rotaxane with two fullerene stoppers (Diederich et al 1995).

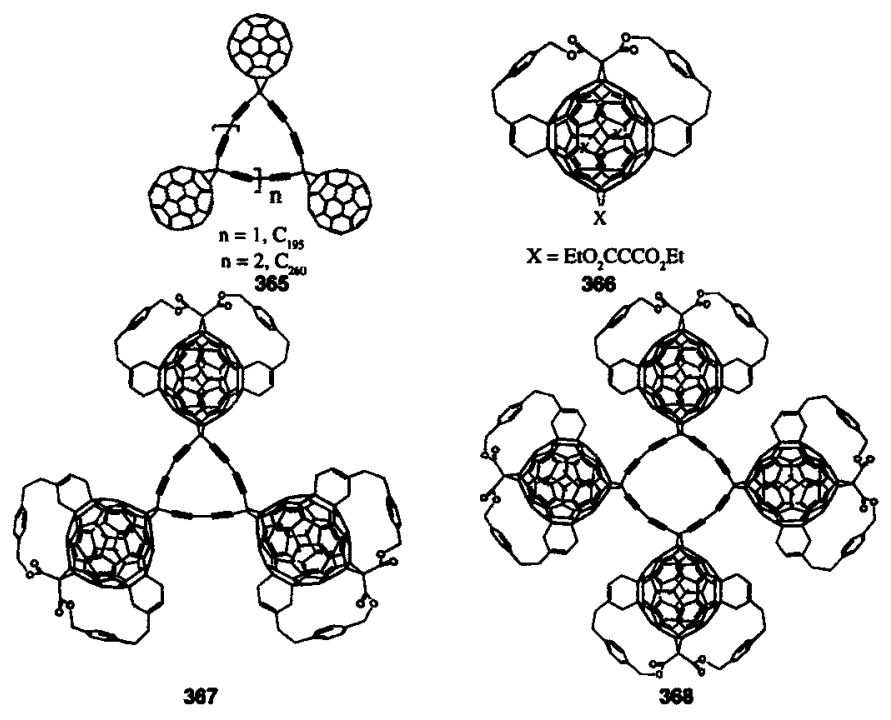

Figure 103. First members of a new class of carbon allotropes $C_{n(60+5)}: C_{195}, C_{260}$ and their solubilized derivatives (Isaacs et al 1995a).

thesis of 363 is based on the oxidative coupling reaction of terminal alkynes functionalized on $\mathrm{C}_{60}(362)$ and copper(I) rotaxane 361 in the presence of Hay catalyst $\left[\mathrm{CuCl}-\mathrm{TMEDA}-\mathrm{O}_{2}\left(\mathrm{TMEDA}=\mathrm{N}, \mathrm{N}, \mathrm{N}^{\prime}, \mathrm{N}^{\prime}\right.\right.$-tetramethylethylenediamine $\left.)\right]$. A dimeric fullerene derivative resulted from the homocoupling reaction of 362 . 


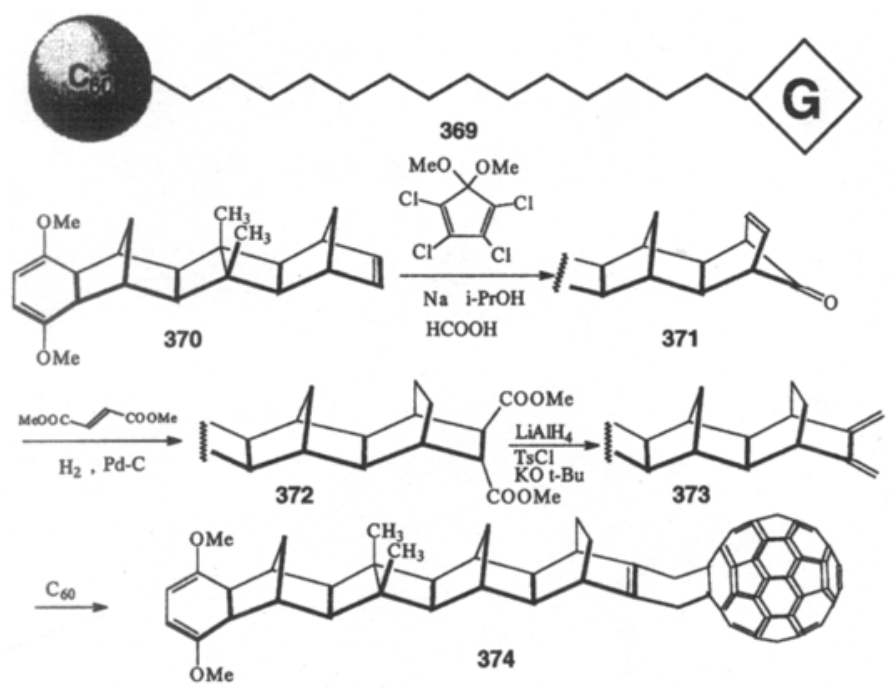

Figure 104. Synthesis of a rigid 'ball-and-chain' system through Diels-Alder functionalization of $\mathrm{C}_{60}$ (Khan et al 1993).

A number of new carbon allotropes of molecular formula $\mathrm{C}_{n(60+5)}$ are synthesized by oxidative cyclization of diethynylmethanofullerene (figure 103). The smallest number of this family $\mathrm{C}_{195}(\mathbf{3 6 5})$ consists of a cyclo- $\mathrm{C}_{15}$ core surrounded by three peripheral fullerenes, whereas $\mathrm{C}_{260}$ is a cyclo- $\mathrm{C}_{20}$ derivative with four fullerenes. Isaacs et al (1995) extended their above work to the synthesis of analogous tri- and tetramers 367 and 368 respectively. The starting material synthesized by the method of template activation (Cardullo et al 1996) subjected to nucleophilic addition/elimination of 1,5-bis (trimethylsiyl)-3-bromopenta-1,4-diyne so as to introduce diethynylmethano group, leading to dialkynylmethanofullerene hexaadduct 366 . Deprotection and subsequent oxidative cyclization led to two major derivatives of the carbon allotropes $\mathrm{C}_{195}$ and $\mathrm{C}_{260}$ providing 367 and 368 .

Khan et al (1993) reported the ball-chain molecule 374 in which the chain comprises a rigid polynorbornyl-bicyclo $[2 \cdot 20]$ hexyl bridge (figure 104). The configuration of the novel bridge diene can be systematically altered and a variety of functional groups $\mathbf{G}$ appended. The application of Diels-Alder cycloaddition to the formation of polymer bound fullerene i.e. synthesis of cyclopentadiene functionalized polymers have been reported (Guhr et al 1994). The reaction of merrified peptide resin (375) in toluene with excess sodium cyclopentadienylide at $-20^{\circ} \mathrm{C}$ formed functionalized polymers (figure 105) which react with $\mathrm{C}_{60}$ at room temperature to give fullerene functionalized polymer (377). This reaction has opened the way for the covalent attachment of fullerenes to a polymer support through Diels-Alder cycloaddition and the product formed has shown to be readily reversible, allowing recovery of $\mathrm{C}_{60}$ upon heating of the resin.

$\mathrm{C}_{60}$ reacts with benzyl radical to form polybenzylated fullerenes. $\mathrm{C}_{60}$ can be incorporated in a copolymer with p-xylylene, the product is unstable and readily reacts with oxygen. Xylylene (378), a diradical analogue of benzylic radical easily 


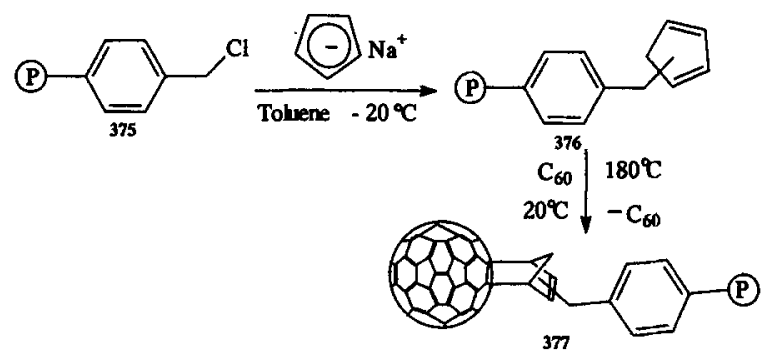

Figure 105. Synthesis of cyclopentadiene functionalized polymers of $C_{60}$ (Guhr et al 1994).

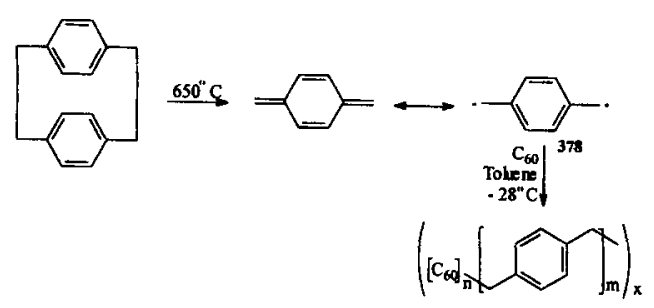

Figure 106. Copolymerization of xylylene with $C_{60}$ (Loy and Asssink 1992).

prepared by flash thermolysis of paracyclophane is known to form poly ( $p$-xylylene) by reacting readily with itself (Loy and Asssink 1992). In this reaction the polymerization of $\mathrm{C}_{60}$ and $p$-xylene takes place by the free radical pathway (figure 106) and the copolymer formed is insoluble which is due to the cross linking through multiple benzylation on the $\mathrm{C}_{60}$ molecule (Tebbe et al 1991).

The fullerenation of polystyrene provides a facile method of homogeneously dispersing fullerene molecules into polymer matrices. Anionic co-polymerization of $\mathrm{C}_{60}$ with styrene monomer gives a mixture of products known as flagellanes and are highly soluble (Taylor and Walton 1993). This can also be processed in the melt. $\mathrm{C}_{60}$ can be incorporated into noncrosslinked polystyrene by reaction with $\mathrm{AlCl}_{3}$. Polystyrene-based fullerene polymers have been of particular interest because of potential technological applications (Cao and Webber 1995; Bunker et al 1995; Camp et al 1995; Weis et al 1995). $\mathrm{C}_{60}$ and $\mathrm{C}_{70}$ co-polymerize with styrene in a standard free radical polymerization either in bulk or co-dissolved in an aromatic solvent (Cao and Webber 1995). The resulting polymers are soluble and behave like ordinary polystyrene in solution except for the dark brown colour. The adsorption spectrum of the co-polymer is strongly modified from that of the parent fullerene, and the fluorescence is blue-shifted and much stronger. $\mathrm{C}_{60}$-styrene random co-polymers with different $\mathrm{C}_{60}$ content are prepared using bulk and solution polymerization techniques (Bunker et al 1995). The $\mathrm{C}_{60}$-styrene co-polymers have quite different adsorption and emission properties from both polystyrene and $\mathrm{C}_{60}$. The significantly larger fluorescence yields in the co-polymers are attributed to reduced symmetry of $\mathrm{C}_{60}$ molecules upon being incorporated into polymer structures. Liu et al (1996) reported preparation of pendant $C_{60}$-polystyrene polymers 379 (figure 107) by use of Friedel-Crafts type reactions. 


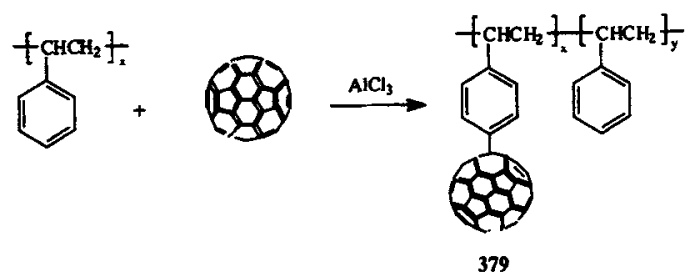

Figure 107. Soluble pendant [60] fullerene-polystyrene polymers (Liu et al 1996).

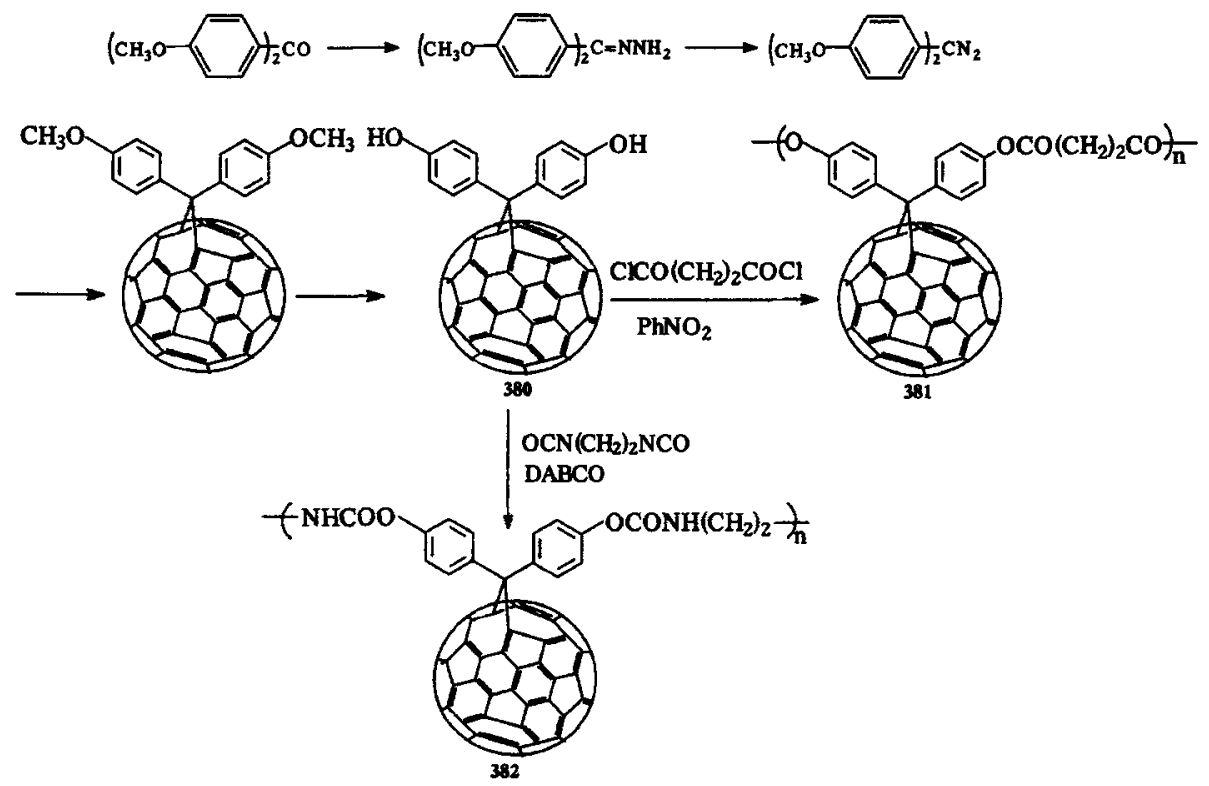

Figure 108. Polyester and polyurethane derivatives of fulleroid (Shi et al 1992).

Fullerene-functionalized polymers were prepared by covalently attaching fullerenes to amino-containing flexible hydrocarbon polymers. These materials are soluble in hexane or THF in which the fullerene is essentially insoluble (Patil and Schriver 1995). A series of amino-terminated polystyrenes with relatively narrow molecular weight distribution was synthesized by living anionic polymerization and subsequent end-capping (Weis et al 1995). The reaction of the terminal amino function with $\mathrm{C}_{60}$ was monitored in situ by UV spectroscopy. Hydroxy- and aminofunctionalized fullerenes also are the potential reactants for the formation of $\mathrm{C}_{60}$ containing polyesters and polyamides (Chiang et al 1992a, b). The methanofullerenes can give rise to pendant chain polymers. The fulleroid $\left(\mathrm{HOC}_{6} \mathrm{H}_{4}\right)_{2} \mathrm{C}_{61}$, (380), with sebacryl chloride or hexamethylene diisocyanate polymerize to produce two charm bracelet type polymers containing $\mathrm{C}_{61}$ molecules dangling from the polymer bone i.e. polyester and polyurethane derivatives of $C_{61}$ (figure 108) (Shi et al 1992). 


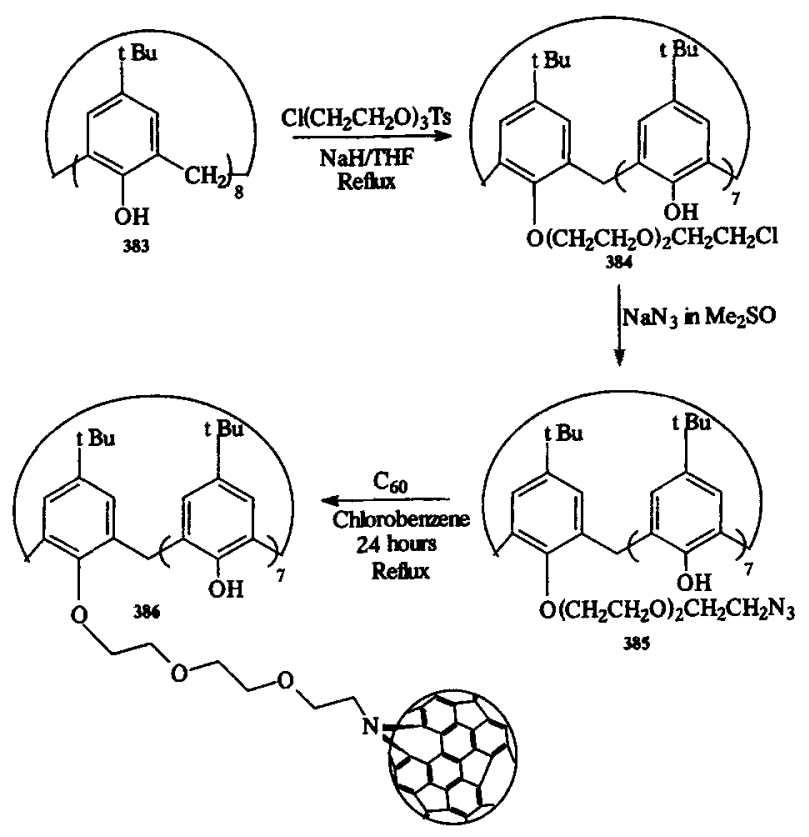

Figure 109. Synthesis of calix fullerene (Shinkai et al 1994).

Polyether modified fullerenes were prepared under mild conditions by reacting $\mathrm{C}_{60}$ or $\mathrm{C}_{70}$ in toluene with a bifunctional amino-terminated poly (oxyethylene) or poly(oxypropylene) (Manalova et al 1994). In the early stages of the reaction soluble products are formed. Later cross-linking proceeds between the polyfunctional fullerenes and the bifunctional polyethers. The non-crosslinked fullerene is soluble in toluene and water; on evaporation of toluene, adhesive films are formed. An adduct of $\mathrm{C}_{60}$ and 2-methyl aziridine was prepared and co-polymerized with Novolac and Bisphenol $A$ to provide three dimensional polymers containing $\mathrm{C}_{60}$ with low coefficients of friction and good wear properties for use as potential solid lubricants (Nigam et al 1995b). Co-polymerization of $\mathrm{C}_{60}$ with paracyclophane at high temperature was studied (Huang et al 1994a). Main chain polymers with the incorporated [60]fullerene units were readily prepared by reaction of buckminsterfullerene with functional bis-o-quinodimethanes. Cross-linking was effectively suppressed by carefully directed admixing of a mono-o-quinodimethane. A polymer of high molecular weight consisting of eighty [60]fullerene units on the average was prepared (Guegel et al 1996). Reactions of $\mathrm{C}_{60}$ with the complex $\mathrm{Pd}_{2}$ (dibenzylidene acetone) $\mathrm{CHCl}_{3}$ results in a ligand displacement reaction to give $\mathrm{C}_{60} \mathrm{Pd}_{\mathrm{n}}$ (Nagashima et al 1992). $\mathrm{C}_{60} \mathrm{Pd}_{3.5}$ catalyzed the hydrogenation of diphenyl acetylene consistent with the presence of palladium atoms on the polymer surface.

$\mathrm{C}_{60}$ functionalized calix[8] arene connected by a polyether chain i.e. calix fullerene has been prepared (Shinkai et al 1994) (figure 109). There are reports of grafting of $\mathrm{C}_{60}$ onto a polyethylene surface. When polyethylene films functionalized 


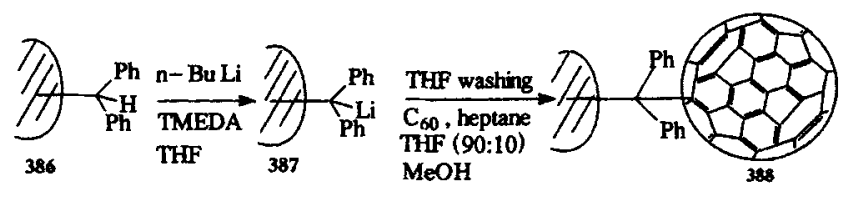

Figure 110. Grafting of $C_{60}$ onto polyethylene surface (Bergbreiter and Gray 1993).

with diphenyl methyl groups react with $n$-BuLi, deprotonated to give a nucleophilic lithiated surface. This surface is used to covalently bind $\mathrm{C}_{60}$ to polyethylene (figure 110) (Bergbreiter et al 1993). The presence of $\mathrm{C}_{60}$ graft was confirmed by XPS, UV-visible and fluorescence spectroscopy.

Starburst dendrimers, which are three dimensional, highly ordered oligomeric and polymeric compounds formed from smaller molecules by reiterative reaction sequences (Tomalia et al 1990), can mimic certain properties of micelles, liposomes and even those of biomolecules. A new branch of 'supramolecular chemistry' has sparked new developments in both organic and macromolecular chemistry. Some examples of such class of compounds include iptycenes (389), which are a class of all-hydrocarbon dendrimer prototypes (Hart et al 1986), dendrimeric macromolecules based on adamantane (390) (Newkome et al 1992) and dendrimeric polyethers (391) (figure 111).

Hawker et al (1994) reported the addition of dendrimeric molecules to fullerenes. The fascinating thing about the dendrimeric addition is the polymeric fragment (due to their global three dimensional structure) which lead to greater encapsulation and the ability to prepare monofunctional, monodisperse materials of known molecular mass. It is the one step cycloaddition reaction of a dendritic azide with $\mathrm{C}_{60}$ (figure 112). Due to the increase of molecular mass by 3400 for each dendrimer addition, only mono- and di-addition products are observed and no higher addition products. When six dendrimer was added to $\mathrm{C}_{60}$, the mono- and di-addition products are found to be 2:3 with no observable higher addition product and this is exclusively due to steric crowding around the $C_{60}$ molecule. Wooley et al (1993) reported the attachment of polyether dendrimers to phenol-functionalized fullerenes (figure 113). The benzylic bromide group at the focal point of a fourth-generation dendrimer (394) reacts with the phenolic groups located at the surface of the functionalized fullerene and thus two dendrimers couple with one fullerene to give the fullerenebound dendrimer 395 .

Fullerenols which contain multiple polar hydroxy functions in a ball-shaped fullerene structure are versatile molecules in the prospective design of three-dimensionally stretched polymers. Chiang et al (1994) reported the synthesis of urethaneconnected polyether star polymers (398) (figure 114) utilizing fullerenol as a molecular core containing six chemically bonded polymer arms per $\mathrm{C}_{60}$ on average, with a narrow distribution of arms per molecule and a polydispersity index of 1.45. Fullerenol 396 was treated with polymer of diisocyanated urethane polyether 397 followed by termination reaction with dodecan-1-ol which afforded the corresponding $\mathrm{C}_{60}$-based urethane-connected polyether dendritic polymers. 


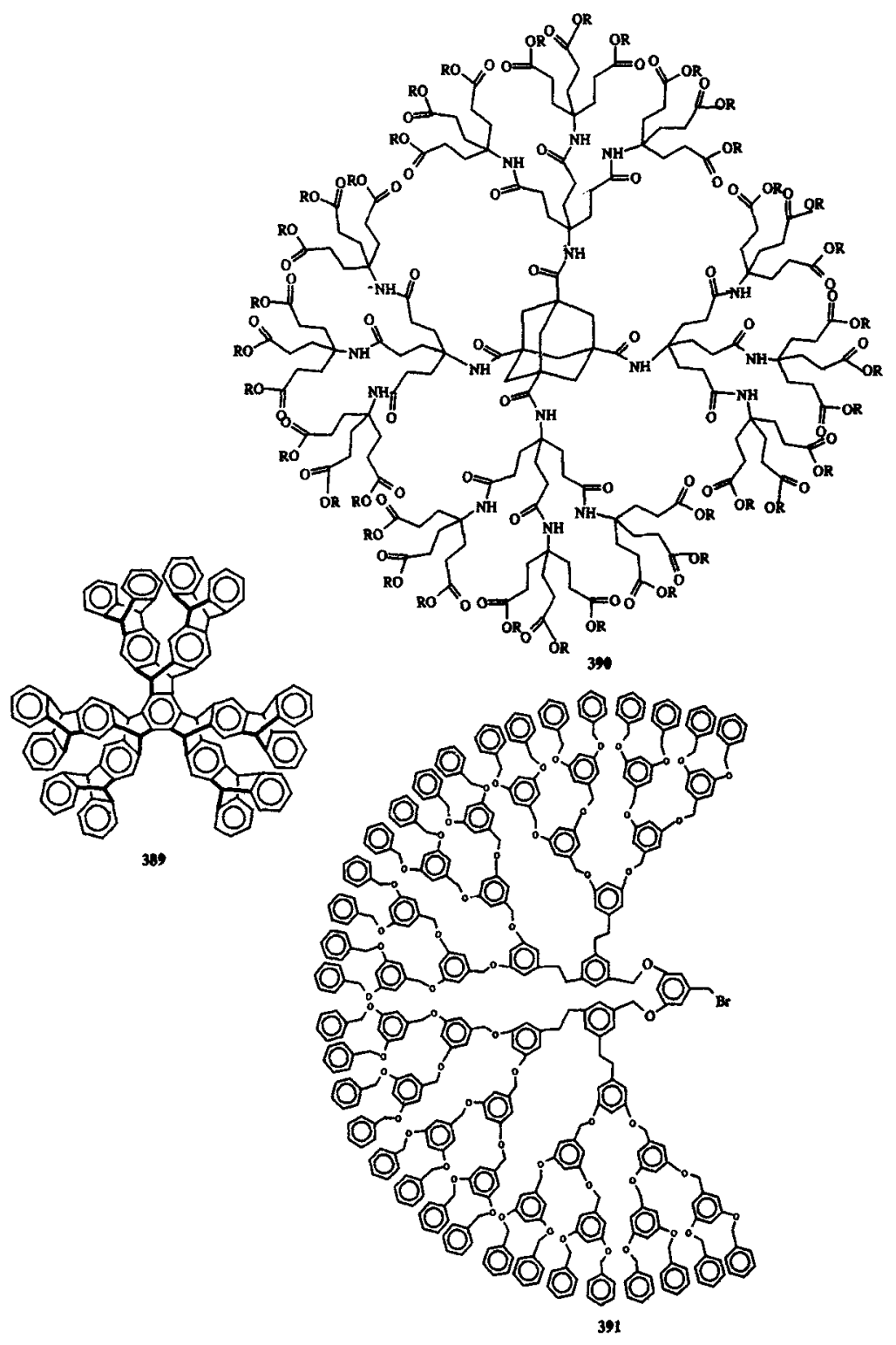

Figure 111. Some examples of dendrimers (Hart et al 1986; Newkome et al 1992; Hawker et al 1993).

The average molecular mass of 398 was obtained as Mn 18000 and Mw 26000, which corresponds to a fullerenol-based dendritic polymer with six linear urethaneconnected polymer arms on average. Polyhydroxylated $\mathrm{C}_{60}$ is thus used as an efficient hyper-cross-linking agent (Chiang et al 1995). These authors (Wang et al 1996b) also reported the synthesis of diisocyanate-terminated polyurethane by the 


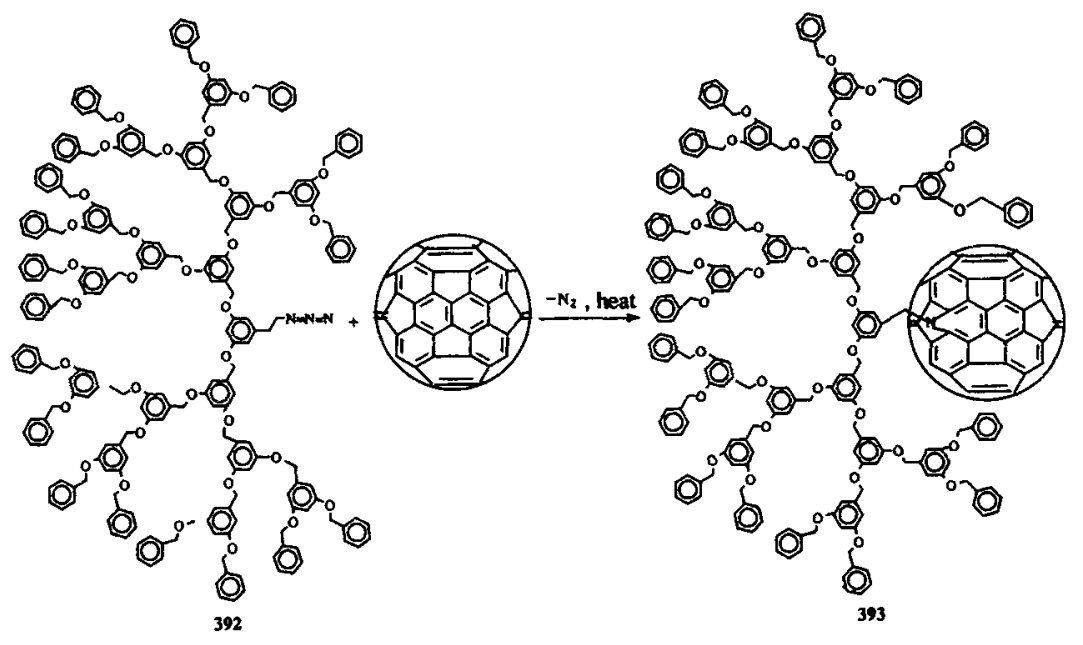

Figure 112. Dendrimer addition to $C_{60}$ (Hawker et al 1994).
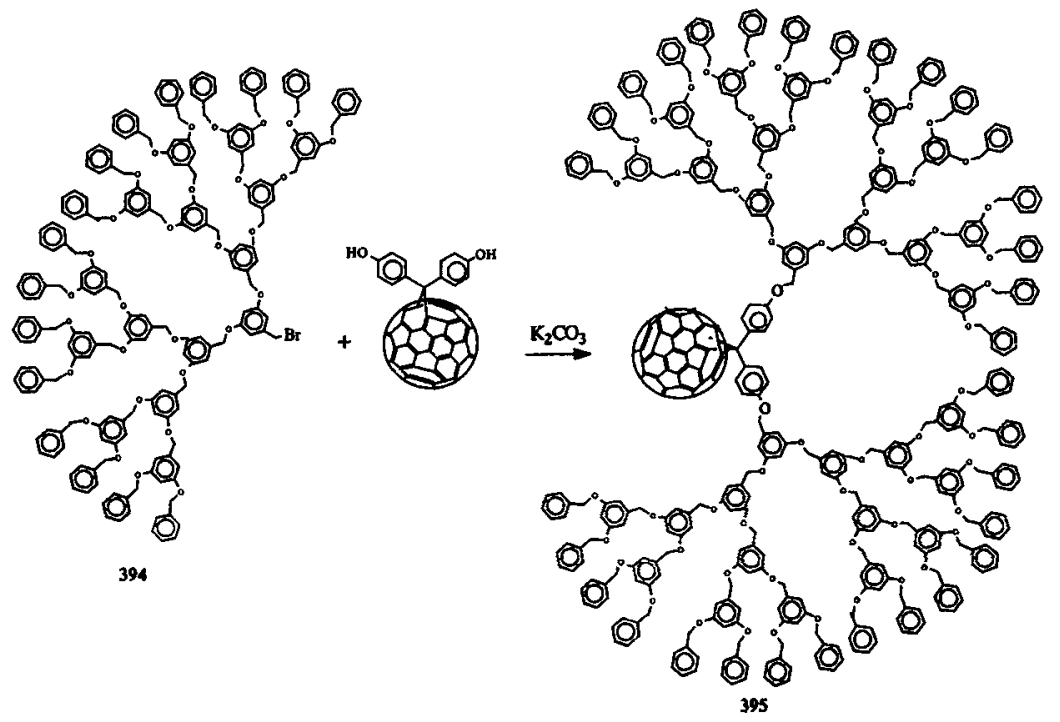

Figure 113. Dendrimer attachment to phenol-functionalized fullerene (Wooley et al 1993).

reaction of poly(tetramethylene oxide) glycol and MDI and then allowing to react with fullerenol. The resultant flexible polymers exhibited greatly enhanced thermal stability in comparison with those of the corresponding linear polyurethane and analogous elastomers, which were cross-linked with 1,1,1-tris(hydroxymethyl) ethane. A synthetic method leading to the preparation of a thin layer of conductive 


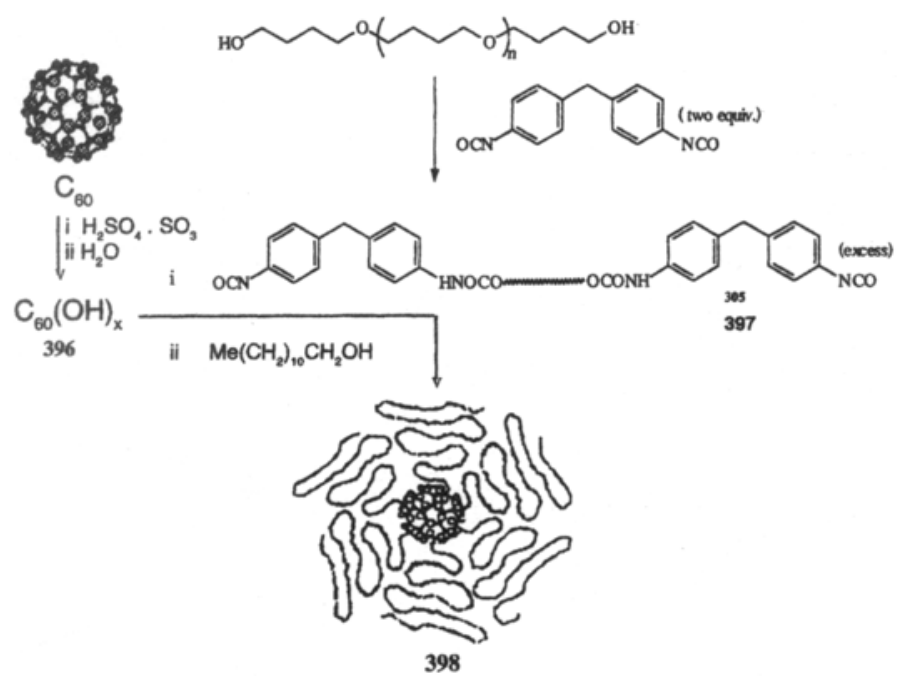

Figure 114. Fullerenol derived urethane-connected polyether dendritic polymers (Chiang et al 1994).

polyaniline/polyurethane IPN at the near surface of a fullerenol-based elastomeric substrate was demonstrated by using aqueous ammonium persulphate as an oxidizing agent in presence of $\mathrm{HCl}$. This new material exhibits a conductivity of $2 \mathrm{~S} / \mathrm{cm}$ at ambient temperature with the retention of most bulk properties of the parent elastomer such as elongation and tensile strength at break.

The fullerene polymers are manufactured from several types of $C_{n}(n$ is integer of geometrically spherical compound) directly bonded through $\mathrm{C}$ at a vacancy of $\geqslant 1$ fullerenes with missing C positions (Ata et al 1996). Such polymers are used as membrane materials. Fullerene functionalized amine containing polymers and polymerizable monomers are characterized by high temperature stability capable of withstanding a temperature of at least about $300^{\circ} \mathrm{C}$ and in some instances as high as $650^{\circ} \mathrm{C}$, when in polymerized form. In some cases enhanced mechanical properties also result in case of cross-linked polymers (Narang et al 1994). Photoconductive composites for copiers are reported (Yoshino et al 1994). The compounds contain substituted poly ( $p$-phenylenevinylenes) and fullerenes.

\section{Conclusion}

The chemistry of $\mathrm{C}_{60}$ and $\mathrm{C}_{70}$ have made significant progress over the years and within a short span hundreds of papers, along with reviews and monographs have appeared on the subject. The field is full of promise and for chemists in general and organic and polymer chemists in particular it would be an exciting branch of research in the coming decades. The future attention would be on the synthesis and 
characterization of many novel molecules. The possible application of such materials in different fields would be the focal point of such activity.

\section{Acknowledgements}

The inspiration for presenting this review emerged from the illuminating lecture of Prof. D R M Walton on 'the exohedral chemistry of $C_{60}$ and $C_{70}$ ' delivered at the Indian Institute of Technology, Kharagpur on the occasion of the 6th Annual General Meeting of the Materials Research Society of India (February 8-10, 1995). We wish to record our deep sense of gratitude to the MRSI for the purpose. Our colleagues have shown keen interest in the preparation of this review and we thank them for many stimulating discussions. In our research group the assistance of $\mathrm{Mr}$ K N Jena, Mr R K Dey and Miss S Acharya helped us in giving a final shape to the article and we thank all of them. We express our thanks to Dr U S Das for providing necessary software support.

\section{References}

Abdourazak A H, Marcinow Z, Sygula A, Sygula R and Rabideau P W 1995 J. Am. Chem. Soc. 1176410 Ajie H et al 1990 J. Phys. Chem. 948630

Akasaka T, Ando W, Kobayashi K and Nagase S 1993 J. Am. Chem. Soc. 11510366

Akasaka T, Mitsuhida E, Ando W, Kobayashi K and Nagase S $1994 \mathrm{~J}$. Am. Chem. Soc. 1162627

Akasaka T, Nagase S, Kobayashi K, Suzuki T, Kato T, Yamamoto K, Funasaka H and Takahasi T 1995 J. Chem. Soc., Chem. Commun. 1343

Aleshin A N, Biryulin Y F, Vimogradova L V, Zgonnik V N, Makarova T L, Melenevskaya E Y, Mironkov N B and Mikheev V P 1995 Pisma Zh. Tekh. Fiz 2164

Amato E 1991 Science 25430

An Y Z, Anderson J L and Rubi Y 1993 J. Org. Chem. 584799

An Y Z, Ellis G A, Viado A L and Rubin Y 1995a J. Org. Chem. 606353

An Y Z, Viado A L, Arce M and Rubin Y 1995b J. Org. Chem. 608330

Anderson S L, Christian J F and Wan Z 1992 J. Phys. Chem. 963574

Andersson T, Nilsson K, Sundahi M, Westman G and Wennerstrom O $1992 \mathrm{~J}$. Chem. Soc., Chem. Commun. 604

Ando W, Akasaka T, Kobayashi K and Nagase S 1993 J. Am. Chem. Soc. 1151605

Anon 1994 Chin. Sci. Bull. 391143

Arce M, Viado A L, An Y, Khan S I and Rubin Y 1996 J. Am. Chem. Soc. 1183775

Armstrong R S and Lay P A 1994 J. Am. Chem. Soc. 11612091

Ata M, Takahashi N and Matsuzawa N 1996 Jpn Kokai Tokkyo Koho JP 0859220

Avent A G, Birkett P R, Darwish A D, Kroto H W, Taylor R and Walton D R M 1996 Tetrahedron 52 5235

Averdung J and Mattay J 1994 Tetrahedron Lett. 356661

Averdung J and Mattay J 1996 Tetrahedron 525407

Averdung J, Mattay J, Jacobi D and Abraham W 1995 Tetrahedron 512543

Balch A L, Catalano V J, Lee J W, Olmstead M M and Parkin S R 1991a J. Am. Chem. Soc. 113 8953

Balch A L, Catalano V J and Lee J W 1991 b Inorg. Chem. 303980

Balch A L, Lee J W, Nall B C and Olmstead M M 1992 J. Am. Chem. Soc. 11410984

Balch A L, Lee J W, Nall B C and Olmstead M M 1993 J. Chem. Soc., Chem. Commun. 56

Balch A L, Cullison B, Fawcett W R, Ginwalla A S, Olmstead M M and Winkler K 1995 J. Chem. Soc., Chem. Commun. 2287

Baich A L, Ginwalla A S, Olmstead M M and Herbet-Irmer R 1996 Tetrahedron 525021

Ballenweg S, Gleiter R and Krätschmer W 1994 J. Chem. Soc., Chem. Commun. 2269 
Ballenweg S, Gleiter R and Krätschmer W 1996 Synth. Met. 77209

Banks M R, Cadogen J I G, Gosney I, Hodgson P K G, Langridge-Smith P R R and Rankin D W H 1994a J. Chem. Soc. Chem. Commun. 1365

Banks M R, Cadogen J I G, Gosney I, Hodgson P K G, Langridge-Smith P R R, Miliar J R A and Taylor A T 1994b Tetrahedron 359067

Banks M R et al 1994c Proc. Electrochem. Soc. 94-24 747

Banks M R et al 1995 J. Chem. Soc., Chem. Commun. 1171

Banks M R et al 1996 Chem. Commun. 507

Banks M R, Cadogen J I G, Gosney I, Hodgson P K G, Langridge-Smith P R R, Patric R and Rankin D W H 1996 Synth. Met. 7777

Bard A J, Zhou F and Jehoulet C 1992 J. Am. Chem. Soc. 11411004

Bartoszek M, Duczek W, Tittelbach F and Niclas H J 1996 Synth. Met. 7793

Bausch A L et al $1991 \mathrm{~J}$. Am. Chem. Soc. 1133205

Bashilov V V, Petrovskii P V and Sokolov V I 1993 Izv. Akad. Nauk. Sci. Khim. 2 428S

Bekiarian P G, Fagan P J and Krusic P J 1995 U. S. Patent US 5382718

Belik P, Kraus A, Gügel A, Spickermann J and Walter M 1994 Proc. Electrochem. Soc. 94-24 701

Belik P, Gügel A, Kraus A, Walter M and Müllen K 1995 J. Org. Chem. 603307

Benincori T, Brenna E, Sannicolo F, Trimarco L, Zotti G and Sozzani P 1996 Angew. Chem. Int. Ed. Engl. 35648

Benito A M, Darwish A D, Kroto H W, Meidine M F, Taylor R and Walton D R M 1996 Tetrahedron 37 1085

Bergbrieter D E and Gray H N 1993 J. Chem. Soc., Chem. Commun. 645

Bethune D S, Johnson R D, Salem J R, de Vries M S and Yanoni C S 1993 Nature 366123

Birkett P R, Avent A G, Darwish A D, Kroto H W, Taylor R and Walton D R M 1995a J. Chem. Soc., Chem. Commun. 683

Birkett P R, Avent A G, Darwish A D, Kroto H W, Taylor R and Walton D R M 1995b J. Chem. Soc., Chem. Commun. 1869

Bloomfield L A, Geusic M E, Freeman R R and Brown W L 1985 Chem. Phys. Lett. 12133

Bohme D K, Petrie S, Javahery G and Wang J 1992a J. Am. Chem. Soc. 1146268

Bohme D K, Javahery G, Petrie S, Ketvirtis A and Wang J 1992b Int. J. Mass. Spectrum. Ion Processes 116 R7

Bohme D K, Petrie S and Javahery G 1993 J. Am. Chem. Soc. 1151445

Boltalina O V, Borschevskii A Y, Sidorov L N, Street J M and Taylor R 1996 Chem. Commun. 529

Borghi R, Lunazzi L, Placucci G, Cerioni G and Plumitallo A 1996 J. Org. Chem. 613327

Bowers M T, Radi P P, Bunn T L, Kemper P R and Malcom M E 1988 J. Chem. Phys. 882809

Bowers M T, Radi P P, Hsu M T, Brodbelt-Lustij J and Rincon M E 1990 J. Chem. Phys. 924817

Bowers M T, Radi P P, Hsu M T, Rincon M E and Kemper P R 1990 Chem. Phys. Lett. 174223

Brendsdal E and Cyvin S J 1989 Theochem: 5755

Broderick W E 1994 J. Am. Chem. Soc. 1165489

Bühl M, Thiel W and Schneider U 1995 J. Am. Chem. Soc. 1174623

Bunker C E, Lawson G E and Sun Y 1995 Macromolecules 283744

Buravov L I, D'Yachenko O A, Konovalikhin S V, Kushch N D, Lavent'ev I P, Spitsyna N G, Shilov G V and Yagubskii E B 1994 Izv. Akad. Nauk. Ser. Khim (Russ.) 2262

Cahill P A and Henderson C C 1995 U.S. Patent US 5475172

Camp A G, Lary A and Ford W T 1995 Macromolecules 287959

Campbell E E B, Ulmer G, Hasselberger B, Busmann H G and Hertel I V 1990 J. Chem. Phys. 936900

Cai R, Chen J, Huang Z, Shao Q, Bai X and Tang H 1995 Eudan Xuebao, Ziran Kexueban 34223

Cao T and Webber S E 1995 Macromolecules 283741

Cardullo F, Isaacs L, Diederich F, Gisseibrechi J, Boudon C and Gross M 1996 Chem. Commun. 797

Chai Y, Gyo T, Jin C, Haufler R E, Chibanate L P F, Fure J, Wang L, Alford J M and Smalley R E 1991 J. Phys. Chem. 957564

Chen D, Workman R and Sarid D 1994 Electron Lett. 301007

Chiang L Y, Upasani R B and Swirczewski J W 1992a J. Am. Chem. Soc. 11410154

Chiang L Y, Swirczewski J W, Hsu C S, Chowdhury S K, Cameron S and Creegan K 1992b J. Chem. Soc., Chem. Commun. 1791

Chiang L Y, Wang L Y, Tseng S, Wu J and Hsieh K 1994 J. Chem. Soc., Chem. Commun. 2675

Chiang L Y, Wang L Y, Wu R and Hsieh K 1995 Mater. Res. Soc. Symp. Proc. 359331

Conwell E M, Mizes H A and Perlstein J 1995 Proc. SPIE-Int. Soc. Opt. Eng. 253087

Cooks R G, Hoke S H (II), Molstad J, Dilettato D, Jay M J, Carlson D and Kahn B 1992 J. Org. Chem. 575069

Cox D M et al 1991 J. Am. Chem. Soc. 1132940 
Cox D E, Zhu O, Fischer J E, Kniaz K, McGhie A R and Zhou O 1992 Nature 355712

Creasy W R and Breena J T 1988 Chem. Phys. 126453

Creasy W R and Breena J T 1990 J. Chem. Phys. 922269

Creegan K M et al 1992 J. Am. Chem. Soc. 1141103

Cremonini M A, Lunazzi L, Placucci G and Krusic P J 1993 J. Org. Chem. 613327

Darwish A D, Abdul-Sada A K, Langley G J, Kroto H W, Taylor R and Walton D R M 1994 J. Chem. Soc., Chem. Commun. 2133

Darwish A D, Abdul-Sada A K, Langley G J, Kroto H W, Taylor R and Walton D R M 1996 Synth. Met. 77303

Diederich F et al 1991 Science 252548

Diederich F, Dietrich-Buchecker C, Nierengarten J and Sauvage J $1995 \mathrm{~J}$. Chem. Soc., Chem. Commun. 781

Dietz T G, Duncan M A, Powers D E and Smalley R E 1981 J. Chem. Phys. 746511

Dong G, Li J and Chan T 1995 J. Chem. Soc., Chem. Commun. 1725

Drovetskaya T, Reed C A and Boyd P 1995 Tetrahedron Lett. 367971

Duggan A C, Fox J M, Henry P F, Heyes S J, Laurie D E and Rosseinsky M J 1996 Chem. Commun. 1191

Eastman M P, Wyse C L, Abe J P, Zoellner R W and Kooser R G 1994 J. Org. Chem. 597128

Edelmann F T 1995 Angew. Chem. Int. Ed. Engl. 34981

Eiermann M et al 1995 Angew. Chem. Int. Ed. Engl. 341591

Endo H, Yoshiyama N and Yamamoto H 1996 Mol. Cryst. Liq. Cryst. Sci. Technol. Sect. A 280289

Ermer O 1991 Helv. Chem. Acta 741339

Fagan P J, Calabrese J C and Malone B 1991a Science 2521160

Fagan P J, Calabrese J C and Malone B 1991b J. Am. Chem. Soc. 1139408

Fagan P J, Krusic P J, Evans D H, Larke S A and Johnston E $1992 \mathrm{~J}$. Am. Chem. Soc. 1149697

Fischer J E and Smith A B $1991 \mathrm{~J}$. Am. Chem. Soc. 1138537

Foote C S and Arbogast J W $1991 \mathrm{~J}$. Am. Chem. Soc. 1138886

Foote C S, Arbogast J W, Darmanyan A P, Rubin Y, Diederich F N, Alvarz M M, Anz S J and Whetten R L 1991 J. Phys. Chem. 9511

Fowler P 1991 Nature 35020

Freiser B S, Roth L M, Huang Y, Schwedler J T, Cassady C J, Amotz D B and Kahr B 1991 J. Am. Chem. Soc. 1136298

Freiser B S and Huang Y 1991a J. Am. Chem. Soc. 1138186

Freiser B S and Huang Y 1991b J. Am. Chem. Soc. 1139418

Freiser B S, Jiao Q, Huang Y, Lee S A and Gord J R 1992 J. Am. Chem. Soc. 1142726

Freiser B S, Kan S Z and Byun Y G $1994 \mathrm{~J}$. Am. Chem. Soc. 1168815

Freiser B S, Kan S Z and Byun Y G 1995 J. Am. Chem. Soc. 1171177

Friedman S H, Decamp D L, Sijbesema R P, Srdanov G, Wudl F and Kenyon L $1993 \mathrm{~J}$. Am. Chem. Soc. 1156506

Garrell R L, Herne T M, Szafranski C A, Diederich F, Ettl F and Whetten R L 1991 J. Am. Chem. Soc. 1136302

Gan L, Zhou D, Luo C, Tan H, Huang C, Lu M, Pan J and Wu Y 1996 J. Org. Chem. 611954

Ganapathi P S, Friedman S H, Kenyon G L and Rubin Y 1995 J. Org. Chem. 602954

Ginzburg B M, Tochilnikov D G, Koreenko O F and Bulatov V P 1995 Pis'ma Zh. Tekh. 2162

Giovane L M, Barco J W, Yadav T, Lafleur A L, Marr J A, Howard J B and Rotello V M 1993 J. Phys. Chem. 978560

Gonźalez R, Knight B W and Wudl F 1994 J. Org. Chem. 597949

Green M L H, Douthwaite R E, Heyes S J, Rosseinsky M J and Turner J F C 1994 J. Chem. Soc., Chem. Commun. 1367

Greenwood P F, Strachan M G, El Nakat H J, Willet G D, Wison M A and Attalla M I 1990 Fuel 69257

Gross M L 1991 J. Am. Chem. Soc. 1138519

Gross M L, Caldwell K A and Giblin D E 1992 J. Am. Chem. Soc. 1143743

Grösser T, Prato M, Lucchini V, Hirsch A and Wudl F 1995 Angew. Chem. Int. Ed. Engl. 341343

Guarr T F, Meier M S, Vance V K and Clayton M 1993 J. Am. Chem. Soc. 1159862

Guegel A, Belik P, Walter M, Kraw A, Harth E, Wagner M, Spickermann J and Muellen K 1996 Tetrahedron 525007

Guhr K I, Greaves M D and Rotello V M 1994 J. Am. Chem. Soc. 1165997

Guhr K, Greaves M and Rotello V 1995 Tetrahedron Lett. 3617

Gupta N and Santhanam 1994 J. Chem. Soc., Chem. Commun. 2409

Haddon R C 1996 J. Am. Chem. Soc. 1183041

Haddon R C et al 1991 Nature 350 46, 320 
Hamano T, Mashino T and Hirobe M 1995 J. Chem. Soc., Chem. Commun. 1537

Hart H, Bashir-Hashemi A, Luo J and Meador M 1986 Tetrahedron 421641

Haufler R E et al 1990 J. Phys. Chem. 948634

Hawker C J, Wooley K L and Fréchet J M J 1993 J. Am. Chem. Soc. 1154375

Hawker C J, Wooley K L and Fréchet J M J 1994 J. Chem. Soc., Chem. Commun. 925

Hawkins J M, Lewis T A, Loren S D, Meyer A, Heath J R, Shibato Y and Saykally R J $1990 \mathrm{~J}$. Org. Chem. 556250

Hawkins J M, Meyer A and Nambu M 1993 J. Am. Chem. Soc. 1159844

Heath J R, O'Brien S C, Curl R F, Kroto H W and Smalley R E 1987 Comments Condens. Matter Phys. 13119

Hebard A F, Zhou O, Zhang Q, Fleming R M and Haddon R C 1995 Thin Solid Films 257147

Henry P F, Rosseinsky M J and Watt C J 1995 J. Chem. Soc., Chem. Commun. 2131

Hintenberger H and Dorenburg E 1959 Z. Naturforsch. Teil. A14 765

Hintenberger H, Dorenburg E and Franzen J 1961a Z. Naturforsch. Teil. A16 532

Hintenberger $\mathrm{H}$ and Franzen J 1961b Z. Naturforsch. Teil A16 535

Hintenberger H, Franzen J and Schuy K D. 1963 Z. Naturforsch. Teil A18 1236

Hirozawa I 1995 Jpn Kokai Tokkyo Koho JP 07309613

Homann K, Gerhardt Ph and Loffler S 1987 Chem. Phys. Lett. 137306

Hosoya H 1986 Comp. Matts. Appl. 12271

Hsu H-F and Shapley J R 1995 Proc. Electrochem. Soc. 95-10 1087

Huang K, Sun H, Li J, Li X, Huang H and Sun M 1996 Zhongnam Gengye Daxue Xuebao 27109

Huang R, Lu W and Yang S 1995 J. Chem. Phys. 102189

Huang S, Yu X, Yang C and Wu L 1994a Chin. Chem. Lett. 5149

Huang Z, Sun Y and Cai R 1994b Chin. Sci. Bull. 39823

Hwang J H, Mou C Y, Sheu H S, Wang Y and Wu M K 1994 Appl. Phys. Lett. 652156

Imahori H and Sakata Y 1996 Chem. Lett. 3199

Ishida T, Shinozuka K, Kubata M, Ohashi M and Nogami T 1995 J. Chem. Soc., Chem. Commun. 1841

Isaacs L, Haldimann R F and Diederich F 1994 Angew. Chem. 1062435

Isaacs L, Haldimann R F and Diederich F 1995a Angew. Chem. Int. Ed. Engl. 332339

Isaacs L, Seiler P and Diederich F 1995b Angew. Chem. Int. Ed. Engl. 341314

Iyoda M, Sultana F, Sasaki S and Yoshida M 1994 J. Chem. Soc., Chem. Commun. 1929

Iyoda M, Ogawa Y, Matsuyama H, Ueno H, Kikuchi K, Ikamoto I and Achiba Y 1995 Fullerene Sci. Technol. 31

Izuoka A et al 1992 J. Chem. Soc., Chem. Commun. 1472

Jagerovic N, Elguero J and Aupagnac J 1996 J. Chem. Soc. Perkin Trans. 16499

Jagerovic N, Elguero J and Aupagnac J 1996 Tetrahedron 526433

Johnson R D, Meijer G and Bethune D S $1990 \mathrm{~J}$. Am. Chem. Soc. 1128983

Johnson R D, deVries M S, Salem J, Bethune D S and Yanoni C S 1992 Nature 355239

Juha L, Hamplova V, Kodymova J and Spalek O 1994 J. Chem. Soc., Chem. Commun. 2437

Kafafi Z H, Flom S R, Sarkas H W, Pong R G S, Merritt C D and Bartoli F J 1994 Proc. SPIE-Int. Soc. Opt. Eng. (Engl.) 2284134

Kalsbeck W A and Thorp H H 1991 J. Electroanal. Chem. 314363

Kampe K D, Egger N and Vogel M 1993 Angew Chem. Int. Ed. Engl. 321174

Kampe K D and Egger N 1995 Liebigs Ann. Chem. 115

Keizer P N, Morton Z R, Preston K F and Krusic P J 1993 J. Chem. Soc., Perkin Trans. 21041

Kellogg G W, Szewezak A A and Moore P B 1992 J. Am. Chem. Soc. 1142727

Khairullin I I, Imeada K, Yakushi K and Inokuchi H 1994 Physica C (Amsterdam) 23126

Khan S I, Oliveer A M, Paddon-Row and Rubin Y 1993 J. Am. Chem. Soc. 1154919

Klein D J, Schmalz T G, Hite G E and Seitz W A 1986a J. Am. Chem. Soc. 10813101

Klein D J, Seitz W A and Schmalz T G 1986b Nature 323703

Klemt R, Roduner E and Fischer H 1995 J. Am. Chem. Soc. 1178019

Kobayashi H, Moriyama H, Kobayashi A and Watanabe T 1993 J. Am. Chem. Soc. 1151185

Kobayashi H, Tomita H, Moriyama H, Kobayashi A and Watanabe T $1994 \mathrm{~J}$. Am. Chem. Soc. 1163153

Komatsu K, Murata Y, Sugita N, Takeuchi K and Wan T S M 1993 Tetrahedron Lett. 348476

Komatsu K, Murata Y, Sugita N and Wan T S M 1994a Chem. Lett. 635

Komatsu K, Murata Y, Tokimoto N, Mori S, Sugita N and Wan T S M 1994b J. Org. Chem. 596101

Kräeutler B and Maynollo J 1995a Angew. Chem. 10766

Kräeutler B and Maynollo J 1995b Angew. Chem. Int. Ed. Engl. 3487

Kräeutler B and Maynollo J 1996 Tetrahedron 525033

Krätschmer W, Lamb L D, Fostiropoulos K and Huffman D R 1990a Nature 347354

Krätschmer W, Fostiropoulos K and Huffman D R 1990b Chem. Phys. Lett. 170167 
Kroto H W, Heath J R, O'Brien S C, Curl R F and Smalley R F 1985 Nature 318162

Kroto H W, Alaf A W and Balm S P 1991 Chem. Rev. 911213

Kroto H W, Crane J D, Hitchcock P B, Taylor R and Walton D R M $1992 \mathrm{~J}$. Chem. Soc., Chem. Commun. 1534

Krusic P J, Wasserman E, Keizer P N, Morton J R and Preston K F 1991a Science 2541184

Krusic P J, Wasserman E, Parkinson B A, Malone B, Holler E R Jr, Keizer P M, Morton J R and Preston K F 1991b J. Am. Chem. Soc. 1136274

Krusic P J, Rae D C, Johnston E, Morton J R and Preston K F 1993 J. Chem. Phys. 971736

Kuthner W, Boulas P and Kadish K M 1992 J. Electrochem. Soc. 139 243C

Laborde E 1992 Tetrahedron Lett. 336607

Lamparth I, Nuber B, Schick G, Skiebe A, Groesser T and Hirsch A 1995a Angew. Chem. Int. Ed. Engl. 342257

Lamparth I, Maichle-Mössmer C and Hirch A 1995b Angew. Chem. Int. Ed. Engl. 341607

Lappas A, Vavekis K and Prassides K 1994 J. Chem. Soc., Chem. Commun. 2743

Lawson G E, Kitaygorodskiy A, Ma B, Bunker E C and Sun Y 1995 J. Chem. Soc., Chem. Commun. 2225

Lee C H, Yu G, Moses D, Sariciftci N S, Wudl F and Heeger A J 1994 Mol. Cryst. Liq. Cryst. Sci. Technol. Sect. A 256745

Leigh D A et al 1992 J. Am. Chem. Soc. 1142727

Levon K, Wang D, Mao J, Lee H K, Tour J M and Schrivens W A 1994 Mater. Res. Soc. Symp. Proc. 349 127

Lineman D N, Somayajula K V, Sharkey A G and Hercules D M 1989 Microbeam. Anal. 24297

Linssen T G, Durr K, Hanack M and Hirsch A $1995 \mathrm{~J}$. Chem. Soc., Chem. Commun. 103

Liu B, Bunker C E and Sun Y 1996 Chem. Commun. 1241

Liu J, Mori A, Kato N and Takashita H 1995 Fullerene Sci. Technol. 345

Liou K and Cheng C 1995 J. Chem. Soc., Chem. Commun. 1603

Loy D A and Asssink R A 1992 J. Am. Chem. Soc. 1143977

Maggini M, Scorrano G and Prato M 1993 J. Am. Chem. Soc. 1159798

Maggini M, Scorrano G, Bianco A, Toniolo C, Sijbesma R P, Wudl F and Prato M 1994 J. Chem. Soc., Chem. Commun. 305

Maggini M, Roffler S and Scorrano G 1995a J. Am. Chem. Soc. 1176572

Maggini M, Dono A, Scorrano G and Prato M 1995b J. Chem. Soc., Chem. Commun. 845

Maggini M, Scorrano G, Bianco A, Toniolo C and Prato M 1995c Tetrahedron Lett. 362845

Maggini M, Scorrano G, Prato M, Brusatin G, Guglielmi M, Mineghetti M and Bozio R 1995d Proc. Electrochem. Soc. 95-10 84

Makrarova T L, Nemchuk N I and Veel A Y 1995 Proc. Electrochem. Soc. 95-10 914

Malhotra R, Tse D S and Mcmillen D F 1994a U. S. Patent US 5336828

Malhotra R, Kumar S and Satyam A 1994b J. Chem. Soc., Chem. Commun. 1339

Manalova N, Rashkov I, Van Damme H and Beguin F 1994 Polym. Bull. (Berlin) 33175

Mathews C K, SaiBaba M, Lakshmi Narasimhan T S, Balasubramanian R, Sivaraman N, Srinivasan T G and Vasudeva Rao P R $1992 \mathrm{~J}$. Chem. Phys. 963566

Matsubara Y, Tada H, Nagase S and Yoshida Z 1995 J. Org. Chem. 605372

Mauzerall D and Huang $1992 \mathrm{~J}$. Am. Chem. Soc. 1149705

Mavunkal I J, Chi Y, Peng S and Lee G 1995 Organometallics 144454

McBranch D, Mattes B R, Koskelo A, Robinson J M and Love S P 1994 Proc. SIPE-Int. Soc. Opt. Eng. (Engl.) 228415

McClaim R D 1995 Proc. Electrochem. Soc. 95-10 72

McElvany S W and Callahan J H 1991 J. Phys. Chem. 956187

McElvany S W, Ross M M, Goroff N S and Diederich F 1993 Science 2591594

McKenzie D R, Davis C A, Cockayne D J H, Muller D A and Vassallo A M 1992 Nature 155622

Meier M S and Poplawska M 1993 J. Org. Chem. 584524

Mikami K, Matsumoto, Ishida A, Takamuku S, Suenobu T and Fukuzumi S $1995 \mathrm{~J} . \mathrm{Am}$. Chem. Soc. 117 11141

Miles W H and Smiley P M 1996 J. Org. Chem. 612559

Miller B et al 1991 J. Am. Chem. Soc. 1136291

Miller G P, Buretea M A, Swirczewski J W and Mc Connachie J M 1994 Mater. Res. Soc. Symp. Proc. 349115

Morosin B, Jacobs J, Henderson C and Schirber J E 1994 Mater. Res. Soc. Symp. Proc. 349151

Morton J R, Preston K F, Krusic P J, Hill S A and Wasserman E 1992a J. Am. Chem. Soc. 1145454

Morton J R, Preston K F, Krusic P J, Hill S A and Wasserman E 1992b J. Phys. Chem. 963576

Murata Y, Motoyama K, Komatsu K and Wan T S M 1996 Tetrahedron 525077

Murphy D W et al 1993 J. Phys. Chem. Solids $\mathbf{5 3} 1321$ 
Murakami H, Watanabe Y and Nakashima N 1996 J. Am. Chem. Soc. 1184484

Nagase S and Kobayashi K 1994 J. Chem. Soc., Chem. Commun. 1837

Nagashima H, Nakoaka A, Saito Y, Kato M, Kawanishi T and Itoh K $1992 \mathrm{~J}$. Chem. Soc., Chem. Commun. 377

Nagashima H, Terasaki T, Saito Y, Jinno K and Itoh K 1995 J. Org. Chem. 604966

Nagashima H, Nakazawa M, Furukawa T and Itoh K 1996 Chem. Lett. 5405

Nakamura E, Yamago S and Yanagawa M 1994 J. Chem. Soc., Chem. Commun. 2093

Narang S C, Ventura S C, Ganapathiappan S and Bhardwaj T R 1994 U. S. Patent US 5, 367,051

Newkome G R, Nayak A, Behera R K, Moorefield C N and Baker G R 1992 J. Am. Chem. Soc. 57358

Nie B and Rotello V M 1996 J. Org. Chem. 611870

Nigam A, Shekharam T, Bharadwaj T, Giovanola J, Narang S and Malhotra R 1995a J. Chem. Soc., Chem. Commun. 1547

Nigam A, Shekharam T, Bharadwaj T, Giovanola J, Narang S and Malhotra R 1995b Mater. Res. Soc. Symp. Proc. 359347

Novello F, Prato M, Ros T D, Amici M D, Bianco A, Toniolo C and Maggini M 1996 Chem. Commun. 903

O’Brien S C, Heath J R, Kroto H W, Curl R F and Smalley R E 1986 Chem. Phys. Lett. 13012

O'Brien S C, Heath J R, Curl R F and Smalley R E 1988 J. Chem. Phys. 88220

Ohkita M, Ishigami K and Tsuji T 1995 J. Chem. Soc., Chem. Commun. 1769

Ohno M, Kojima S and Eguchi S 1995 J. Chem. Soc., Chem. Commun. 565

Ohno M, Azuma T, Kojima S, Shirakawa Y and Eguchi S 1996a Tetrahedron 524983

Ohno T, Martin N, Knight B, Wudl F, Suzuki T and Yu H 1996b J. Org. Chem. 611306

Okotrub A V, Shevtsov Y V, Kuropyatnik I N, Potapova O, Gnasanonova L I, Trubina S V, Kravchenko V S and Mazalov L N 1994 Sverkhprovodimost: Fiz. Khim. Tekh. 7866

Olah G A, Bausch J W and Surya Prakash G K 1991a J. Am. Chem. Soc. 1133205

Olah G A, Busci I, Lambert C, Aniszfeld R, Trivedi N J, Sensharma D K and Surya Prakash G K 1991b J. Am. Chem. Soc. 1139385,9387

Osawa S, Osawa E and Harada M 1996 J. Org. Chem. 61257

Osterodt J, Nieger M and Vögtle F 1994 J. Chem. Soc., Chem. Commun. 1607

Osterodt J and Vögtle F 1996 Chem. Commun. 547

Ouyang M, Wang K Z, Zhang H X, Xue Z Q, Huang C H and Qiang D 1996 Appl. Phys. Lett. 682441

Patel H M, Didymus J M, Wong K K W, Hirsch A, Skiebe A, Lamparth I and Mann S 1996 Chem. Commun. 611

Patil A O and Schriver G W 1995 Macromol. Symp. 9173

Paquette L A and Graham R J 1995 J. Org. Chem. 602958

Paquette L A and Trego W E 1996 Chem. Commun. 419

Paul P, Xie Z, Bau R, Boyd P D W and Reed C A 1994 J. Am. Chem. Soc. 1164145

Petrie S, Javahery G, Wang J and Bohme D K 1992 J. Am. Chem. Soc. 114.6268

Prato M, Li Q C and Wudl F 1993a J. Am. Chem. Soc. 1151148

Prato M et al 1993b J. Am. Chem. Soc. 1151594

Prato M, Lucchini V, Maggini M, Stimpfl E, Scorrano G, Eiermann M, Suziki T and Wudl F 1993c J. Am. Chem. Soc. 1158479

Prato M, Maggini M, Scorrano G and Lucchini V 1993d J. Org. Chem. 583613

Rao C N R, Aiyer H N and Govindaraj A 1994 Bull. Mater. Sci. 17563

Rohfling E A, Cox D M and Kaldor A 1984 J. Chem. Phys. 813322

Ross M M and Callahan J H 1991 J. Phys. Chem. 955720

Rotello V M, Howard J B, Yadav T, Conn M M, Viani E, Giovane L M and Lafluer A L 1993 Tetrahedron Lett. 1561

Roth G and Adelmann P 1992 J. Phys. 1. France 21541

Rubin Y, Khan S I, Freedberg D I and Yeretzian C 1993 J. Am. Chem. Soc. 115344

Rubin Y, Parker T C, Khan S I, Halliman C L and McElvany S W 1996 J. Am. Chem. Soc. 1185308

Schick G, Kampe K and Hirsch A 1995 J. Chem. Soc., Chem. Commun. 2023

Schlueter J A, Seaman J M, Taha S, Cohen H, Lykke K R, Wang H H and Williams J M 1993 J. Chem. Soc., Chem. Commun. 972

Schmalz T G, Seitz W A, Klein D J and Hite G E 1986 Chem. Phys. Lett. 130203

Schneider N S, Darwish A D, Kroto H W, Taylor R and Walton D R M 1994 J. Chem. Soc., Chem. Commun. 463

Schuster D et al 1994 Proc. Electrochem. Soc. 94-24932

Scuseria G E 1991 Chem. Phys. Lett. 180451

Scurlock R D and Ogilby P R 1995 J. Photochem. Photobiol. A 9121

Shapley J R, Kaefod R S, Xu C, Lu W, Hill M G and Mann K R 1992 J. Phys. Chem. 962928 
Shi S, Khemani K C, Chan Li and Wudl F 1992 J. Am. Chem. Soc. 11410656

Shinkai S, Adams H and Stirling J M 1994 J. Chem. Soc., Chem. Commun. 2527

Shinohara H, Sato H, Saito Y, Ohkohchi M and Ando Y. 1992 J. Phys. Chem. 963571

Shiu L et al 1994 J. Chem. Soc., Chem. Commun. 647

Shiu L, Chien K, Liu T, Lin T, Her G and Luh T $1995 \mathrm{~J}$. Chem. Soc., Chem. Commun. 1159

Shu L, Wang G, Wu S and Wu H 1995 J. Chem. Soc., Chem. Commun. 367

Smalley R E, Heath J R, O'Brien S C, Zhang Q, Liu Y, Curl R F, Kroto H W and Tittel F K $1985 \mathrm{~J} . \mathrm{Am}$. Chem. Soc. 1077779

Smalley R E et al $1988 \mathrm{~J}$. Am. Chem. Soc. 1104464

Smith A B III, Strongin R M, Laurent B, Furst G T and Romanow W J $1993 \mathrm{~J}$. Am. Chem. Soc. 115 5829

Smith A B III, Strongin R M, Bard L, Furst G T, Romanow W J, Owens K G and Goldschmidt R J 1994 J. Chem. Soc., Chem. Commun. 2187

Smith A B III, Strongin R M, Brard L. Furst G T, Romanow W J, Owens K G, Goldschmidt R J and King R C 1995 J. Am. Chem. Soc. 1175492

Smith A B III et al $1996 \mathrm{~J}$. Org. Chem. 611904

Smith A B III and Tokuyama H 1996 Tetrahedron 525257

Sun D, Liu Z, Guo X and She Y 1996 Gaodeng Xuexiao Huaxue Xuebao 1719

Suzuki T, Li Q, Khemini K C, Wudl F and Almarsson 1991 Science 2541186

Suzuki T, Li Q, Khemani K C and Wudl F 1992 J. Am. Chem. Soc. 1147300

Tago T, Minowa T, Okada Y and Nishimura J 1993 Tetrahedron Lett. 348461

Taylor R, Hare J P, Abdul-Sada A K and Kroto H W $1990 \mathrm{~J}$. Chem. Soc., Chem. Commun. 201420

Taylor R, Parsons J P, Avent A G, Rannard S P, Dennis T J, Hare J P, Kroto H W and Walton D R M 1991 Nature 351277

Taylor R, Walton D R M, Birkett P R, Hitchcock P B and Kroto H W 1992 Nature 357479

Taylor R and Walton D R M 1993 Nature 363685

Taylor R, Avent A G, Birkett P R, Crans J C, Darwish A D, Langley G J, Kroto H W and Walton

D R M 1994 Mater. Res. Soc. Symp. Proc. 349107

Tebbe F N et al $1991 \mathrm{~J}$. Am. Chem. Soc. 1139900

Tebbe F N et al 1992 Science 256822

Tokuyama H, Isobe H and Nakamura E $1994 \mathrm{~J}$. Chem. Soc., Chem. Commun. 2753

Tomalia D A, Naylor A M and Goddard W A III 1990 Angew Chem. Int. Ed. Engl. 29138

Tomioka H and Yamamoto K 1995 J. Chem. Soc., Perkin Trans. I 63

Torres-Garicia G and Mattay J 1996 Tetrahedron 525421

Tsuda M, Ishida T, Nogami T, Kurono S and Ohashi M 1993 J. Chem. Soc. Chem. Commun. 1296

Walter M, Guegel A, Spickermann J, Belik P, Kraus A and Muellen K 1996 Fullerene Sci. Technol. 4101

Wang C Z, Xu C H, Chan C T and Ho K M 1992 J. Phys. Chem. 963563

Wang G, Shu L, Wu S, Wu H and Lao X 1995 J. Chem. Soc., Chem. Commun. 1071

Wang J, Javahery G, Petrie S and Bohme D K 1992 J. Am. Chem. Soc. 1149665

Wang J, Javahery G, Baranov V and Bohme D K 1996 Tetrahedron 525191

Wang L, Chiang L Y, Kuo C S, Lin J G and Huang C Y 1996 Mater. Res. Soc., Symp. Proc. 413571

Wang Y 1992 Nature 356585

Warrener R N, Elsey G M and Houghton M A $1995 \mathrm{~J}$. Chem. Soc., Chem. Commun. 1417

Watanabe A, Ito O, Watanabe M, Saito H and Koishi M 1996 Chem. Commun. 117

Weaver M J, Zhang Y and Gao X 1992 J. Phys. Chem. 96510

Wei X, Vardeny Z V, Sariciftci N S and Heeger A J 1996 Phys. Rev. B: Condens. Matter 532187

Weis C, Friedrich C, Muelhaupt R and Frey H 1995 Macromolecule 28403

Wen-Yi T, Jenn-Tsuen L, Chung-Yuan M, Soofin C, Shang-Bin L, Peter P C and Hann-Wen L 1996 J. Am. Chem. Soc. 1184411

West R, Oka K, Takahashi H, Miller M and Gunji T 1994 ACS Symp. Ser. 57292

Williams R M, Zwier J M and Verhoeven J W 1995 J. Am. Chem. Soc. 1174093

Wilson S R and Lu Q 1993 Tetrahedron Lett. 348043

Wilson S R, Wu Y, Kaprinidis N A and Schuster D I 1993a J. Org. Chem. 586548

Wilson S R, Kaprinidis N A, Wu Y and Schuster D I 1993b J. Am. Chem. Soc. 1158495

Wohlers M, Herzog B, Belz T, Bauer A, Braunth R T and Schloegl R 1996 Synth. Met. 7755

Wooley K L, Hawker C J and Frechet $1993 \mathrm{~J}$. Am. Chem. Soc. 1159836

Wu S, Shu L and Fan K 1994 Tetrahedron Lett. 35919

Wudl F 1992 Acc. Chem. Res. 25157

Wudl F, Allemand P M, Koch A, Rubin Y, Diederich F, Alvarez M M, Anz S J and Whettan R L 1991 a $J$. Am. Chem. Soc. 1131050 
Wudl F, Penicaud A, Hsu J, Reed C A, Koch A, Khemani K C and Allemand P M 1991b J. Am. Chem. Soc. 1136698

Wudl F et al 1991c Am. Chem. Soc. Symp. Series 481161

Wudl F et al 1992a Acc. Chem. Res. 25106

Wudl $\mathrm{F}$ et al 1992b Fullerenes synthesis, properties and chemistry of large carbon clusters, (eds) G S Hammond and V J Kuck (Washington DC: American Chemical Society) p. 161

Wudl F, Sijbesma R, Srdanov G, Castoro J A, Wilkins C, Friedman S H, Decamp D L and Kenyon G L 1993 J. Am. Chem. Soc. 1156510

Wudl F, Janssen R A J and Hunmelen J C 1995 J. Am. Chem. Soc. 117544

Xie Q, Perez-Cordero E and Echegoyen L 1992 J. Am. Chem. Soc. 1143978

Yamada K, Komyama H, Kitazawa K and Tabata S 1994 Jpn. Kokai Tokkyo Koho JP 06244440

Yamago S, Tokuyama H, Nakamura E, Prato M and Wudl F 1993 J. Org. Chem. 584796

Yamago S, Takeichi A and Nakamura E 1994a J. Am. Chem. Soc. 1161123

Yamago S, Yanagawa M and Nakamura E 1994b J. Chem. Soc., Chem. Commun. 2093

Yan M, Cai S X and Keana F W 1994 J. Org. Chem. 595951

Yang G and Yuan F 1995 Gangneng Cailiao 26741

Yannoni C S, Meijer J G, Bethune D S and Salem J R 1991 J. Phys. Chem. 959

Yoshida M, Morishima A, Morinaga Y and Iyoda M 1994. Tetrahedron Lett. 359045

Yoshino K, Yashimato K, Tada K, Araki H, Kawai T, Ozaki M and Zakhidov A A 1995 Proc. SPIE-Int. Soc. Opt. Eng. 253060

Yoshino K, Yin X H, Muro K, Kiyomatsu S, Morita S, Zakhidov A A, Noguchi T and Ohnishi T 1993 Springer Ser. Solid-State Sci. 117286

Yoshino K, Anbaa E Z, Oonishi T and Noguchi M 1994 Jpn. Kokai Tokkyo Koho JP 06, 179, 802

Zhang X and Foote C S 1994 J. Org. Chem. 595235

Zhang $X$ and Foote C S $1995 \mathrm{~J}$. Am. Chem. Soc. 1174271

Zhang S, Brown T L, Dee Y and Shapley J R 1993a J. Am. Chem. Soc. 1156705

Zhang X, Willems and Foote C S 1993b Tetrahedron Lett. 8187

Zhao W, Tang J, Puri A, Li Y and Chen L 1995 Proc. Electrochem. Soc. 95-10 143

Zhu L, Wang S, Lu J and Li Y 1994 Phys. Rev. A: At., Meel., Opt. Phy. 493096

Zhou F and Gary J V B 1994 J. Am. Chem. Soc. 1165485 